\title{
Sugar Babies and Sugar Daddies: An Exploration of Sugar Dating on Canadian Campuses
}

by

Sarah Daly

A thesis submitted to the Faculty of Graduate and Postdoctoral Affairs in partial fulfillment of the requirements for the degree of

\author{
Master of Arts \\ in \\ Law and Legal Studies \\ Carleton University \\ Ottawa, Ontario \\ C) 2017, Sarah Daly
}




\begin{abstract}
$\underline{\text { Abstract }}$
This thesis contributes to a small body of research that examines the 'sugar baby phenomenon' in a Canadian context. To date, most of what is known about sugar babies' experiences is through anecdotal accounts filtered through the media. By drawing on the content of one popular sugar baby forum, as well as data gathered from two in-depth qualitative interviews with two active sugar babies, this thesis explores the lived experiences and perceptions of the participants. In particular, this study seeks to determine whether sugar babies articulate shared motivations; how they navigate sugar dating's blurring of traditional romance and sex work; and how they exercise power and agency within their relationships. Key findings are that sugar dating's blend of conventional dating and sex work creates a new conceptual space that both enhances the degree of power and agency exercised by sugar babies, and constrains it in ways both traditional and novel.
\end{abstract}




\section{ACKNOWLEDGEMENTS}

This thesis has been made possible thanks to the encouragement and guidance of my supervisor and friend, Prof. Ummni Khan. Thank you for your outstanding editorial support, and helping me turn a loose idea that I stumbled over into a piece of work I'm truly proud of.

Thank you to my brilliant committee - Prof. Marie-Eve Carrier-Moisan, Prof. Lara Karaian and Prof. Neil Sargent for your time, efforts and feedback.

To my interviewees - thank you for your invaluable insights, and sharing your personal experiences with me.

I would also like to thank my family, M\&M Polowin and my feisty friends for the continuous love and support they've given me throughout this process.

Finally, it is to Jacob Polowin, my best friend and partner, that I dedicate this work. Your fierce love and dedication to helping me achieve my goals is what made, and continues to make, the (nearly) impossible, possible. 
$\underline{\text { Table of Contents }}$

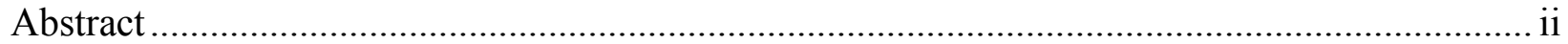

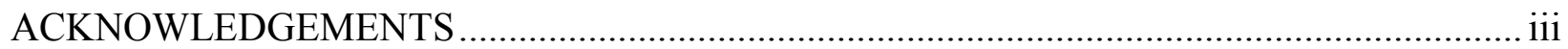

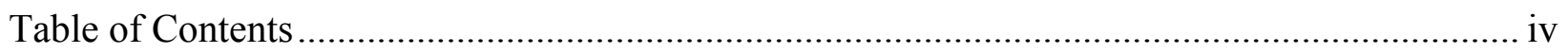

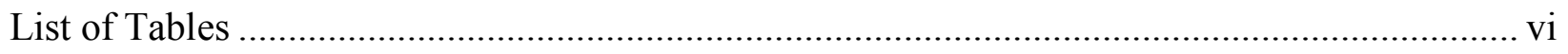

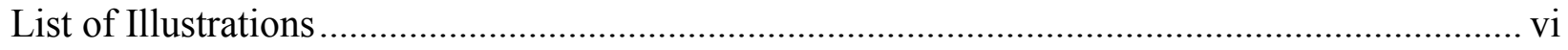

List of Appendices ............................................................................................................ vi

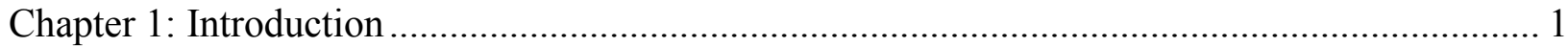

Chapter 2: Literature Review and Background of Study..................................................... 9

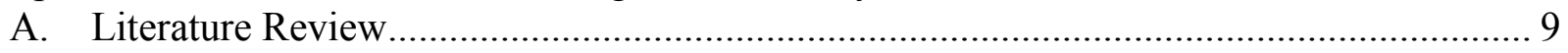

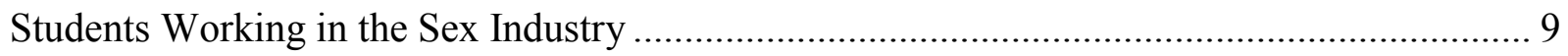

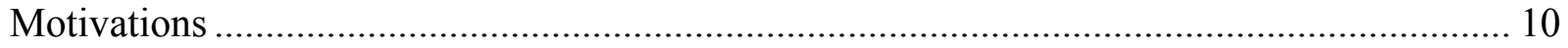

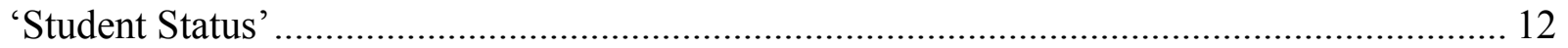

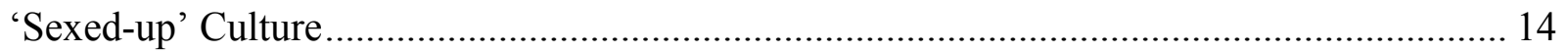

Changing Economic and Social Landscape .................................................................. 16

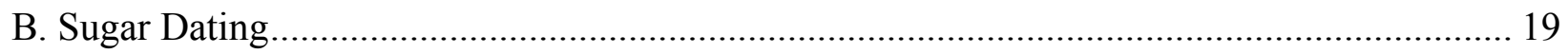

Sugar Babies and Sugar Daddies: Historical Context...................................................... 19

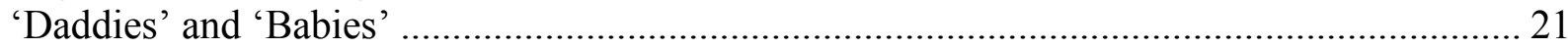

The Sugar Babies and Sugar Daddies of Seeking Arrangement........................................... 24

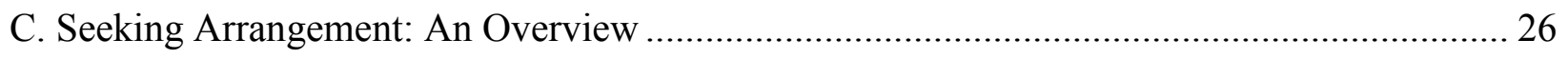

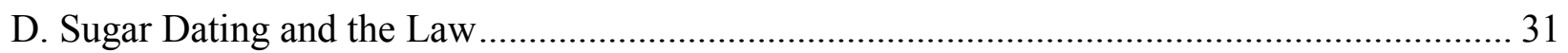

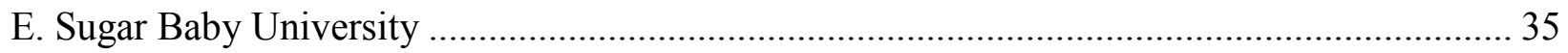

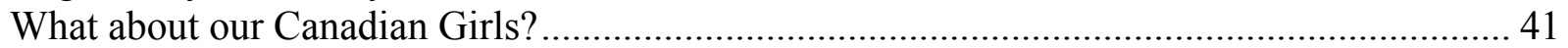

Chapter 3: Theoretical Framework and Methodology ...................................................... 46

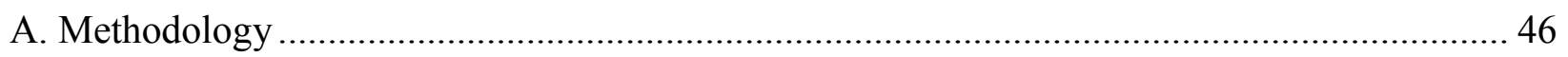

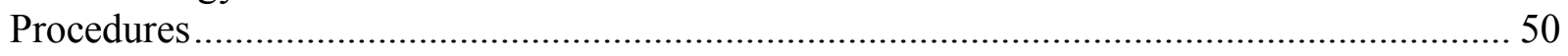

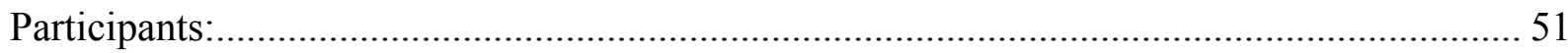

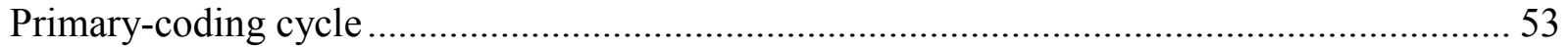

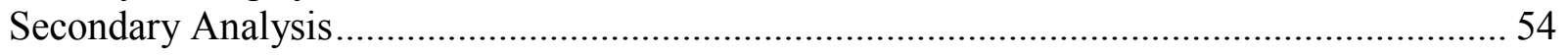

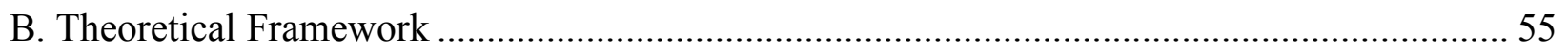

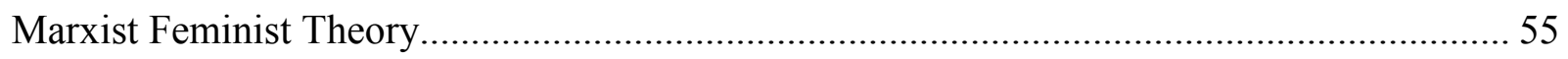

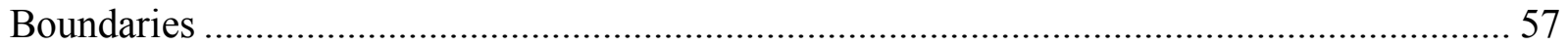

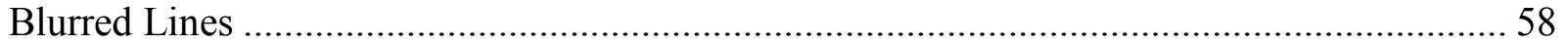

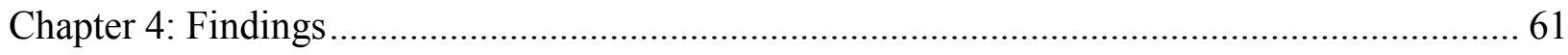

A. How do sugar babies conceptualize the sugar dating relationship? ................................... 61

Similarities and Differences in 'Sugar Dating' to Traditional Relationships ........................ 61

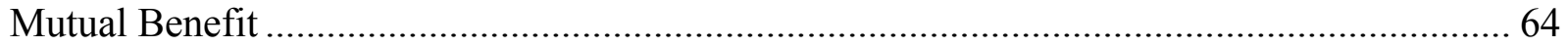

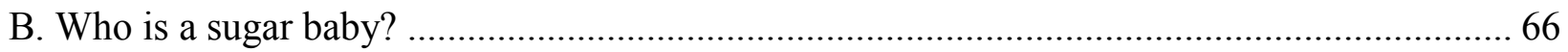




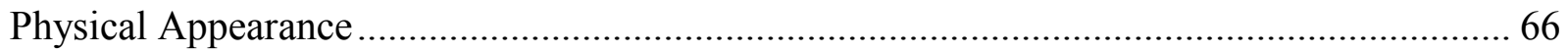

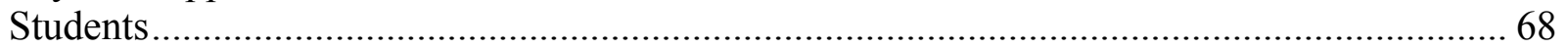

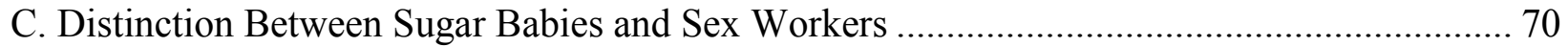

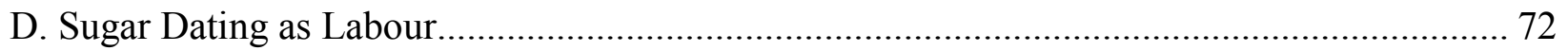

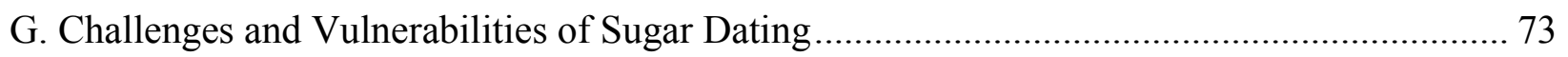

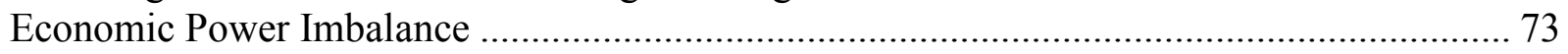

Lack of Experience and Established Norms ......................................................................... 74

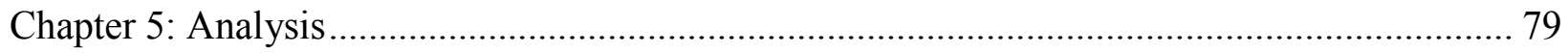

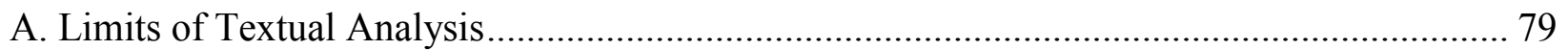

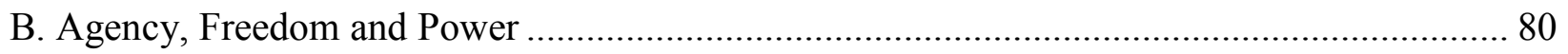

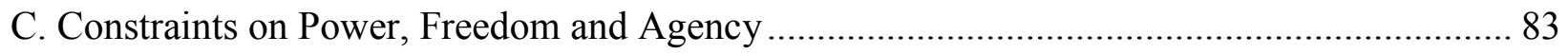

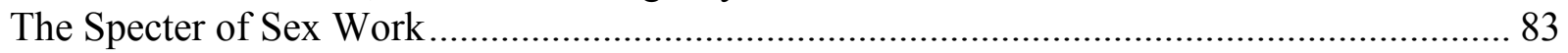

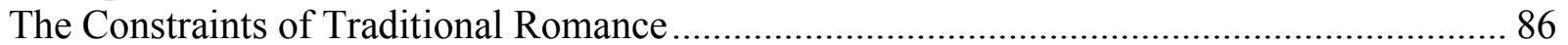

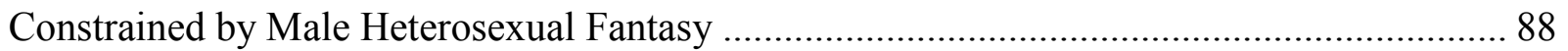

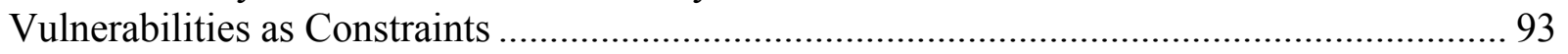

Sugar Dating as its Own Phenomenon................................................................................... 94

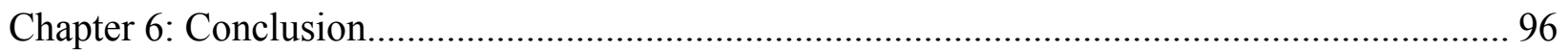

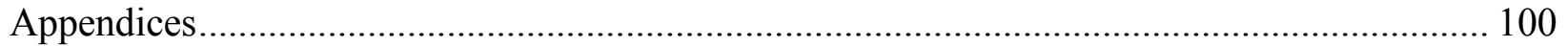

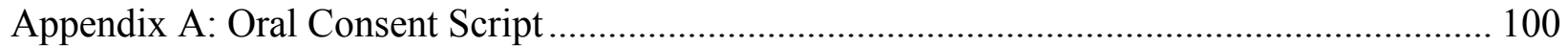

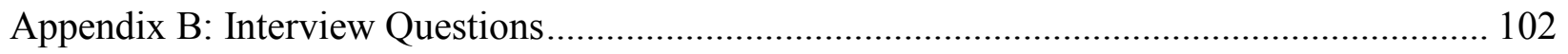

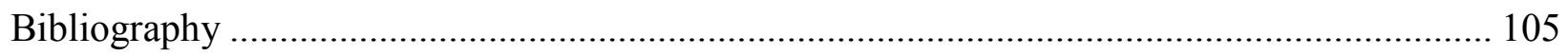




\section{$\underline{\text { List of Tables }}$}

Table 1 - Growing Trend of Sugar Babies and Sugar Daddies in Canada ................................. 27

Table 2 - Canadian Student Sugar Babies on SeekingArrangement.com.................................. 38

Table 3 - Top 20 Universities with Highest Numbers of Sugar Babies as of January 1, 2017 ... 39

Table 4 - Top 20 Canadian Universities for New Sign Up's in 2016

\section{$\underline{\text { List of Illustrations }}$}

Illustration 1 - Canadian users on SeekingArrangement.com ............................................. 27

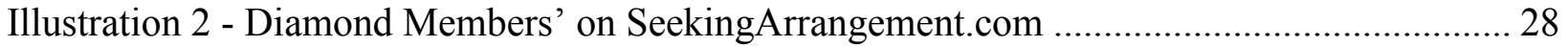

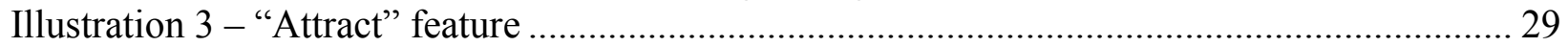

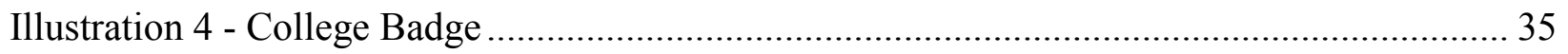

Illustration 5 - Sugar Baby University (SBU) Logo ............................................................. 35

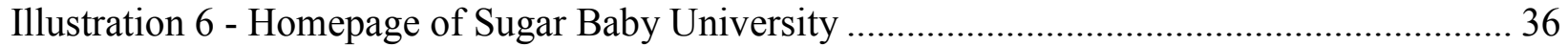

Illustration 7 - Promotional Video: "What's your number?" ................................................ 36

\section{$\underline{\text { List of Appendices }}$}

Appendix A.................................................................... 100

Appendix B. .............................................................. 102 


\section{Chapter 1: Introduction}

What is a sugar baby? According to Jolene, a student who has been sugaring for a few years:

The shortest description is that [being a sugar baby] is halfway between a girlfriend and an escort. To broaden that, it's less focused on an exchange of money for services and companionship [...] It's a little less 'wham, bam, thank you ma'am'. It's more about spending time with [a sugar daddy] who is interested in you - and interested in sponsoring your goals. It's like: 'you have student debt I'm going to help you do that. You want to start a business; I'll help you with that.' As far as the girlfriend side goes, part of your responsibilities - as I'll call it - is to be low-stress, look your best, be sexually available (if you decide sex is part of your arrangement), not constantly obviously - but you can't say you will, and then every time they want to you say no - it's part of the job description.

The financial side is, like, amazing - because being a student, and being young, is hard the job market isn't great, the cost of living is going up, it's hard to make ends meet; having someone help you with that is pretty awesome. The trips, the dinners, the amazing restaurants - even if you don't end up in an arrangement with them, you still have a nice meal out of it and occasionally cash as well. The emotional side is much more tiring [than the physical side]. If you didn't make a connection with your sugar daddy, the emotional stuff is so much more exhausting. You know, pretending you care. The physical stuff is over quickly, and you don't have to think about it - move on, whatever - however you feel about it. But the emotional stuff [pauses]... it drains you. Yes, there are a lot of similarities in a traditional relationship, which is why I - and other sugar babies I know separate it from escorting. Not to shame escorts - but it's just different.

- Jolene, Canadian student sugar baby 
I open with this excerpt from an interview conducted with a female Canadian university student 'sugar baby' to highlight the complexities of the 'sugar dating' phenomenon. Sugar dating is a recent trend wherein a 'sugar baby' offers some form of companionship and intimacy to a 'sugar daddy' - or less frequently, 'sugar mommy' — in exchange for some form of financial compensation (Nayar, 2016). The precise terms of the exchange are negotiated between the parties, but the premise is that there will be an equitable exchange of companionship and intimacy for financial compensation (Cordero, 2015; Miller, 2011; Motyl, 2012).

The concept of sugar dating is not new; historically, men and women would negotiate questions of money, intimacy and security in a variety of romantic contexts (Miller, 2011; Motyl, 2013; Nelson, 1993). In this sense, sugar dating resembles conventional dating in that both parties come to a relationship with different resources and expectations, and each party's ability and willingness to meet said expectations determine its success. However, sugar dating marks a significant divergence by requiring the resources and expectations of money and intimacy to be articulated at the outset. This necessitates a frank and open discussion of the exchange of financial compensation for companionship or intimacy in a way that violates the norms and rituals of conventional modern courtship. Moreover, sugar dating is being facilitated by the Internet through over 20 sugar dating websites, ${ }^{1}$ allowing for a sharp growth in user-registration rates by Canadian students enrolled in post-secondary institutions (Cordero, 2015).

Canada is in the midst of a student debt crisis (OECD, 2015). New estimates suggest that post-secondary student debt now totals over $\$ 16$ billion. With roughly 1.7 million students in the

\footnotetext{
${ }^{1}$ Other "sugar daddy" dating sites include sugardaddyclub.ca, sugardaddie.com, establishedmen.com, meetsuccessfulmen.com, millionairematch.com, sugardaddyfinder.com, mutualarrangements.com, wealthymen.com and dateamillionaire.com - and most popularly, SeekingArrangement.com (Cordero, 2015; Motyl, 2013).
} 
country, the average student debt is $\$ 26,819$ for a four-year bachelor's degree. The cost of postsecondary tuition has risen by $40 \%$ higher over the past decade (Statistics Canada, 2016). In addition, research suggests that there are increasing rates of precarious and low-paid, part-time employment for youth, and the cost of living is continuing to rise (Canadian Labour Congress, 2016; Statistics Canada, 2016). In light of the current economic climate, evidence suggests that Canadian students are turning to SeekingArrangement.com (SA), the world's largest sugar dating website, as an alternative method of financial aid (Logan, 2017; Nasrulla, 2016; Pardiwalla, 2016; Wade, 2016).

Launched in 2006, SA has a membership of five million people worldwide, across 139 countries, with a ratio of one sugar daddy or mommy to four sugar babies - resulting in what the website and mainstream media has termed 'the sugar baby phenomenon' (Cordero, 2015; Nayar, 2016; Zimmerman, 2015). The dominant image of a sugar baby is of an attractive female student or recent graduate who is both young (between 21 and 27 years old) and heterosexual (Wade, 2016; Zimmerman, 2015). ${ }^{2}$ As part of SA's marketing campaign called the Sugar Baby University, which solicits young women to join the site for its economic and social incentives, SA has gathered statistics on the nearly 2 million women who have registered as sugar babies using a .edu address - constituting roughly half of all sugar babies. This provides some indication about the socio-demographics of the sugar dating world. According to a $2017 \mathrm{SA}$ press release, there are currently 206,800 Canadian university or college students who are registered to the site. If these figures are accurate, this suggests that more than one in ten postsecondary students in Canada are seeking financial support from SeekingArrangement.com

\footnotetext{
2 Though evidence suggests more diversity in gender and sexuality among sugar baby users (i.e. see BrodesserAkner, 2015; Pardiwalla, 2016).
} 
(Wade, 2016). ${ }^{3}$ However, it should be noted that a sugar baby's student status is not necessarily verified by SA or an independent third party. For reasons discussed below, non-students may have a financial incentive in marketing themselves as 'students'. 4

Sugar dating has sparked interest and controversy in the media, with sugar babies being featured on Dr. Phil, the Anderson Cooper Show, MTV's True Life and most recently CBC's First Hand documentary entitled Sugar Sisters (SeekingArrangement Press, 2017). Given that sugar dating is premised on the explicit exchange of intimacy for financial compensation, sugar babies are often asked: "How is this not prostitution?" and "Why is this not prostitution?" (Miller, 2011; Motyl, 2013; Reed, 2015). While there are clear legal reasons for sugar babies to justify their relationships, there are arguably social judgments that underlie these speculations. On the one hand, some critics perceive sugar dating as a euphemism for 'prostitution', ${ }^{5}$ construing the participating students as naïve, vulnerable and exploited (Cribb, 2015; Greenslade, 2014; Johnson, 2012; McIntosh, 2016; Nasrulla, 2016; Skidmore, 2015; Teitel, 2016; Wong, 2014). On the other hand, some scholars argue that this broad interpretation fails to take into account the different types of 'arrangements' and the complexity of sugar dating, which may in fact be equally beneficial for both parties (Cribb, 2015; Miller, 2011; Motyl, 2013).

To some extent, extensive media interest in the sugar baby phenomenon may be part of a broader cultural fascination with the exchange of intimacy for money, manifesting in conflicting

\footnotetext{
${ }^{3}$ Of the 1.7 million, 979,000 are full-time students and 312,000 are part-time students (Universities Canada, 2017)

${ }^{4}$ Notably, in a personal e-mail with Alexis Germany, spokesperson for SA, she clarified that this 1 in 10 statistic reflects students who list their occupations as student, and have not necessarily registered with their .edu account. In chapter 2, I will outline the 'fasting growing sugar baby universities' based on students' registering with their .edu account. Bearing this disparity in mind, SA can confirm that 7157 or $3.4 \%$ of the 206,800 Canadian students are registered to the website - reflecting $0.42 \%$ of all Canadian students.

${ }^{5}$ I reference "prostitution" in the mainstream media's phrasing. From hereon in, I reference "prostitution" as "sex work" - which was coined in 1978 by sex worker activist Carol Leigh (also known as 'Scarlot Harlot'). It encompasses a wide range of sexual services, and positions selling sexual services as a form of labour (Berg, 2014).
} 
and polarizing images of individuals who participate in such an exchange (Sanders, 2015; Zelizer, 2005). On a spectrum ranging from 'drug-addicted street victim', to a 'glamorous, empowered, high-paid escort', where do Canadian student sugar babies fit (Sanders, 2015)? Do they fit at all? Media hype and sensationalism aside, these polarized conceptions of sugar dating overlap with historical and contemporary debates within feminist circles, including 'sex work' vs. 'prostitution', 'agency' vs. 'coercion', and 'good sex vs. 'bad sex' (Miller-Young, 2014; Sanders, 2015; Vance, 1984; Van der Meulen, Durisin, \& Love, 2013). ${ }^{6}$ These debates form part of the discursive backdrop of the sugar dating phenomenon.

While there is insight that can be gleaned from researching the variety of outside opinions on sugar dating, and their social, moral and legal underpinnings, this is not the focus of my research. Rather, recognizing that most of what is currently known about the Canadian student sugar dating experience comes from anecdotal stories that have been filtered through the media, I am interested in exploring how Canadian student sugar babies themselves make sense of the relationships they seek. Drawing on the content of one popular sugar baby forum, as well as data gathered from my interviews with two active sugar babies, my thesis explores the lived experiences and perceptions of the participants. In this way, I employ a feminist methodology that centers on sugar babies' experiential knowledge (Doucet, 2007). While I acknowledge that sugar dating relationships come in a variety of forms, ${ }^{7}$ sugar dating seems to be a gendered phenomenon. The vast majority of sugar babies identify as female, most of whom are seeking heterosexual relationships with male sugar daddies. ${ }^{8}$ In light of this dynamic, my thesis and

\footnotetext{
${ }^{6}$ For a discussion on the contentious debate regarding the meaning of women in prostitution, see: (Koken, 2012, pp. 210-211); or more broadly, (Love et al., 2013).

${ }^{7}$ For example, see anecdotal evidence of a gay male student sugar baby: (Baker, 2016). or dating a female sugar momma: (Vice, 2015).

${ }^{8}$ Of this 206,800 student sugar babies in Canada, 195,562 identify as female students and 11,238 identify as male
} 
research focus on the experiences of this numerically dominant group.

There is a dearth of information on student sex workers in a Canadian context, and academic research on sugar dating is in its infancy (Lavoie, Thibodeau, Gagné, \& Hébert, 2010; Reed, 2015; Motyl, 2013; Nayar, 2016; Zimmerman, 2015). Thus, the purpose of this study is to contribute to a scarce body of research that examines the 'sugar baby phenomenon' in a Canadian context. In particular, my research focuses on the following questions: how do sugar babies manage the blurring of lines between sex work and traditional romantic relationships inherent to sugar dating? Do sugar babies articulate shared understandings about how sugar dating compares and differs from traditional understandings of sex work and 'non-sugar' conventional relationships? What are their motivations for being in a sugar relationship? How do sugar babies identify within their relationship - do they perceive themselves as sex workers, as girlfriends, as neither or as both? Finally, how do they exercise power and agency within these relationships?

To achieve this aim, Chapter 2 outlines the existing literature on student's motivations, perceptions and experiences working in the sex industry (Haegar \& Deil-Amen, 2010; Roberts, Bergstrom \& La Rooy, 2007; Roberts et al., 2010; Roberts, Jones \& Sanders, 2013; Sanders \& Hardy, 2015). I will examine the changing economic landscape - including the 'mainstreaming' and 'normalization' of the sex industry - which has arguably made sugar dating more socially acceptable (Bernstein, 2007; Sanders, 2008; Sanders, 2015). In addition, I will highlight how recent scholarship on sex work suggests that the 'girlfriend experience', "which mimics (or even reproduces) the emotional intimacy of a loving relationship in addition to satisfying sexual needs" (Nayar, 2016, p.2), is becoming an increasing central feature of sexual services 
(Bernstein, 2007; Sanders, 2008). Thus, I will situate the sugar dating phenomenon within the broad category of 'sexual labour', with sugar babies providing a form of the 'girlfriend experience'. I will then provide an overview of the SeekingArrangement website, highlighting the increasing registration rates for Canadian students enrolled in post-secondary institutions and discussing the dominant narrative that characterizes media coverage of the sugar dating phenomenon.

In Chapter 3, I will describe the methodology used to gather and analyze the data. I will employ a social constructivist epistemology, as this paradigm recognizes the notion that multiple truths exist. The constructivist researcher accepts the idea that through sharing multiple views and honoring differences and contexts, one can gain a better understanding of their experiential realities (Tracy, 2013). To this end, I will conduct a qualitative textual analysis of user comments on the online, publicly accessible "LetsTalkSugar" forum. LetsTalkSugar is a website created by SA that allows sugar babies and sugar daddies to post questions or comments under different sugar-related topics. I will also analyze two in-depth interviews to understand the experiential reality of sugar dating articulated by two Canadian student sugar babies. The interviews were audio-recorded, transcribed, analyzed and coded based on reoccurring themes. Both methodologies - with their strengths and weaknesses - are instruments that offer different insights to the sugar dating subculture (Tracy, 2013).

The key findings that emerged from this data will be discussed in Chapter 4, which delves into questions including: What is sugar dating? What is a 'sugar baby? What motivates sugar babies? How is sugar dating not sex work? Finally, how is power and agency exercised in their sugar relationships? To theoretically frame the analysis, I will draw on Marxist feminist insights to recognize women's labour-power and the value of social reproduction, Elizabeth 
Bernstein's (2007) notion of 'bounded authenticity', Erving Goffman's (1959) dramaturgical theory to analyze social interactions, and Arlie Hochschild's (1983) 'emotional labour’ framework.

Bearing the limits of the study in mind, Chapter 5 will demonstrate that sugar babies recognize and value the difference between a sugar relationship and a traditional relationship. While emotional involvement is encouraged, it should not exceed the objectives of the 'sugar' relationship. Sugar babies report that their primary motivator is money, suggesting that they openly accept the economic underpinnings of a sugar relationship. However, they use subtle, and at times contradictory distinctions to separate themselves from sex workers. These distinctions complicate how they negotiate agency and power in their relationships. The implications of these conceptions will be discussed.

In Chapter 6, I will provide concluding thoughts. I will note that this study provides one snapshot of the experiential reality of sugar dating as articulated by two Canadian student sugar babies, and users on the 'LetsTalkSugar' website. Whilst I do not in any way suggest that there is a correlational relationship between the growing phenomenon of sugar babies and the increasing cost of with post-secondary education in Canada, I suggest that the results can be used as a point of reference for future research endeavors - including motivations for students accessing the informal economy, the continued 'normalization' of the sex industry, and the potential disruption of contemporary understandings of modern dating. 


\section{Chapter 2: Literature Review and Background of Study}

\section{A. Literature Review}

\section{Students Working in the Sex Industry}

Research suggests that there is a growing phenomenon of female university students working in the sex industry to pay for their post-secondary studies (Haegar \& Deil-Amen, 2010; Roberts, Bergstrom \& La Rooy, 2007; Roberts, Sanders, Myers \& Smith, 2010; Roberts, Jones \& Sanders, 2013; Sanders \& Hardy, 2015). The phenomenon appears to be international, having been documented primarily in the United Kingdom (Roberts et al., 2007; Roberts et al., 2010; Roberts et al., 2013; Sanders \& Hardy, 2015), but also Australia (Lantz, 2005), the United States (Bernstein, 2007; Haegar \& Deil-Amen, 2010; Motyl, 2013; Reed, 2015) and France (Duvall Smith, 2006). Such studies have examined students' engagement in pornography (Deil-Amen, 2010), erotic massaging, webcamming (Sinacore et al., 2015), stripping (Roberts et al., 2010) and most popularly, escorting (Koken, 2012; Sagar, Jones, Symons \& Bowring, 2015).

It is estimated that approximately $2 \%$ of students in these countries fund their studies through sex work (Roberts et al., 2010). An earlier study (Roberts et al., 2000), in the UK estimated a rate of $3-4 \%$, which is close to the French figures. There are notable methodological challenges, including the nature of a marginalized, hidden population (Shaver, 2005; Willman, Livy \& Ditmore, 2010) and the social stigma attached to sex work (Betzer, Kohler \& Schlemm, 2015; Bruckert \& Hannem, 2013; Haeger \& Deil-Amen, 2010; Koken, 2012) that make arriving at precise figures difficult. Nonetheless, there is a dearth of information on post-secondary student sex workers in Canadian context (Sinacore, Jaghori \& Rezazadeh, 2015; Lavoie, Thibodeau, Gagne \& Hebert, 2010). 
One study conducted by Lavoie, Thibodeau, Gagne and Hebert (2010) found that of 815 secondary students in the province of Quebec, 4\% bought and 3\% sold sex, with a higher number of females selling, and more males buying sex. Given the sexual nature of university campuses (Bradshaw, Kahn \& Saville, 2010; Heldman \& Wade, 2010; Ronen, 2010; Snapp, Lento, Ryu \& Rosen, 2013), one can anticipate that the percentages of university students buying and selling sex will be the same, or potentially higher. Building on this previous study, Sinacore, Jaghori \& Rezazadeh (2015) examined the narratives of four female Canadian university students working in the sex trade (two erotic massagers and private escorts, one stripper and webcam performer and one lap dancer). Consistent with previous literature, the study identified that money was the primary motivator that resulted in both the receptiveness of students to sex work, as well as their willingness to engage in it on an going basis (Haegar \& Deil-Amen, 2010; Lantz, 2003, 2005; Miller, 2011; Roberts et al., 2007; Roberts et al., 2010; Roberts et al., 2013; Ross \& GomezRamirez, 2014; Sagar et al., 2015; Sanders \& Hardy, 2015).

\section{$\underline{\text { Motivations }}$}

Past and present studies indicate that rising tuition costs, cuts to bursaries, and the increased pressure of student debt has contributed to students entering the sex industry (Haegar \& Deil-Amen, 2010; Roberts et al., 2007; Ross \& Gomez-Ramirez, 2014; Sanders \& Hardy, 2015). Other reasons include ineligibility for governmental income support, the lack of stability in the youth labour market - which is largely comprised of casual, uncertain and low-paid jobs (Lantz, 2005) - and the inability of the family unit to financially support its children through university (Lantz, 2005, 2003; Reed, 2015; Sanders \& Hardy, 2015). In addition, numerous studies indicate the primary reasons for entering and staying in the sex industry, as opposed to other types of employment are: labour conditions; shorter working hours; flexibility; higher 
wages; cash-in-hand work; increased autonomy; and independence (Haegar \& Deil-Amen, 2010; Hafer, 2011; Lantz, 2003, 2005; Reed, 2015; Roberts et al., 2010; Roberts et al., 2007; Sanders \& Hardy, 2015). Sex work is conducive to student life as it allows students to maximize their incomes within a shorter period of time (Haegar \& Deil-Amen, 2010; Roberts et al., 2007), especially compared to other poorly paid jobs that are often available to students (Haeger \& Deil-Amen, 2010; Hafer, 2011; Lantz, 2003, 2005; Roberts et al., 2010; Ross \& GomezRamierz, 2014).

Similarly, both Haegar and Deil-Amen (2010) and Lantz (2005) highlight the monetary benefits and immediate financial stability and work-life balance as major motivating factors towards students' involvement within the sex industry. As a result, studies indicate the sex industry is an attractive and lucrative option for students to finance their post-secondary education, as it offers the quickest and highest rate of return (Berstein, 2007; Haeger \& DeilAmen, 2010; Lantz, 2005; Miller, 2011; Roberts et al., 2007; Roberts et al., 2010; Sanders \& Hardy, 2015).

Finally, international students may perceive the sex industry as a lucrative employment option given the various institutional barriers they face on exchange (Cusick, Roberts \& Patton, 2009; Gross, 2006; Lantz, 2003; 2005; Sinacore et al., 2015). For example, the combination of inflated university fees and charges with visa restrictions that only permit international students to work a maximum of 20 hours per week means the illegal, quick and cash-in-hand aspects of sex work may be particularly appealing (Lantz, 2005; 2003, Sanders \& Hardy, 2015). The trend of increasing fees, limited time abroad, possible language barriers and additional living and course-related expenses are major forces driving international students towards work in the sex industry (Lantz, 2003; 2005; Sagar et al., 2015; Sinacore et al., 2015). 
However, while student sex workers report having more money and time to complete their studies, this may not necessarily result in higher academic achievement. Some students report a lack of academic motivation, while others report dropping out of school altogether so that they can make more money in sex work (Dolman, 2008; Milne, 2006). Poor academic performance has negative implications for students' future aspirations, personal relationships, and mental well-being (Hodgeson \& Simon, 1995). In addition, sex work-related stigma, as well as the emotional and sexual demands of the labour itself, places a unique burden on the women who participate (Koken 2010; Haegar \& Deil-Amen, 2010; Lantz, 2005; Pheterson 1990; Sagar et al., 2015). One 2010 study conducted by Haegar and Deil-Amen noted that college sex workers were more concerned about facing negative stereotyping than physical or sexual violence.

Research has illustrated that students who face significant stereotyping in the college environment are more likely to drop out than their peers (Osborne \& Walker, 2006). Many students fear disclosure of their sex work to classmates, professors, friends and family, (Haegar \& Deil-Amen, 2010; Lantz, 2005) conceptualized as anticipatory stigma (Goffman, 1963; Quinn \& Chaudoir 2009; Sanders, 2005; Scrambler, 2007; Unger, 1998, 2000). The burden of keeping their work lives a secret can cause a high amount of stress, and also impedes some students from finding a social support network at school (Haegar \& Deil-Amen, 2010; Sagar et al., 2015).

\section{'Student Status'}

Not only does the notion of students working in the sex industry run contrary to popular perceptions of university life, it also conflicts with the stereotypes of women who are employed as sex workers (Bernstein, 2005, 2008). Myths of those who work in the sex industry are commonplace. Specifically, the typical popular image of the sex worker is of a runaway, drug 
addict, or delinquent, or of a victim forced into the sex industry by coercion or desperation. Likewise, many people assume that sex work does not require skills, and that sex workers lack intelligence or have no other marketable skills and, as a result, work with their bodies (Bernstein, 2007; Sanders \& Hardy, 2015). On the other hand, recent studies suggest that the 'student status' of the women working in the sex industry is seen as attractive and highly desirable because it reflects their youth (Roberts et al., 2007), their sexualized identity and education level (Bernstein, 2007). Research suggests that student sex workers can command higher wages than older sex workers (Roberts et al., 2007; Moffat \& Peters, 2004) - irrespective of whether they are, in fact, students (Roberts et al., 2010).

There is often a noted disparity between how student sex workers view themselves (as respectable women) and how they view other women who work in the sex industry (Haegar \& Deil-Amen, 2010). They will often highlight their education and aspirations for a more mainstream' career (such as nursing, teaching or counselling) to differentiate themselves from the 'other' (non-student) women (Haeger \& Deil-Amen, 2010; Koken, 2012; Roberts et al., 2010, Sinacore et al., 2014). As such, they often do not embrace the identity of a sex worker, but instead find ways to manage the conflicting, dual role. Students methods of justification differ, but are often focused on defending their work against feminist critiques of the sex industry (Grasse, 1999; Mattson, 2005; Ruffin, 2006). Thus, student sex work, though controversial, may be less socially stigmatized, as it is understood as a method to supplement one's income while obtaining an education. In other words, it is framed as a transitional, temporary phase (Sanders, 2005). 


\section{‘Sexed-up' Culture}

While involvement within the sex industry is typically perceived as deviant and outside of the realm of mainstream of society (Lantz, 2003), there have been significant changes in the economic, social and cultural acceptance of sexual consumption in the urban economies of western countries during late capitalism (Bernstein, 2007; Haeger \& Deil-Amen, 2010; Holt \& Blevins, 2007; Sanders, 2008; 2015; Zimmermann, 2015). Students are living in a 'sexed up' culture that has created a more relaxed and liberal attitude towards sex work, thus making the choice to participate in the industry more feasible (Attwood, 2006; Brents \& Sanders, 2010; Cusick, Roberts, \& Paton, 2009; Haeger \& Deil-Amen, 2010; Sanders \& Hardy, 2015; Sevcikova \& Daneback, 2011). In addition, the growing public tolerance and understanding of the financial vulnerabilities of the student population, regardless of socioeconomic class, has arguably contributed to the attitudinal changes amongst the general public towards students involved in the sex industry (Attwood, 2006; Brents \& Sanders, 2010; Roberts et al., 2010; Roberts et al., 2013; Sanders \& Hardy, 2015). More specifically, the expectation now placed on students to support themselves throughout school, in combination with inflated tuition prices and often inadequate government support has increased public tolerance of students making the decision to engage in sex work (Roberts et al., 2010; Sanders \& Hardy, 2015).

The term 'sex work' encompasses a wide range of behaviors that imply varying levels of intimacy (Sagar et al., 2015; Weitzer, 2010), and thus can be distinguished through the categorization of 'direct' and 'indirect' sex work. According to Sagar et al. (2015), 'direct' sex work refers to the sale of sexual services that involves contact with a client, such as street-based prostitution. 'Indirect' sex work is classified as sexual services that do not necessarily involve direct intimate contact with a client per se, but may focus on emotional and psychological 
labour, including webcamming, phone sex or erotic dancing. In this conception, most students participate in indirect sex work (Roberts et al., 2010; Sagar et al., 2015; Sanders, 2015).

However, recent scholarship on sex work suggests that the lines between direct and indirect sex work are becoming increasingly blurred. Cultivating feelings of intimacy, connection and romance are increasingly central features of sexual services, such as the 'girlfriend experience', which mimics the emotional intimacy of a loving relationship along with satisfying physical sexual needs (Bernstein, 2007; Frank, 1998; Love et al., 2013; Sanders, 2008; Zelizer, 2005). For example, in her study of male customers seeking the 'girlfriend experience', Sanders (2008) draws out their desire for genuine connection with, and mutual pleasure enjoyed by, a sex worker.

The girlfriend experience occurs whenever the woman is enthusiastic about the sex act and makes the client feel special, as though they were in a "consensual, non-commercial relationship" (Sharpe \& Earle, 2003, p. 50; Hughes 2004). Such an experience may involve a sex worker allowing the john to kiss them on the lips and perform oral sex on them. Or, it might involve going to dinner and a movie, followed by intercourse (Sanders, 2005; Sanders \& Hardy, 2015). Similarly, Bernstein (2007) argues that middle-class and independent escorts seek out this authentic interpersonal connection. However, she states that both escorts and clients desire an authentic relationship, only so long as it is clearly bound by a financial exchange - a concept she refers to as "bounded authenticity" (p. 474). Scholars argue that the growing demand for sex workers who perform feelings of romantic yearning and passion is part of the 'normalization' or 'mainstreaming' of sex industries (Attwood, 2006; Bernstein, 2007; Brents \& Sanders, 2010; McNair, 2002; Sanders, 2015). 


\section{Changing Economic and Social Landscape}

The organization and marketing of the sex industry is such that 'sex' as a privatized product is now sold alongside mainstream industries - including leisure, entertainment and pleasure industries such as tourism (DeCurtis, 2003; Hughes, 2004), and technology (Sevcikova \& Daneback, 2011). Mainstreaming refers to the expansion of the sex industry due to the use of conventional business models, increased visibility, growth of middle-class clients and middleclass sex workers. In turn, these trends encourage the normalization of the sex industry (Bernstein, 2007; Brents and Sanders, 2010). Mainstreaming is facilitated through the process of 'upscaling', which involves moving away from working-class contexts towards middle-class contexts, where sexual services are made more desirable by the notion that middle class sex workers choose this work out of free will and enjoyment, rather than strictly economic need (Brents \& Sanders, 2010, p. 43). As a result, clients become "un-self-conscious" (Bernstein 2007, p. 392) about their participation in these practices because their acts are viewed as consumption for recreational purposes (as opposed to a client with desperation).

Without impeding on a client's masculinity or belief that he does not need to purchase relations, men can access numerous beautiful partners who report experiencing a more authentic encounter, than the historically impersonal nature of encounters with 'streetwalkers' (Bernstein, 2007; Sanders, 2013). Sanders (2013) argues that this is a "continuation, rather than a transformation of middle-class cultural definitions of where a sexual relationship can legitimately come from, how it can be provided" (p. 197). The market has fed on these changes through the expansion of the sex industry. As such, sexuality has been fashioned into commodities, creating new meanings and experiences connected to buying and selling sex. 'Emotional consumption' (Egan, 2005), 'emotional connectedness through “mutual” satisfaction, 
romance and friendship' (Sanders, 2008) and 'bounded authenticity' (Bernstein, 2007) enables 'the girlfriend experience' to be marketed (Sanders, 2005) and consumed (Sanders, 2008). These enhanced meanings purchased through commercial sex contribute to new forms of sexual and emotional labour, which provide both viable economic earning power for women, and a desired commodity for men who seek to buy fantasies that are bounded and contractual emotional and sexual experiences (Bernstein, 2007; Haegar \& Deil-Amen, 2010; Nayar, 2016). The freedom to choose is facilitated by the availability of new technologies, primarily the Internet, which remain largely unregulated.

The Internet has been co-opted by the sex trade to provide online communities where individuals can indulge in and explore sexual desires and find companionship in all forms (Fullick, 2013; McWilliams \& Barret, 2014; Ranzini \& Lutz, 2016; Sevcikova \& Daneback, 2011). There are now tens of thousands of websites dedicated, in one way or another, to buying and selling intimate services - most popularly, escort agencies (Sharpe \& Early 2003; Hughes, 2004), and other sex-oriented contact websites. The Internet has made it easier for indoor sex workers to work without third-party management, to conduct their business with minimal interference from the criminal justice system, and to recoup greater profits by honing their sales pitches to a more elite audience, while still offering the enticing 'no strings attached' encounter (Bernstein, 2001; 2007; Lane 2000; Prasad, 1999; Quinn \& Forsyth, 2005).

Intimate relations pursued in the marketplace are "marketed as uncomplicated" and “free” (Brents \& Sanders, 2010, p. 46; Bernstein, 2001; Sanders \& Hardy, 2015). Scholars such as Brown (2015) and Rottenberg (2014) discuss a 'neoliberal rationality' becoming the norm, where relationships are tracked for progress, manipulated for return on investments, and evaluated by cost-benefit rations (Bernstein, 2001; Bernstein, 2007; Brents \& Sanders, 2010). 
This lends an "element of disposability [...] if they are not providing full satisfaction" (Brents \& Sanders 2010, p. 44; Brown, 2005; Egan, 2005; Rottenberg, 2014).

Studies suggest that as the critique of marriage as a transactional or bargaining relationship becomes more salient, so too has a cynicism towards what is seen as a 'hypocritical' illusion of 'romantic love' (Prasad, 1999, p. 202; Nayar, 2016). For example, in her study of regular customers of sex workers, Prasad (1999) argues that patrons of sex workers voiced complaints about the hidden exchange of money and sex in marriage, recalling critiques made by feminists such as Mary Wollstonecraft and Carol Pateman (1988) (Crafton, 2011; Nayar, 2016). ${ }^{9}$ These patrons "valued prostitution" for offering freedom from "the social complications, obligations, and ambiguities" of idealized romantic love (1999, p. 204). Prasad's (1999) analysis suggests that, at least for some, the intimacy of "neutral, more cleanly exchangeable pleasures of eroticism" is preferred over the complications and unspoken bargaining associated with romantic love (p. 206).

While there has certainly been a "mellowing" of social attitudes towards commercial sex to some extent, 'mainstreaming' has been uneven process (Sanders \& Hardy 2015, p. 759; Brents and Sanders, 2010). With the shift of making the sale of sex more mainstream, there is also social ambivalence that results in peculiar policy implementation when it comes to valuing and protecting its workers (Nayar, 2016). For example, sex work has been further regulated under Canadian criminal law. Effective December 2014, the conservative government passed Bill C36, the Protection of Communities and Exploited Persons Act which made it illegal to purchase

\footnotetext{
${ }^{9}$ Pateman (1988) for example, defines the difference between paid sex and loving sex as: '[the] difference between the reciprocal expression of desire and unilateral subjection to sexual acts with the consolation of payment: it is the difference for women between freedom and subjection' (p. 204).
} 
sex for the first time ever in Canadian history. ${ }^{10}$ According to the Canadian Department of Justice, the new legal framework reflects a significant paradigm shift away from the treatment of prostitution as 'nuisance', as found by the Supreme Court of Canada in the Bedford case ${ }^{11}$, toward treatment of prostitution as a form of sexual exploitation that disproportionately and negatively impacts on women and girls.

While Bill C-36 anchors itself to the goal of community protection from public nuisance, it also advances an understanding of sex workers as consistently vulnerable and exploited - but also criminalized. Sex workers are put in a unique and somewhat contradictory social position of needing to be 'protected' but also 'punished', in some circumstances. From its very own title, Bill C-36 conveys two particular groups worthy of inclusion and protection in connection with the governance of sex work: the "community" and "exploited persons" (Campbell, 2015). Thus Bill C-36 requires sex workers to either be 'in' or 'out' of the community; they must choose to perform their role as either victims or criminals.

As described above, the tensions between more liberal attitudes towards consumers in the sex industry, and further criminalization of those involved helps provide context for a relatively new online phenomenon: sugar dating (Greenslade, 2014; Mckeon, 2013; Motyl, 2013; Reed, 2015; Zimmerman 2015).

\section{B. Sugar Dating}

\section{$\underline{\text { Sugar Babies and Sugar Daddies: Historical Context }}$}

Sugar dating is a trend which can be described as a relationship wherein a sugar daddy or, less frequently, a sugar mommy (wealthy man or woman) agrees to financially compensate

\footnotetext{
${ }^{10}$ The act continues to criminalize any party involved with the sale of sex in public places where children might reasonably be expected to be present (Department of Justice - Canada, 2014).

${ }^{11}$ For a full discussion of the Bedford case, see (Campbell, 2015)
} 
(either through cash and/or gifts) a sugar baby (young and in-need female, or less commonly, male) in return for a companionship of some degree (Nayar, 2016; Miller, 2011). According to the Oxford English Dictionary (2017), the term 'sugar' is slang, but is often used as a modifier to 'sweeten' something, and as a euphemism for money.

While its origins are obscure, some think the term sugar daddy might stem from the 1908 marriage between Adolph Spreckels, an American heir to a sugar fortune, with a woman 24 years his junior. His wife, Alma de Brettville called him a sugar daddy (Gobind \& du Plessis, 2015; Selinger-Morris, 2016). Historical popular fiction suggests that sugar daddies were subject to a variety of crude stereotypes. For example, in the 1927 silent Laurel and Hardy film Sugar Daddies, an oil tycoon struggles to escape a woman he accidentally married while drunk, succeeding by pretending to be his butler's wife (Sellinger-Morris, 2016; Nelson, 1993). Likewise, Eric Partridge's (1949) A Dictionary of the Underworld pejoratively defines a sugar daddy as: “(a) a fatuous, elderly man supporting, or contributing to the support of a 'gold digger' or other loose girl or woman."

More recently, Nelsons (1993) applies the concept of a 'gentleman' to help understand the behaviours of sugar daddies. ${ }^{12}$ His exploratory study of 209 women, and 59 sugar daddies, who were involved in extramarital affairs (not with each other) revealed that the sugar daddies' behaviour was ruled by a code of conduct, and that there was an etiquette to the sugar daddy role. This allowed them to conceive their behaviour as honourable - perceiving themselves as a "ladies' man", "something of a Casanova, virile and wealthy enough to maintain a woman in luxurious style," rather than anti-social or deviant (p. 50). Moreover, the sugar daddies and mistresses framed their relationships not as a sex-for-hire arrangement, but as more benevolent

\footnotetext{
${ }^{12}$ For a thorough discussion on the origins of a 'gentleman', please see: (Nelson, 1993 p. 52-58)
} 
(Nelson, 1993).

Nelsons (1993) also traces a historical overview of how the concept of a 'kept woman' has been reformulated throughout history. A kept woman is suggested to mean someone who is maintained in a comfortable (or even lavish) lifestyle by a wealthy man so that she would be available for his sexual pleasure. As the term implies, the man would assume responsibilities for her debts - although not legally required to do so - in the same way he did for his wife. A kept woman was not a prostitute or sex worker; while in some sense sex and money were exchanged, the main difference was having an emotional and social relationship, rather than a direct, quid pro quo between the money and sex act. In addition, the 'kept' status follows the establishment of a relationship of indefinite term as opposed to an explicit paid sexual transaction (Nelson, 1993).

\section{'Daddies' and 'Babies'}

Linguistic scholars suggest that the terms 'daddy' and 'baby' are rife with metaphor, as they symbolize a relationship that can be recognized cross-culturally. According to the Oxford English Dictionary (2017), the etymology of 'daddy' is unclear. However, the OED reports that it first appeared in the $15^{\text {th }}$ century, in representations of rustic, humble or childish speech. The $O E D$ states: “the forms $d a d a$ and tata, meaning 'father,' originating in infantile or childish speech, occur independently in many languages" (Robb, 2014). In other words, 'dad' or 'daddy' might come from baby talk. There are global variations of the term 'daddy' ${ }^{13}$, which seems to reflect a shared experience of kinship. Moreover, the origin of 'baby' is also obscure - but is

\footnotetext{
${ }^{13}$ For example, the variations of the term 'daddy' include 'tata' in Poland, and 'baba' in South Asia; there are different language uses for the term father, like Spanish 'padre' and German 'Vater'. Many other languages have similar terms for 'baby', including the French bebe to the Chinese baobei (Robb, 2014).
} 
thought to form from babies 'babbling'. That widespread understanding of what it's like to have a parent is part of the reason the word dad pops up so often in slang.

The 'daddy-baby' relationship reflects a disparity in gendered power. Now, the $O E D$ (2017) defines “daddy" as a noun, one's father; "the oldest, best, or biggest" example of something 'the daddy of all potholes'; or "the best or most successful person." 'it's you who's calling the shots now-you're the daddy'. In contrast, the OED (2017) defines "baby" as a noun, A very young child; and, as a verb, treat (someone) as a baby; pamper or be overprotective towards; and as an adjective; Comparatively small or immature of its kind; One's particular responsibility or concern; A lover or spouse (often as a form of address).

The $O E D$ (2017) reports that 'baby' was first used in the seventeenth century as a romantic term of endearment. In Aphra Behn's 1694 novel, Love-Letters Between a Nobleman and His Sister, Philander, the male hero, declares himself "not able to support the thought that any thing should afflict his lovely Baby" (Robb, 2014). ${ }^{14}$ Some research provides an evolutionary explanation for men infantilizing their romantic partner. In Konrad Lorenz's (1943) study, he argued that babies' cuteness is an evolutionary advantageous adaptation without which they wouldn't survive; adults need some sort of incentive to provide them with constant care, and Lorenz thought that motive was admiring their cuteness. He believed men carry this preference into adulthood by looking for women who retain elements of babyish "cuteness" (Glocker et al., 2009). But men's possible impulse toward infantilizing can't explain the whole story. For one thing, though "baby" began its career as a term of affection for women - the OED's first five entries refer to a female - today, it's applied just as often to men (Robb, 2014).

\footnotetext{
${ }^{14}$ In spite of the novel's title - and as fitting as it would be if "baby" were coined in an incestuous context - the term "sister" is a relation by marriage (Robb, 2014).
} 
Some scholars take issue with the term 'baby' as infantilizing, reflecting abnormal sexual desires and possessive behavior. According to Dr. Logan Levkoff, the author of several books on sex and relationships:

A 'baby' is an actual thing - there's an image of something [...] babies are like the ultimate possession. When someone is your baby, they're yours. If we're using the term because we want to maintain some kind of hold over our partner, then maybe it's time to reevaluate the relationship. (Robb, 2014).

On the other hand, it has been pathologized whether calling a partner 'daddy' is an indicator of 'daddy issues'. According to sex therapist Vanessa Marin,

Yes, 'daddy' can mean 'father,' but we also use the word to indicate when someone is the boss, in charge, a protector, or doing a good job. That's usually the meaning women are going for in the bedroom. It's a bit of a 70s porn cliché. I've never run across a woman who called her partner 'daddy' because she genuinely liked fantasizing that he was her father. ${ }^{15}$

The Freudian implications, too obvious to be missed, might provide insight for why sugar babies and sugar daddies are stigmatized (Squires, 2016). ${ }^{16}$

On the other hand, some scholars - such as Bruess and Pearson's (1993) study - contend that happier couples tend to use more private language or 'idiosyncratic communication'. In their study, they interviewed 154 married couples, ranging from newlyweds to empty-nesters, on how satisfied they felt with their relationship, and asked them to describe the personal idioms with their

15 There are, however, daddy/baby fetishes in the BDSM community. For example, "DDlg" stands for Daddy Dom/little girl, usually with only the Daddy getting capitalization. With this kink, men take care of their "littles", providing toys and discipline. The littles, in turn, bring a joyful innocence to the relationship. The DDlg community thrives on Tumblr, where different blogs are set up for DDlg for women who describe themselves as being "Mentally age 3-6, physically all grown up." (Squires, 2016). While this is an important area of research, I am taking the position that 'sugar babies' and 'sugar daddies' do not inherently fall within this category.

16 Given that English is a playful language, the term 'dad' continues to be reformulated to have different meanings. For example, a new form of Internet slang is calling a public figure whom they admire 'dad' or 'mom' on social media (Steinmetz, 2016). Moreover, the term 'dad-bod' has become an idealized figure for some (Park, 2015; Peters, 2015). There is, however, no desirable 'mom-bod' (Peters, 2015); although the concept of a 'MILF' (Mother I'd like to Fuck) is highly sexualized and exists in a variety of cultural contexts (Atkinson, 2016) and 'Step-mom' and 'MILF' were ranked \#2 and \#3 in top searches on Pornhub in 2016 (Hay, 2016). 
partners. The findings revealed that 116 couples said they used at least one idiom; altogether, the couples reported a total of 370. Bruess and Pearson (1993) discovered a strong positive correlation between marital satisfaction and reported number of idioms, though both variables declined as couples aged. This suggests that using pet names, such as 'baby' may also be a cue to intimacy. This baby/daddy dynamic may reflect the valid desires of sugar babies/sugar daddies to form a loving, nurturing and paternalistic relationship. However, this concept arguably contributes to the incestuous stigma of babies and daddies. While babies seem to accept their label, there is evidence that sugar daddies have resisted the label of a sugar daddy. ${ }^{17}$ This may be because the term sugar daddy has been equated to a 'John' who exploits vulnerable women (Doyle, 2016; Livingston, 2016; McIntosh, 2016), and are using their power to have access to sugar babies.

\section{$\underline{\text { The Sugar Babies and Sugar Daddies of Seeking Arrangement }}$}

Comparing the historical understandings of a sugar daddy and kept woman to SA's descriptions of sugar daddies and sugar babies reveals some consistencies. When SA was first launched, it described sugar daddies as:

Rich and successful. Single or married, you have no time for games. You are looking to mentor or spoil someone special - perhaps a 'personal secretary'? secret lover? student? Or a mistress for an extra-marital affair'?

Notably, the website has gone under multiple renovations for public relations purposes

(Cordero, 2015). However, the site's current iteration describes sugar daddies (and mommies) as:

\footnotetext{
${ }^{17}$ For example, on March $10^{\text {th }}, 2017$, a member of the junta-appointed National Reform Steering Assembly (NRSA) was charged after slapping a server for calling him a "sugar daddy" at Greyhound restaurant with his date who was hired to be there. Anusawn later said in an interview with Bright $T V$ that he did assault Chartalongkorn, but only because the waiter called him $p a$, a term which translates to "sugar daddy" - or old, moneyed man - which he found inappropriate. "I don't like that word. The term is connected to massage salons, that kind of thing," Anusawn said. "He could have called me phee [brother] or leung [uncle.]" (CoconutsBangkok, 2017); In an interview with the New York Post, one sugar daddy comments: "Don't treat me like an ATM, I won't treat you like a hooker" This sugar daddy says he "hates" the term, 'sugar daddy'. He states he "prefers to be a person who might prefer to do the same things as a sugar daddy, I just don't like the term 'Sugar daddy"' (Klausner \& Hauswirth, 2017).
} 
“[s]uccessful men and women who know what they want. They're driven, and enjoy attractive company by their side. Money isn't an issue, thus they are generous when it comes to supporting a Sugar Baby." A sugar baby is defined as: "attractive people looking for the finer things in life. They appreciate exotic trips and gifts. Sugar Babies get to experience a luxurious lifestyle, and meet wealthy people on a regular basis."

Brandon Wey, known as Brandon Wade in the public forum, is the Founder and CEO of SeekingArrangement.com. In an interview with Business Insider, Wade says that he created the site in 2006 "for his own benefit". Growing up, Wade was a self-proclaimed "nerd" who grew up "very lonely, shy, and perhaps socially inept." Wade states that his dating life was "horrible", so he joined other dating websites, and a dating agency where he could watch other people's videos and decide if he wanted to date them. Despite being a MIT graduate and later obtaining a MBA from the Sloan school of management, he didn't receive his first kiss until he was 21; he was “obviously still suffering from [his] [in]ability to pick women up". It was his unsuccessful dating life that sparked his idea to launch SA, where individuals could be direct with what their expectations were. Wade states:

I think all relationships start off in a very superficial manner. As humans, we're controlled very much by our genes and hormones. For men it's a visual thing. That's why women upload photos that reveal their skin and show off their figures [...] Women tend to look at men in terms of how successful they are, what sort of job they have, how much money they make. That's how men and women judge each other at a very superficial level. I think it's OK to use the elements to attract the opposite sex at the very beginning. (Edwards, 2012).

Following this belief, Wade has turned SA into a $\$ 30$ million sugar daddy dating empire with over 5.5 million members worldwide (Edwards, 2012).

As revealed by recent scholarship on sex work, the movement of the sex industry indoors 
and online has resulted in a diversified landscape of leisure, entertainment and pleasure industries (Bernstein, 2007; Moffat and Peters, 2004; Nayar, 2016; Roberts et al., 2007; Roberts et al., 2010). Moreover, the integration of sexual commerce with other services (such as technology) achieves an "upscaling" effect that is highly desirable by middle-class providers and consumers in the sex industry (Brents \& Sanders, 2010, p. 43). In the vision promoted by SA, sugar daddies are successful (typically) men who enjoy high socio-economic status, and sugar babies are attractive (typically) women who enjoy the 'luxuries' in life. This suggests that sugar daddies aren't buying a service per se, they're investing (most often, financially) in a relationship because they can afford to do so and enjoy the access to women who may otherwise be inaccessible. On the other hand, this suggests that sugar babies are not on SA out of financial desperation. Rather, they want 'sugar', or additional compensation - they don't need it. However, the vision that Wade provides and SA markets does not necessarily align with the statistics of sugar babies registered to the website.

\section{Seeking Arrangement: An Overview}

As of January 2017, there were 631,678 Canadian users on SeekingArrangement.com. 


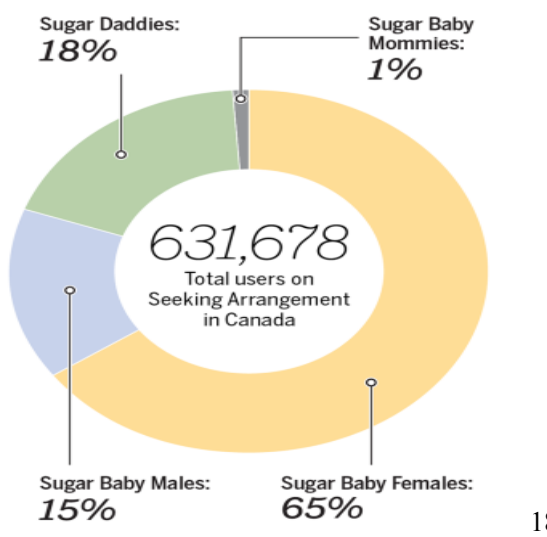

Illustration 1 - Canadian users on SeekingArrangement.com

Canadian membership is composed of 115,000 sugar daddies, and just 7,000 sugar mommies. There are nearly 100,000 male sugar babies (over 11,000 of whom are students), compared to approximately 510,000 female sugar babies (195,000 of whom are students). Between 2012 and 2016, user registrations increased 150\%, with the majority of new users signing up as sugar babies, as opposed to sugar daddies.

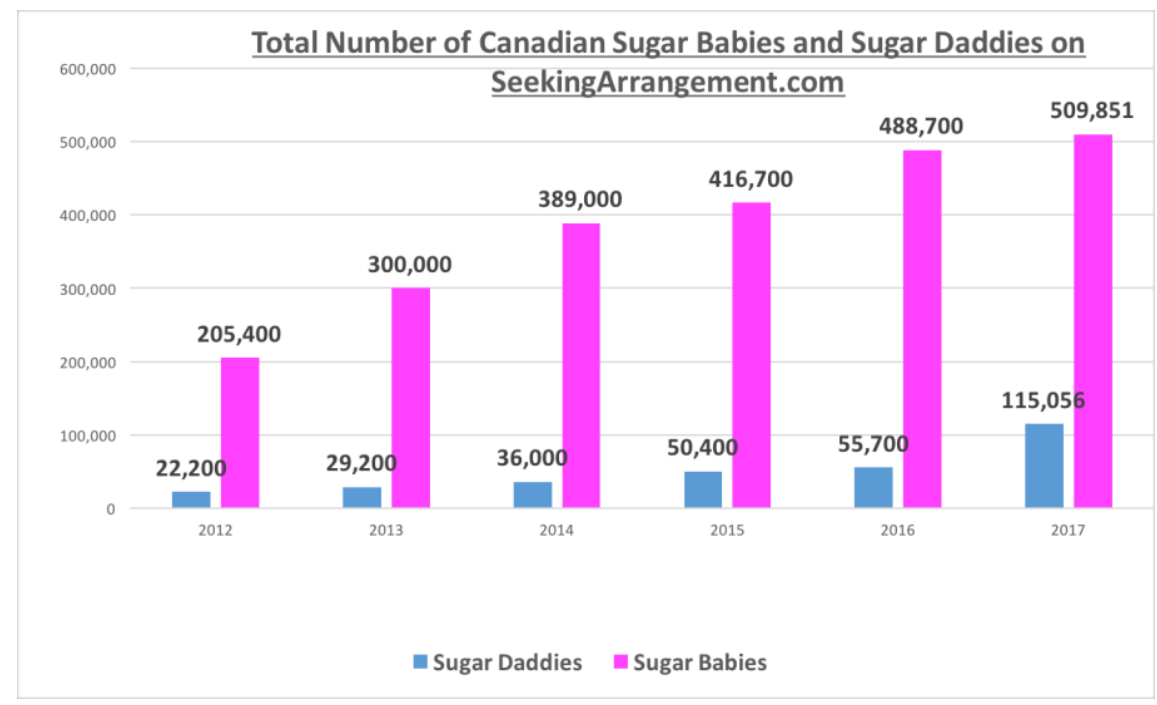

Table 1 - Growing Trend of Sugar Babies and Sugar Daddies in Canada

18 Image from (Logan, 2017). Note that the 1\% should say "Sugar Mommies", not "Sugar Baby Mommies". 
SA works in a similar fashion to traditional dating websites in that profiles are available to browse and include photos of users and a description of their interests. Users can contact each other by sending messages, 'favouriting' one another, and sharing private photos. The website charges sugar daddies and mommies \$53.33 USD per month to maintain access to the site, while sugar baby profiles are free of charge. SA states that the sugar daddy's credit card statement will read "2BUYSAFE.COM/W8TECH," for their protection.

Furthermore, there are different classes of membership that allow sugar daddies/mommies to flaunt their affluence. "Premium" members pay a monthly fee of between \$53.33 USD and \$69.95 USD, depending on the package they purchase ${ }^{19}$, while "Diamond" members pay $\$ 1,200$ per month, and must verify their net worth through tax return data (Nayar, 2016). SA explains 'Diamond' members by stating:

Diamonds truly are a girl's best friend. Like an experienced jeweler checking the value of a gem, SA verifies the profile claims of Sugar Daddies who wish to enter our Diamond Club. All Sugar Babies can relax in the knowledge that these Daddies are the real dealno Splenda or saccharine here.
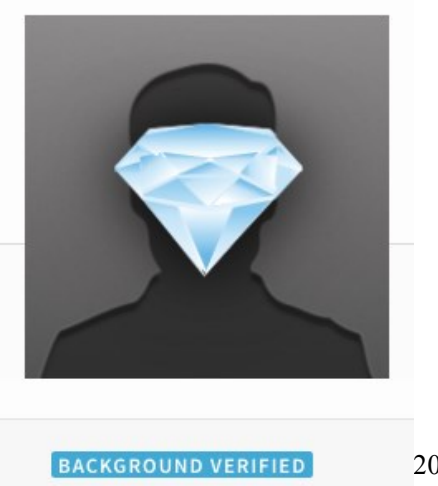

Illustration 2 - Diamond Members' on SeekingArrangement.com

\footnotetext{
${ }^{19}$ Last verified March $30^{\text {th }}, 2017$ : sugar daddies or mommies can sign up for one month premium for $\$ 53.33,3$ months premium for \$69.95 USD, or 6 months premium for \$59.95 USD.

20 Screenshot taken on March $30^{\text {th }}, 2017$ from a sugar daddy's profile page on www.seekingarrangement.com
} 
Diamond profiles will also be the first to appear in sugar babies' searches, and will be at the very top of sugar babies' homepages. SA claims that this will result in over 40 page views per day than Premium members. Moreover, all users are offered an 'Attract' boost by paying anywhere from $\$ 10$ USD to $\$ 60 \mathrm{USD}^{21}$ to have their profile featured across the site to other users in their area.

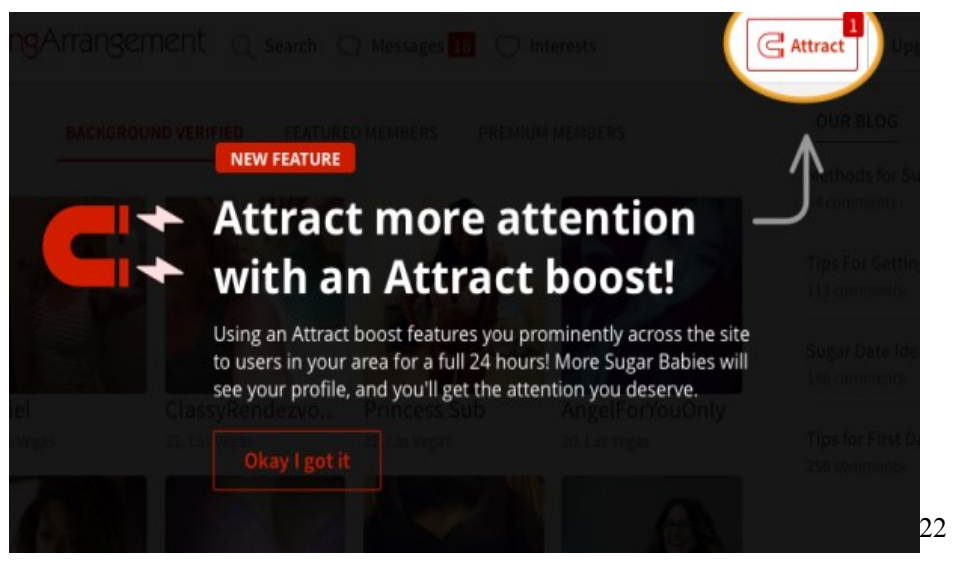

Illustration 3 - "Attract” feature

Superficially, SA's setup resembles conventional online dating. However, the main feature that sets SA apart from traditional dating websites is its focuses on 'arrangements' between sugar babies and sugar daddies/mommies, as both parties set their intimate and financial expectations out in their profiles. ${ }^{23}$ Sugar daddies must list their income, net worth, the amount they are willing to pay, and what they expect to get in return, whereas sugar babies state a general amount they are hoping to be paid. SA differentiates itself from traditional relationships by stating that it offers: "relationship on [their] terms: where beautiful, successful people fuel

\footnotetext{
${ }^{21}$ Users can get '1 Attract Boost for 24 hours' for $\$ 9.99$ USD/per Attract; ' 5 Attract Boosts' for $\$ 7.99$ USD/per Attract (billed \$39.95 USB); or 10 Attract Boosts for \$5.99 USD/per Attract (billed \$59.90 USD billed) (Last verified March $30^{\text {th }}, 2017$ from www.seekingarrangement.com)

${ }^{22}$ Supra at note 18.

${ }^{23}$ For example, on Match.com members have the option not only to include their own salary, but also to check a box indicating the salary range of a desirable match. Some studies suggest that men who claim low salaries often receive much less attention from women, as do men who select "would rather not say" on their profile (Wrenn, 2014).
} 
mutually beneficial relationships". From here, the two individuals can use this information to negotiate a personalized arrangement through messaging one another.

A description of an "arrangement" is provided on the website, with Brandon Wade stating:

Every successful relationship is an arrangement between two parties. In business, partners sign business agreements that outline their objectives and expectations.

Likewise, romantic relationships can only work if two people agree on what they expect, and what they can give and receive from each other. Sugar Daddies and Mommas seek the company of attractive people with whom they can foster their ideal relationship, whatever they may mean to them (SeekingArrangement, 2017).

Within a contemporary neoliberal framework, this distinction reflects the notion of 'bounded authenticity' by suggesting that contractual and commercial relationships are more genuine and reliable than traditional dating (Bernstein, 2007). The site characterizes traditional dating relationships as selfish, messy and insincere, offering arrangements as an ideal substitute. The site works to create arrangements between people that are honest, forthright and goaldirected. However, the mix of explicit economic transaction and vague references to 'intimate' relations have caused controversy. Some critics have argued that this is merely a form of prostitution (Cribb, 2015; Greenslade, 2014; Nasrulla, 2016), while others contend that this is a new take on dating (Miller, 2016; Motz, 2014; Nayar, 2016). The controversy likely stems from a lack of clarity over what exactly is being exchanged, as well as how the 'authenticity' of a relationship is to be measured. 'Intimacy', and 'authenticity' are value-laden terms, whose definition is generally more reflective of author's values than of a neutral or objective understanding.

It's worth noting that the term "intimacy" has multiple meanings. The Oxford English Dictionary offers these main definitions: 
1. (a) the state of being personally intimate; intimate friendship or acquaintance; familiar intercourse; close familiarity (b) euphemism for sexual intercourse (c) closeness of observation, knowledge or the like.

2. Intimate or close connection or union. (as referenced in Zelizer, 2005, p. 14).

In contrast to historical understandings of a commercial transaction between a sex worker and a client being linear and non-emotional (Crafton, 2011; Love et al., 2013), sugar dating is consistent with recent scholarship on sex work which suggests that cultivating feelings of intimacy, connection, and romance are increasingly central features of sexual services (Nayar, 2016). While this may be indicative of new class-based distinctions, and reflect the new 'respectability' of middle-class sex work, the rhetoric in which it is cloaked helps circumvent the legal barriers that sugar dating may be subject to (Bernstein 2007, p. 474).

\section{Sugar Dating and the Law}

To date, there have been few legal cases that examined sugar daddy solicitation, and none in Canada. However, the story of cardiologist Dr. Roger Weiner suggests that using these key terms like 'relationship' and 'intimacy' is important to circumvent legal barriers. In one chat with a sugar baby, through SugarDaddieForMe.com, Weiner said,

[d]inner and a nite [sic] at the Peabody........ what would you like as your consulting fee?.......is it negotiable. I would suggest that the more adventurous you are, the higher the fee. What are your boundaries? What is the 'kinkiest' thing you ever did?

Weiner told another user to "send a photo and maybe [S]anta will start ur [sic] gifts tonight." Weiner propositioned another SugarDaddyForMe member, suggesting that they should get together for an interview and that she must prepare for the interview by wearing "victoria secret undies [sic]." He later told her, "If you are bored and would like to use your cute little body to get your first allowance we could meet in a motel..." On May 17, 2009, the Mississippi cardiologist was arrested by the FBI and charged with human trafficking and prostitution (Miller, 
2011). Notably, Dr. Roger Weiner's charges were later thrown out based on the court not having federal jurisdiction (Miller 2011, p. 62-63).

Although prostitution charges are seldom brought against sugar daddy website participants, law enforcement has shown an interest in sugar daddy arrangements that involve crimes such as extortion. For example, Stephen Dent, a 54-year old, married, Harvard educated multimillionaire, Connecticut businessman and DuPont heir, was blackmailed by SA users. It is rumored that Dent paid a woman he met on the site $\$ 15,000$ to have sex with him for one night at a nearby hotel (Miller, 2011). Dent allegedly wrote the following to one sugar baby:

[I] am not available at night or [on] weekends. Furthermore, we would need to meet only when initial thoughts are cash compensation in the range of $\$ 2,000-\$ 3,000$ per meeting, assuming we meet about twice a month, plus expenses. (Miller, 2011, p. 63)

The woman that Dent met online allegedly had a mafia boyfriend who demanded $\$ 40,000$ from Dent after he found out that his girlfriend and Dent had sex. A few months after the first extortionist was arrested, Dent was still using SA and was blackmailed again. The second time, the extortionists were a couple from Ohio who were charged with attempting to extort $\$ 50,000$ in addition to the $\$ 100,000$ Dent already paid them. While Dent concedes that he has sent emails offering to pay for sex, the police did not charge him with a crime because they did not want to deter other sugar daddy extortion victims from coming forward (Miller, 2011). ${ }^{24}$

Motyl (2013) and Miller (2011) have conducted a theoretical analysis to determine if sugar dating could, in fact, be considered prostitution under the American criminal law. Both scholars rejected the broad interpretation that sugar dating is simply a new form of prostitution,

\footnotetext{
${ }^{24}$ It is interesting to note the contrast in the police approach in this case with the typical attitude of law enforcement towards sex workers. It is rare that police decline to charge sex workers, in order to not deter them from coming forward to report potential abuse. For example, prior to Bill c-36, Ottawa-area street-based sex workers were regularly criminally charged for solicitation - in addition to a variety of other offences including jaywalking, loitering, mischief and trespassing - municipal and provincial regulations that otherwise were rarely enforced (Bruckert \& Hannem, 2013, p. 302).
} 
and argued that the nature of these relationships are complex. For example, Motyl (2013) has broken down sugar dating into three different types of arrangements (based on sugar daters' blogging content), both in terms of time spent on each arrangement and the degree to which social companionship was actually present, with the intent of determining if sugar dating relationships are, in fact, criminal at any level. A "Category One" arrangement is a paid per-visit arrangement (as opposed to a monthly allowance) and lacks any form of social companionship; a "Category Two" arrangement mimics traditional dating and has high levels of companionship; and, a "Category Three" arrangement is a combination of "Category One" and "Category Two", offering long-term sex arrangements coupled with little companionship (p. 947).

Similarly, Miller (2011) found it necessary to help distinguish between sugar dating and prostitution by categorizing their differences into four groups: the monetary aspect; the language used to characterize the relationship and what the sugar daddies want in a partner; the length of the relationship; and, perhaps most importantly, whether the arrangement involves sex. Miller (2011) ultimately concludes that while not all sugar dating relationships have a sexual contract, "sugar babies still fulfill each required element of prostitution" (p. 12).

Moreover, both scholars seem to agree that sugar dating is difficult for law enforcement to criminalize because the relationship itself is essentially a complex and convoluted mix of prostitution and dating. Miller (2011) contends that the differences between prostitution and sugar dating can largely be explained by the institutionalized responses to the two industries. Miller (2011) argues that there are three main reasons why sugar dating is the more difficult of the two to criminalize: a lack of funding for law enforcement agencies; the use of coded language and euphemisms on sugar dating sites; and finally, the fact that clientele associated with sugar culture are not as easily identifiable as the average "streetwalker" and "John" (45). 
Some scholars note that "sugar babies, particularly college students, view themselves not as prostitutes coerced into the sex industry, but as problem-solving, empowered women looking for benefactors to pay for schooling", whereas sugar daddies enjoy being observed in public with a beautiful young woman (Motyl 2013, p. 948). Furthermore, anecdotal evidence suggests that there is more to sugar relationships than a sex-for-money exchange, and arrangements typically include other elements such as dinner or companionship (Motyl, 2013).

However, this latter aspect - that the arrangement typically includes some degree of companionship - is a common feature of escorting, as well as sugar dating (Sanders, 2005, 2015; Sharpe \& Earle, 2012). Furthermore, both tend to use coded language to negotiate the terms of arrangement. The two are most readily distinguished by the ongoing exchange that characterizes a sugar relationship, as opposed to the typical per-encounter manner in which escorts are compensated. However, the criminalization of escorting, in contrast with the lack of criminalization of the sugar dating, reveals the degree to which the two lie on the same spectrum of activity, and the degree to which small nuances divide that spectrum. Moreover, it is often the institutional responses to those nuances, more than any easily identifiable moral lines, that determine whether an activity will be criminalized, rather than merely stigmatized.

While there are clear legal reasons for careful distinguishing between sugar dating and prostitution, social judgments also underlie these claims. Brandon Wade, CEO and founder of SeekingArrangement has come under attack by various media outlets for taking on the role of a 'pimp' or middleman and capitalizing on the sale of women's bodies. The negative publicity was triggered by SA's launch of a marketing campaign that depicts female college students turning to sugar dating to pay for their education and living expenses in the midst of a student debt crisis and an ongoing recession (Hervey, 2016; Nayar, 2016). 


\section{E. Sugar Baby University}

Sugar Baby University (SBU) is a feature offered on SA where prospective sugar babies can receive a free, premium membership if they register with their university-affiliated account. Once their e-mail address has been verified, they receive a "college badge" on their profile. ${ }^{25}$

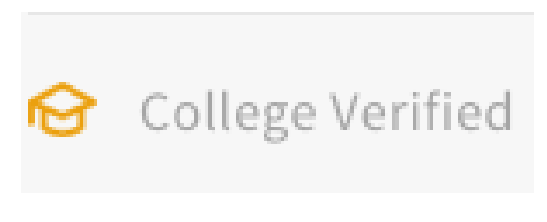

Illustration 4 - College Badge

Created in 2011, SBU - whose digital presence is modeled on the traditional aesthetic of a university - is an example of mainstreaming and normalization in the sex industry. On the SBU homepage, there's a bright red banner with a white logo that says "SBU est. 2015"; visually, the logo passes as a standard university or college banner. Underneath this banner in bold capitalize script states "SUGAR BABIES HACK STUDENT DEBT CLOCK".

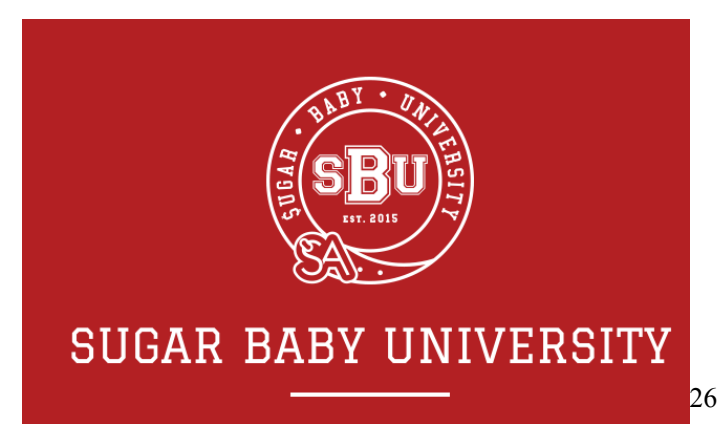

Illustration 5 - Sugar Baby University (SBU) Logo

On the homepage, there is a link to a promotional video for SBU which features three attractive women - one Caucasian, one Black, one Latina - dressed in casual (modest) attire, who seem like they could be average fellow university students. The student in the middle is

${ }^{25}$ Interestingly, on the SeekingArrangement homepage, there is no direct link for Sugar Baby University. When conducting this research, I had to google "SeekingArrangement - sugar baby university" to be redirected to the site. ${ }^{26}$ Retrieved from: SeekingArrangement, 2017, Sugar Baby University. Last accessed March $30^{\text {th }}, 2017$ : https://www.seekingarrangement.com/sugar-baby-university/ 
holding a small rectangular chalkboard that states "Sugar Baby University" with the fake university logo.

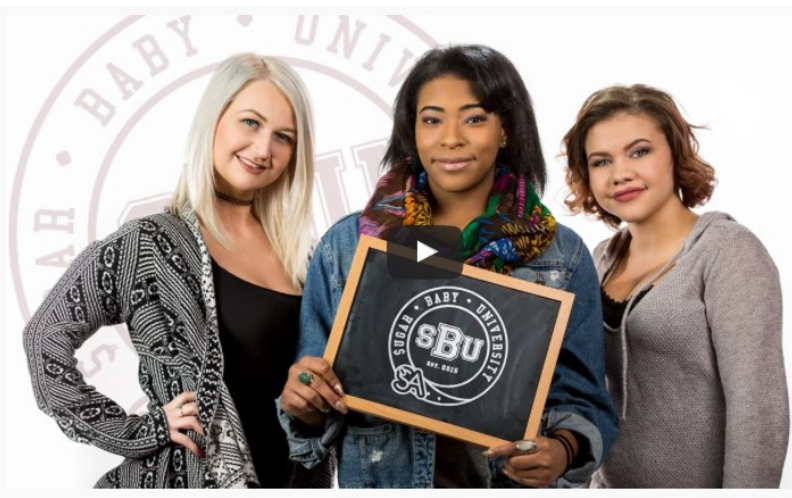

SAY GOODBYE TO COLLEGE DEBT

And hello to a higher class education

27

Illustration 6 - Homepage of Sugar Baby University

The video begins with six twenty-something year old women who are writing on a rectangular chalkboard in front of them. They each write down and declare their "numbers" to the camera, ranging from $\$ 17,000$ to $\$ 75,000$.

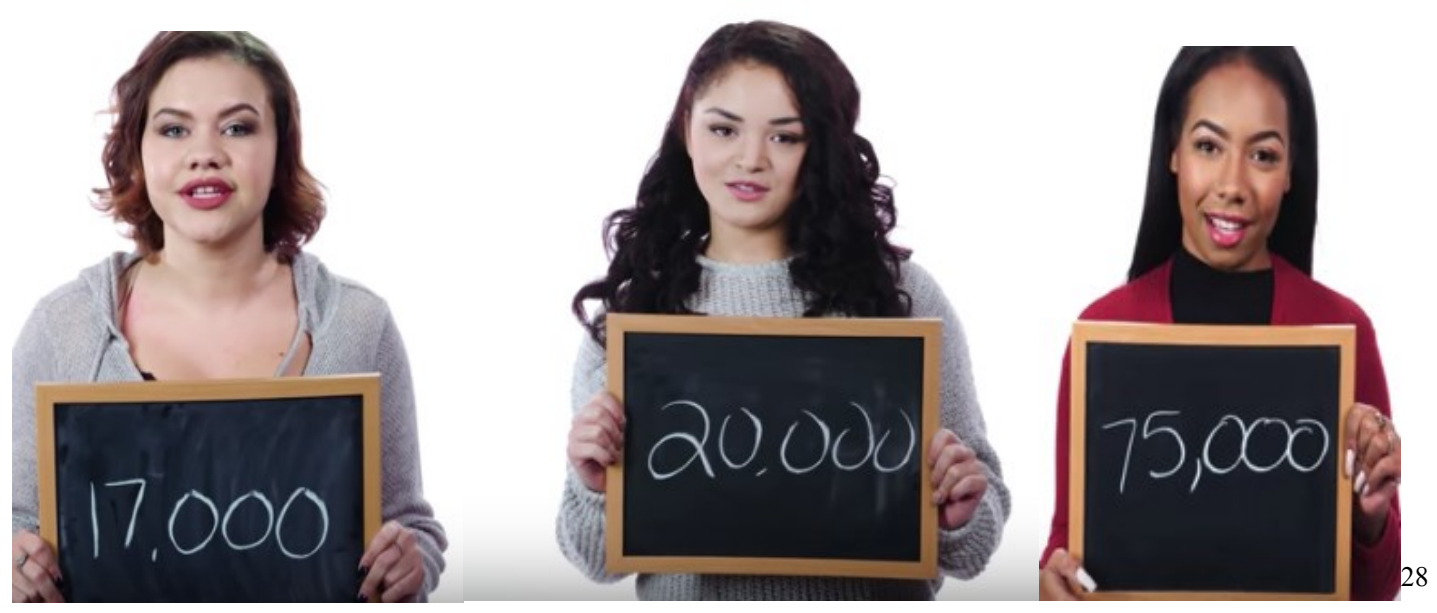

Illustration 7 - Promotional Video: "What's your number?"

The student holding the $\$ 75,000$ states "get your head outta the gutter; we're talking

${ }^{27}$ Ibid.

${ }^{28}$ Ibid. The images are screenshots from the 'SBU' promotional video, available on the SBU homepage. 
about student debt." Each student is representative of a certain part of the world - in the US, UK and Canada. Each student describes the state of student debt in the country they represent: "In the US, $70 \%$ of college students graduate enough student debt to buy a brand new luxury car" ${ }^{29}$; "Almost $60 \%$ of US graduates have no clue when their student loans will be paid off"; " $2 / 3$ of students here in the UK are unlikely to ever pay off their student loans;" "To some, college is an option - here in South America, it’s a necessity"; "Here in Canada, student debt will top \$16 billion dollars." One student then says "[1] ook at how much this student debt clock has risen during this video." Each of the students then declare what their "number" used to be, and state "but then I found a sugar daddy." The video concludes with the American student stating "if you don't want to become another statistic, go find your sugar daddy at SeekingArrangement.com."

Underneath this promotional video, students are then urged to "SAY GOODBYE TO COLLEGE DEBT, and hello to a higher class education." Underneath this script, the website states:

[b]ills never get in the way for College Sugar Babies. It is easier than ever for students to connect with Sugar Daddies on SeekingArrangement.com. FAFSA and grants can be a nightmare--that's if you are approved. With SeekingArrangement.com's Sugar Baby University, students from all backgrounds and income levels are welcome. No minimum GPA required. Join today and get your education paid for by a generous sponsor.

If one scrolls down lower, one is provided with a link to "USA" or "Canada" to see current school rankings. Underneath this text, it states "[a]lmost two million college and university students have joined SeekingArrangement.com for their Sugar Baby Scholarship". The website then lists American colleges, including: NYU, ASU, Texas, Temple University and Kent State University.

\footnotetext{
${ }^{29}$ This is interpreted to mean that the amount of student debt they have acquired could have provided them with a brand new luxury car.
} 
Perhaps because of the premium membership, or increased coverage in the media, SA claims to have 5.5 million users worldwide $-40 \%$ of whom list their occupation as students. According to the 2017 press release, there are currently 206,800 Canadian university or college students who are registered to the site. There are currently 1.7 million students registered in university (979,000 full-time students and 312,000 part-time students) (Stats Canada, 2016), suggesting that just over $12 \%$ of all students in Canada are seeking financial support from SA. Of this total, 195,562 are female students and 11,238 are male students, constituting $11.5 \%$ and $0.5 \%$ of all Canadian students, respectively. The registration rate for users on SA has steadily increased from 2011 onwards, most remarkably by nearly $24 \%$ from $2015-2016$.

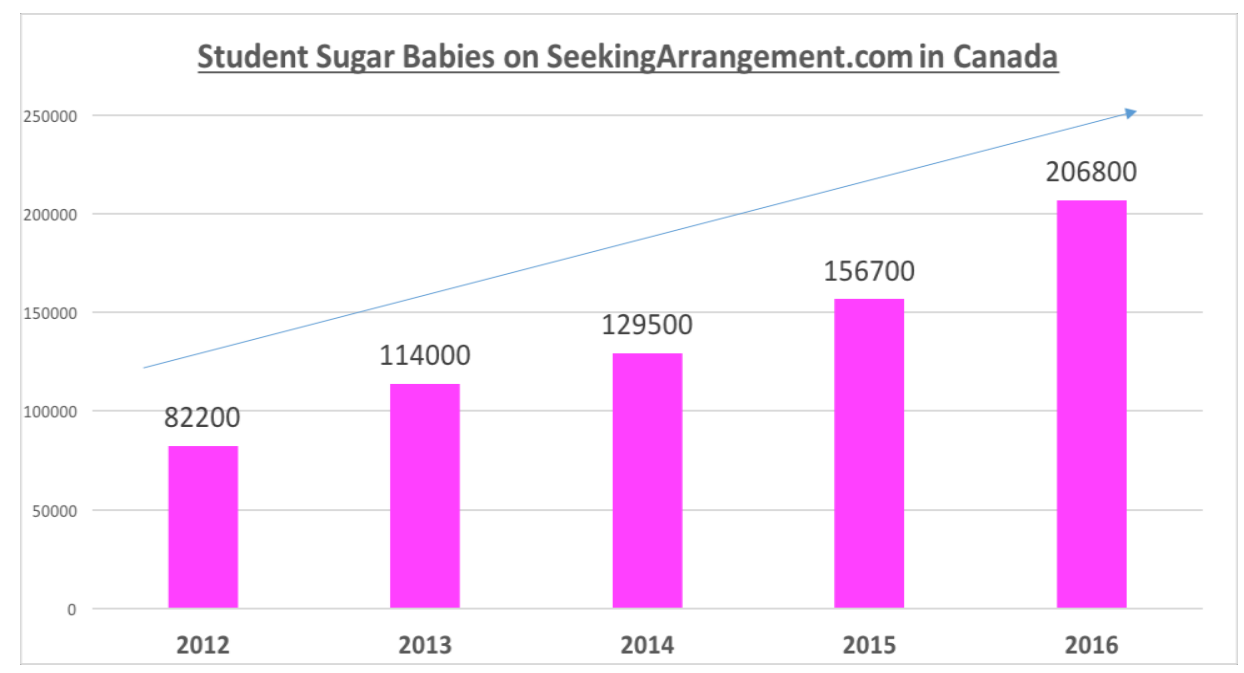

Table 2 - Canadian Student Sugar Babies on SeekingArrangement.com

It is worth reiterating that in a personal e-mail, Alexis Germany, spokesperson for SA, clarified that this 1 in 10 statistic reflects students who list their occupations as student, and have not necessarily registered with their .edu account. Consistent with literature, this may be a strategy employed by users to exploit the 'sexy' student status (Roberts et al., 2007; Moffat \& Peters, 2004). Furthermore, these statistics have not been verified by an independent third party. Bearing this in mind, SBU released the highest-ranking universities for students registered with 
their .edu e-mail, which constitutes 7157 or merely $3.4 \%$ of the 206,800 Canadian students they claim are registered to the website. ${ }^{30}$

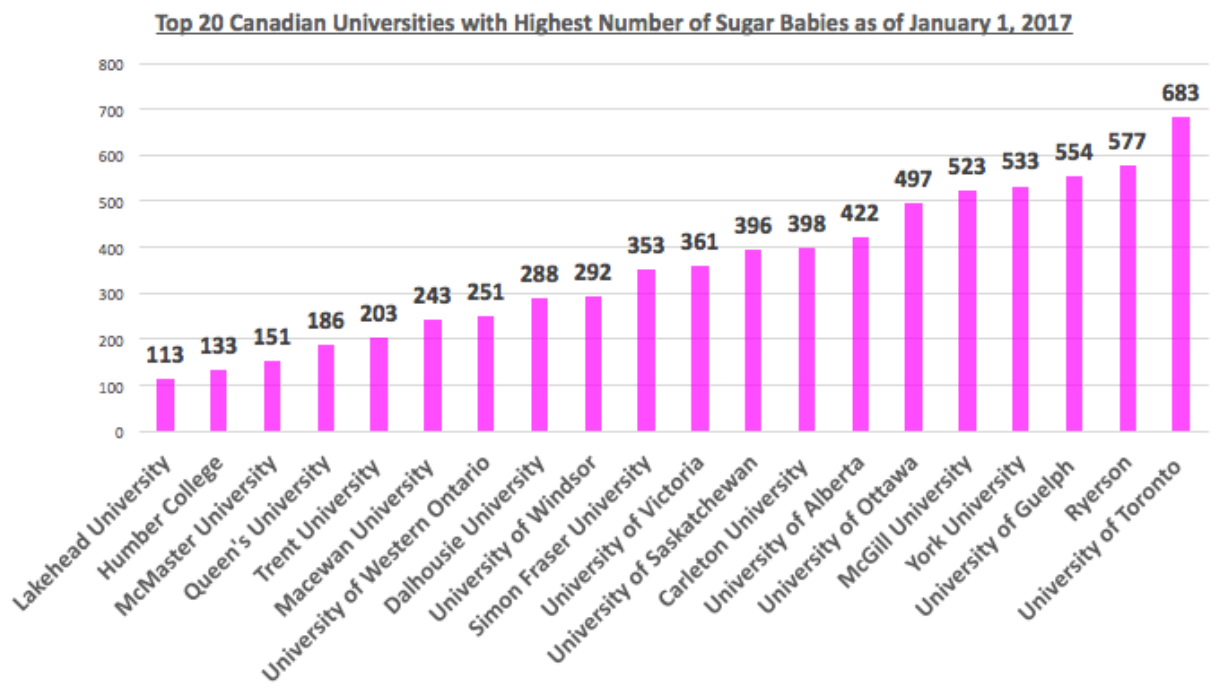

Table 3 - Top 20 Universities with Highest Numbers of Sugar Babies as of January 1, 2017

As demonstrated in Table 3 and Table 4, the universities with the highest number of sugar babies - and new sugar baby sign-ups are heavily concentrated in Ontario.

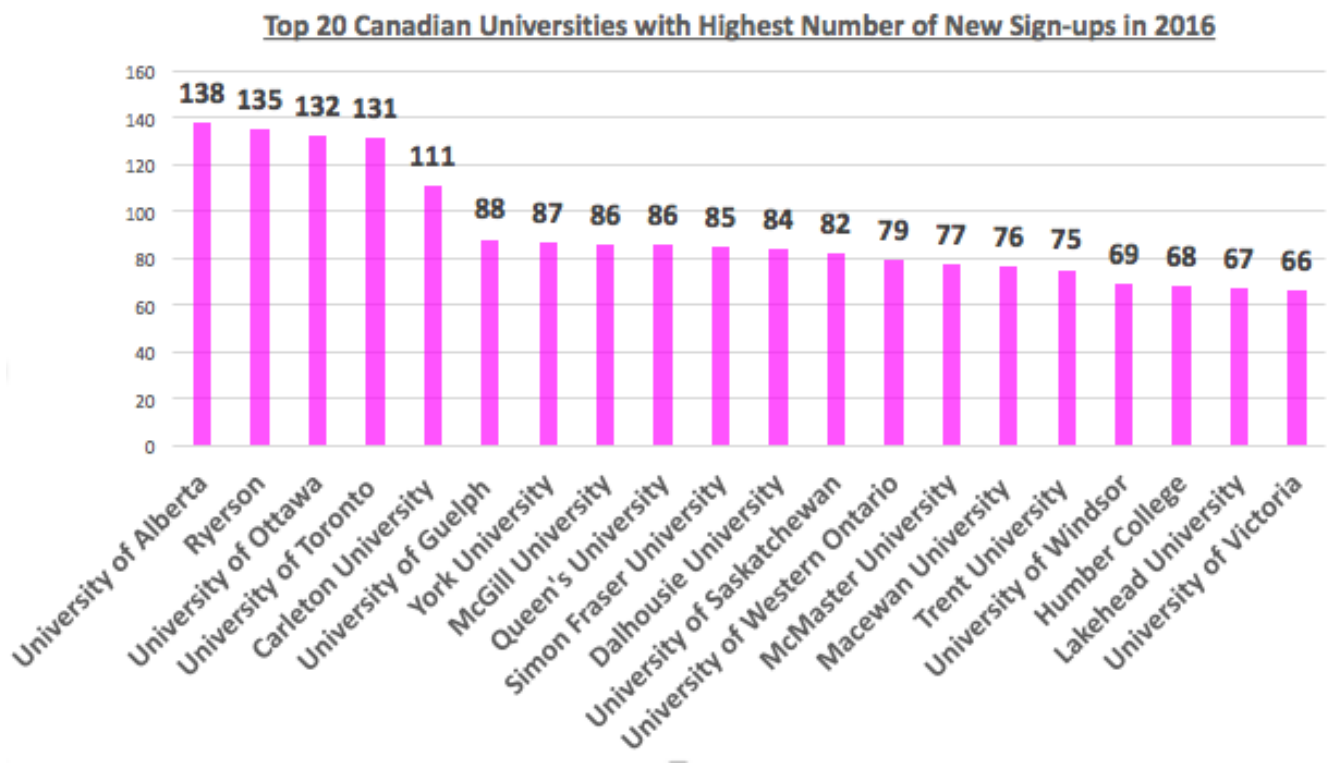

Table 4 - Top 20 Canadian Universities for New Sign Up's in 2016

30 The top three majors of student sugar babies are nursing, business and performing arts. 
One could speculate that this may be a result of Ontario having highest cost of living compared to other regions in Canada. In the Ontario budget released in February of last year, the provincial government vowed to redesign the Ontario Student Assistance Program (OSAP), introducing free college or university tuition to full-time students whose parents earn $\$ 50,000$ or less per year (Ministry of Finance, 2016). Yet, this dramatic change may not impact the rising popularity in sugar dating. According to SA, 35\% of Canadian post-secondary members are from upper-middle or high-income families who traditionally don't rely on OSAP, according to the platform. This leaves $65 \%$ from lower to lower-middle class families. The ratio of undergraduate students to graduate students is $82 \%$ to $18 \%$, respectively. This suggests that the population is comprised of young (typically aged 18-24) students who may be in need of financial assistance (SeekingArrangement, 2017).

In the 2017 press release, Wade explicitly makes the connection between sugar dating and student debt, writing that: "[students] are graduating with thousands of dollars of debt [which] is having an impact on students' mental health. Some see this as a controversial solution. But, instead of waiting for the government to take action, these students are taking matters into their own hands." Wade envisions sugar dating as a rational and entrepreneurial response to the spiraling problem of student debt - indeed, there is an undertone of praise for those who are "taking matters into their own hands." In this view, it is incumbent upon students to come up with individual solutions to the student debt crisis, as opposed to taking collective political action to address it.

Clearly, Wade has a vested interest in promoting such a philosophy. Yet, his statement which describes a starkly neoliberal vision - reflects the degree to which this ideology has come to characterize the public and governmental approach to post-secondary education in Canada 
(Goodnight, Hingstman \& Green, 2015). In public discourses, the spiraling cost of increasingly privatized and corporatized education tends more and more to be accepted as a fact of life unconnected to any particular identifiable causes (Bullen, 2017; Hervey, 2016; McIntosh, 2016). Students and prospective students come to see student debt as an immutable environmental condition, rather than one that can be meaningfully addressed by collective (public) action. In this conception, sugar dating is but one of many entrepreneurial and creative individual responses to the cost of education. Notwithstanding the prevalence of this neoliberal discourse, scholarly views on sugar dating in Canada remain widely varied, as will be examined below.

\section{What about our Canadian Girls?}

Contemporary configurations of sex work, and sex work policy have emerged from a complex and contested history. ${ }^{31}$ The polarized perspectives in feminist debates see women who sell sexual services are victims of a patriarchal, capitalist system that allows male domination to exploit the bodies of women, or are engaging in a form of legitimate labour (Love et al., 2013). Uniquely, sugar dating occupies a space that objectively seems to blur the lines between sex work and traditional dating. Sugar babies insist that they engage in arrangements or relationships, not services - and that they offer companionship or intimacy for financial compensation, but not necessarily sex. This has left critics wondering: how is this not sex work? Why is this not sex work? Moreover, the dominant image of a sugar baby contradicts stereotypical images of sex workers; they are generally young, educated and middle-class, resulting in somewhat of a moral panic in the media.

Scholars who have been asked to comment in the media have suggested a variety of thoughtful opinions. However, the dominant narrative in the media is that 'sugar babies' may be

\footnotetext{
${ }^{31}$ For a broad overview in a Canadian context, see: (Love et al., 2013).
} 
misguided participants involved in 'sex work' who are in need of guidance, or even saving (Cribb, 2015; Greenslade, 2014; Johnson, 2012; McIntosh, 2016; Nasrulla, 2016; Skidmore, 2015; Teitel, 2016; Wong, 2014). They are either naïve about their decisions, unaware of the legal consequences of their actions, or in an inherently exploitative relationship. For example, Rebecca Sullivan, the current director of the women's studies program at the University of Calgary, noted that however such arrangements are painted, in almost every case it ultimately boils down to cash for sex, which creates not only a stigma for the women involved, but may also limit their future prospects. In an interview with The Calgary Herald, she warns: "This is sex work. It may not be just providing (sexual acts), but they're providing intimate relationships for a fee," adding she is in favour of legalizing and regulating prostitution to help remove the stigma that surrounds sex workers (Logan, 2017). "There is a high level of stigma. Even though it might be conducted in secret, it can cause personal and professional consequences (Logan, 2017). While unclear of what these consequences may be, Sullivan's vague (and somewhat threatening) comment suggests that becoming a 'sugar baby' will have a negative impact on their future.

Similarly, Rebecca Bromwich, an instructor in legal studies at Carleton University, says she wonders if the girls - and the sugar daddies - know what they're getting into (McIntosh, 2016). In an interview with Ottawa Community News, Bromwich said while the site doesn't explicitly spell out that sex acts are traded for money, it may be tough for some girls to get help from the law if an interaction goes wrong, because at the core the relationship is an illegal arrangement. Bromwich compared the situation to the difference between a prostitute and an escort - at the end of the day, both are consensual sex workers. "They might not understand that that's what they're agreeing to," she said of sugar babies. Bromwich said Bill c-36 - designed to 
help sex workers - doesn't do much to protect them because they can't do anything if there's an abuse of the contract. Bromwich said sugar daddies might also end up left out in the cold: "If something goes south they would want to share liability with the website, but it wouldn't be possible," she said, adding the likelihood of being able to sue the site, in the event of some unforeseen consequence of seeking out an arrangement with a sugar baby would likely be unsuccessful. While Bromwich thoughtfully brings light to the potential legal implications of 'sugar dating', her comment suggests that sugar babies may be misguided or uninformed of their actions. Moreover, she assumes that every sugar relationship is premised on an exchange of sex for money.

Some critics argue that 'sugar dating' is inherently exploitative. In an interview with Global News, Jacqueline Warwick, coordinator of the Women and Genders studies program at Dalhousie University says she "worr[ies] naturally some of the people involved may be getting themselves in over their heads into a dangerous situation [...] It sounds like something that's fraught with possible danger. I don't like the hierarchical setup of the sugar daddy" (Wong, 2014). However, Brook Urick, spokesperson for SA, circumvents legal and social barriers of SA by making the generalization that

The risks involved with prostitution are countless, and include exposure to crime, abuse, sexually transmitted diseases and theft of service. Many prostitutes are also subject to physical and emotional abuse, especially when involved with a pimp. And in Sugar, sex is never a requirement, only an aspiration (Singh, 2016).

This age-old narrative helps separate 'sugar dating' from 'sex work', while implying a certain classism and elitism of 'sugar' dating - the users have access to the Internet, and are not sex workers by desperation. This reinforces historical understandings of 'good sex' and 'bad sex’, while conflating 'prostitution' with 'exploitation' (Miller-Young, 2014). Urick's comment 
works to inscribe sugar dating practices within normative expectations of proper 'respectability', while also transgressing them (Bernstein, 2007; Carrier-Moisan, 2015).

However, Warwick then states that she understands why some young women might think the set-up is a good way for them to fund their education. Warwick comprehends why some sugar babies decide to pursue a sugar relationship: "In our society, young women are bombarded with messages telling them the most valuable thing about themselves is their look and sex appeal. In a way it's a rational choice to try and capitalize on that to serve one's own education goals" (Wong, 2014). Warwick urges against rushing to judgment about the women who register on the website "I would not want to shame and blame these young women. Who knows the decisions behind making this kind of decision might be. I'm sure it's very complex," (Wong, 2014).

Echoing this narrative, some scholars are more sympathetic in their assessment of sugar dating, particularly given the current economic conditions - mainly the state of student debt. Emily van der Meulen, an associate professor at Ryerson University who specializes in sex industry and labour organizing, stated in an interview with the Toronto Star "it's not at all surprising that young people, especially young women, are looking to find other ways to make money." (Cribb, 2015) Similarly, Dusty Johnstone, a women's studies professor at the University of Windsor said students are likely embracing the sugar baby lifestyle because of societal pressure to get an education, despite the high cost of going to school. In an interview with $C T V$ Canada, she notes "we are telling students, 'You need to have an education,' but we are not providing sufficient economic resources for many students to access that in a way that's really attainable," (Elliott, 2016). 
In an interview with Guelph Today, Karen Wendling, a University of Guelph philosophy professor whose research and teachings focus on feminism, says that there are different ways of looking at the sugar baby/sugar daddy dynamic. On the one hand, she says it's "nothing crazy" and is merely the "free will" of a usually "smart, intelligent women who know what they want.[...] but as a feminist, I find it problematic: older, financially successful men have more power." Wendling notes that while there is potential for abuse, this exists in all relationships: "Is it morally wrong? Not unless there's harm [...] A lot of feminists would ask, 'is this harming women?' The answer is, it's a case-by-case basis" (Saxon, 2017).

Bearing in mind the various opinions on the social, moral and legal implications of sugar dating, I am interested in exploring how Canadian student sugar babies themselves understand the nature of their sugar relationships. Indeed, with the 'normalization' and 'mainstreaming' of the sex industry, and in the midst of a current student debt crisis, the widespread trend of student participation in sugar dating seems logical (Greenslade, 2014; Mckeon, 2013; Moytl, 2013; Reed, 2015). 


\section{Chapter 3: Theoretical Framework and Methodology}

\section{A. Methodology}

In this chapter, I will describe the methodology employed to conduct the qualitative textual analysis of the data from the LetsTalkSugar forum, and the qualitative semi-structured interviews. LetsTalkSugar is a website created by SA that allows sugar babies and sugar daddies to post questions or comments under different 'sugar' topics. From this online forum, I have analyzed 1317 comments under the topics of "advice" (675 comments), "sex" (208 comments), "money" (351 comments) and "relationships" (137 comments). These are the most popular forums, with the most responses; they also help address my research question. This sampling method was deemed most theoretically useful in that conversation ebbed and flowed in ways that eventually covered a variety of topics within one blog post. The natural ebb and flow could not have been observed if posts with fewer responses were examined (Tracy, 2013). Responses typically occur over the course of several days or even weeks after a post is published to the blog and even after a newer post has succeeded the original.

With the large amount of data available on LetsTalkSugar (over 7000 comments), focusing in-depth on 1317 comments allowed for a detailed and concise analysis. Limiting the analysis to posts under these four topics between 2015 and 2017 offers a recent snapshot of the state of sugar dating in 2017. In general, comments' discussions did not solely revolve around the initial topic of the blog, and the topics of sex, money and relationships frequently overlapped. Thus, comments were analyzed without specific reference to the topic itself.

Comments chosen for analysis were posted by members of SA and represent a wide range of experience levels with the website, from 'newbies' to seasoned members. In the sample comments, there were more sugar babies than sugar daddies commenting. The majority of the 
commenters in this sample were interested in heterosexual relationships, and were not sugar mommies or male sugar babies. Accordingly, the findings will be framed in terms of heterosexual relationships between older men and younger women, and will focus primarily on the experiences of sugar babies. Notably, it is uncertain if all of the comments posted by participants are students. However, SA claims that students constitute a high percentage of sugar babies in Canada and globally. In addition, particular attention was given to comments that described tuition needs and other financial constraints (such as rent, cost of textbooks, etc.) associated with being a student in Canada.

The textual analysis of the LetsTalkSugar forum provides insight into a unique communicative environment for sugar babies. Freed from the unavoidable and understandable concerns of stigma and judgment engendered by an interview, this forum allows sugar babies to communicate with peers with similar lived experiences to their own, hidden behind the relative anonymity of the Internet (Dobson, 2014). In such a forum, many of the participants possess an implicit and shorthand understanding of some of the more challenging aspects of the occupation that may prove difficult to articulate to those who have not experienced it. It is logical to expect that such a community, brought together by shared experience, would facilitate a level of honesty and introspection not shared with outsiders - that the forums of LetsTalkSugar would form a uniquely insightful communal diary.

This is certainly true, to a degree. Yet, the utility of textual analysis of LetsTalkSugar must be qualified by certain concerns. To begin with, it has become clear that online interactions are governed by social and communicative norms in a manner similar to face-to-face or written interactions (Tsiplakou, 2009). Online interactions are marked by a performative construction of a sociolinguistic identity unique to the online medium, and are inevitably influenced by its 
communal norms (Dobson, 2014; Tsiplakou, 2009). As such, LetsTalkSugar cannot be conceived of as a perfect vacuum within which the true identities and experiences of its members are laid bare. It is a community built on shared experience, but one that demands as much performance as any other. Furthermore, computer-mediated communication is typically a more deliberate process than verbal communication. As will be discussed below, an oral interview has the benefit of capturing different kinds of communicative nuances. Behind a computer, a pregnant pause is invisible, and the backspace easily covers the interviewee's backtracking. While the styles and norms of online communication draw on offline speech styles, they are by no means identical (Androutsopolous, 2008). As such, a proper discourse analysis of online communication must be premised on the understanding that the participants have the opportunity to consciously review each piece of communication before it is submitted to the forum.

As described by Rolfe (2006), there are four major criteria in qualitative research with respect to trustworthiness of data: credibility, transferability, dependability, and confirmability. Credibility refers to making an effort to confirm that the findings reflect the reality of the participants. To ensure that the analysis reflects the reality of the participants and strengthen credibility, triangulation was employed. Triangulation refers to comparing data gathered from a variety of sources to ensure consistency. Iterative questioning, which includes clarification of responses, elucidating contractions and rephrasing to ensure accuracy of interpretation can also help ensure credibility (Sinacore et al., 2014). This can be facilitated through qualitative interviewing (Tracy, 2010).

Thus, to supplement this textual analysis, I will also draw on a linguistics analysis of indepth qualitative interviews to better understand the phenomenological reality articulated by two Canadian student sugar babies. The main goal was to examine how 'sugar daters' make sense of 
the relationships they seek. In particular, I am interested in whether they articulate shared understandings about how sugar dating compares and differs from traditional understandings of sex work and 'non-sugar', conventional relationships. This method benefits from a natural spontaneity that allows the interviewee to explore her experience in depth, within a flexible framework (Tomura, 2009). The flexibility of the interview allows responses to be clarified, and unexpected themes or responses to be further explored. It excels at drawing out the lived experience of the interviewees, and is particularly conducive to research questions premised on the social constructivist notion that truth is relative to perspective (Lowes \& Prowse, 2001). Finally, the real-time oral interview allows the interviewer to pick up on the rich nuances of human verbal communication that are so revealing of the true emotional state and meaning of the speaker - stutters, sighs, pregnant pauses, and the like (Wiles, Rosenberg \& Kearns, 2005). These elements are often lost in transcription (Polkinghorne, 2005).

However, this approach is not without its drawbacks. The very flexibility that is the strength of this research method can lead to the interview focusing too heavily on topics that may be interesting, but ultimately not relevant to the research. Furthermore, the interview questions will inevitably reflect, to a degree, the biases and preconceptions of the interviewer, regardless of his or her best efforts (Lowes \& Prowse, 2001). Though this may be mitigated through the careful structuring of neutral and generalized lines of inquiry, questions that are overly "watered down" may not appropriately delve into the situation factors that are essential for understanding an interviewee's responses. In short, the more general and neutral the question are, the greater the chance that they will not actually target the issues most important to any particular interviewee.

The interviews were conducted with the understanding that individuals use discourse to 
perform their identities and make sense of the social structures they occupy (Lazar, 2007).

Discourse refers to "the way in which narratives are patterned in both public and private conversations in reference to existing systems of power as they operate through cultural categories such as race, gender or socioeconomic positions" (Tracy, 2013).

\section{Procedures}

After approval was secured from the Carleton University Research Ethics Board, I initially tried to exclusively recruit participants through the SeekingArrangement website. To be

eligible for the study, participants had to identify as female, be a minimum of 18 years old, speak fluent English, have been involved in a sugar dating relationship with a sugar daddy that formed through SA, and also be enrolled at an accredited post-secondary institution in Canada. The participants were required to have access to a strong Internet connection, as the 60-90 minute semi-structured interviews were conducted over Skype.

I created a profile on SeekingArrangement.com as a sugar daddy, which identified myself (including my institutional affiliations) and included a brief description of the study so that any SA member that viewed my profile could clearly see that it was for research purposes only. The spot reserved for a photo upload instead had the words "Student Researcher at Carleton University". Using the website's internal search engines, I filtered through the large number of users to find the desired sample group by selecting Canada as the country, Ottawa as the location, and "student" as the occupation for the potential sugar baby. Participants in the surrounding area were emailed (via the site) a short description of the study and an invitation to participate in an interview.

Initially, I intended on interviewing four student sugar babies. However, consistent with 
research, there were significant methodological challenges recruiting participants for this study (Cordero, 2015; Roberts et al., 2007; Sinacore et al., 2014). The difficulty in collecting data from student sugar babies may reflect a fear of being 'outed,' and the stigma associated with working in what some consider to be part of the sex industry (Goffman, 1963; Shaver, 2005). As such, only two student sugar babies were interviewed. One of the participants (Sasha) was recruited through the SA website, and one of the participants (Jolene) was recruited through snowball sampling.

Snowball sampling occurs where someone recommends or refers potential participants if they know they could provide rich information about their lived experiences (Patton, 2015). I had informed a fellow graduate student that I was trying to recruit student sugar babies, and she asked one of her previous participants if they would be interested in partaking in my study. The previous participant voluntarily contacted me directly through my student e-mail account. Notably, one downfall of snowball sampling is that it can introduce biases into the data due to the social referral mechanism. The likelihood that I was restricted to a social network, and perhaps missed the experiences of individuals who may have shared their similar lived experiences remains a concern (Atchison, Bungay \& Oliffe, 2016). However, given the small sample size, generalizations cannot be made either way. Moreover, I took this recruitment challenge as an opportunity to learn more about where and how sugar babies communicate. ${ }^{32}$

\section{Participants:}

Jolene is a 22-year-old Caribbean undergraduate student sugar baby enrolled at Carleton

\footnotetext{
${ }^{32}$ For example, I learned that sugar babies often post on Tumblr and Instagram, and will use the term 'sugar baby' on Craigslist's 'casual encounters' webpage. This could potentially give rise to a new study that examines the role of information and communication technologies of 'sugar dating'.
} 
University in Ottawa. She identifies as a bisexual female, and is involved in a 'sugar' relationship with a male. Jolene also works as a massage parlor attendant, and has some student debt.

Sasha is a 24-year-old Caucasian graduate student sugar baby enrolled at Carleton University in Ottawa. She identifies as a straight female, and is involved in a 'sugar' relationship with a male. Sasha uses 'sugaring' as her primary source of income, and has some student debt.

Those that were recruited in the study were told that their participation was voluntary and that they could withdraw at any time. There was no identifying information recorded and each participant received a pseudonym. An oral consent script was read to each participant including a standard overview of the study with the potential risks and benefits of participants. I also sent each respondent an electronic version of the consent form for his/her records [see Appendix A].

Each interview took approximately one hour and was recorded through Skype. The interviews were semi-structured, beginning with basic demographic information and leading to overarching questions. The questions were then narrowed in scope to gain a deeper understanding of the individual's experience [see Appendix B]. Follow-up questions were used to elucidate certain concepts and themes that emerged though the interview and that were particularly relevant to research questions.

Consistent with the confidentiality agreement, all Skype calls were recorded in audio format only; no video recording was conducted. The Skype names were separated from the responses and each respondent was given a pseudonym (even if their Skype handle was already a pseudonym) to further protect their identity. Measures taken to ensure confidentiality included storing all data in a password-locked computer and in a password-locked folder specifically 
created for this research project. The data obtained was kept in a safe, locked cabinet that was only accessible to the researcher and researcher supervisor.

\section{Primary-coding cycle}

Recognizing that any corpus of rich data can be analyzed in multiple ways, I began with the question "what is a story here?" rather than "what is the story here?" I then began the process of coding. Codes are words or short phrases that capture a "summative, salient, essencecapturing, and/or evocative attribute for [..] language-based or visual data" (Saldana 2009, p.3 as cited in Tracy, 2013). The data derived from the LetsTalkSugar forum and qualitative interviews was approached with an initial open-coding process, where it was read and re-read to begin to establish initial patterns and themes. This helped determine the first-level codes, which focus on "what" is present in the data; they are descriptive, and show the basic activities and processes in the data.

Given that I have knowledge of the terminology used by 'sugar daters' and phrases that recur on SA, I created in vivo codes, which use the language and terms of the participants themselves (such as 'arrangements', 'mutually beneficial', 'POT') (Tracy, 2013). One initial pattern that emerged was the abundance of discussions related to sex work and the repeated insistence that sugar arrangements may be similar, but not the same. Traditional romantic discourses - such as 'relationship', 'chemistry', 'mutual attraction', 'trust', and 'honesty' - were used frequently to frame sugar relationships. On the other hand, labour-related discourses such as 'exchange' and 'work' were also frequently employed. Throughout the coding process, I used the constant comparative method to compare the data applicable to each code, and modify a code definition to fit new data (Tracy, 2013). This is a circular, iterative and reflexive process that 
helps to avoid "definitional drift" - where the meaning of a code shifts throughout the analysis so that it may represent a different event or phenomena from its initial intended purpose (Saldana, 2009). As more categories emerged, I looked for how certain words or phrases related to each other, making new categories that represented Sugar Dating interactions and connections between these new clusters and existing social phenomenon.

\section{$\underline{\text { Secondary Analysis }}$}

As part of the secondary-cycle coding, I critically examined the descriptive codes already identified in the primary cycles and began to organize, synthesize and categorize them into interpretive concepts (Tracy, 2013). Thus, the question sparked was "what could the story be?" As part of this process, I relied on prospective conjecture, where I considered novel theoretical juxtapositions and borrowed from other fields, models and assumptions (Doucet, 2007; Tracy, 2013). I began to notice discursive trends that related to the insights from Marxist feminism, Bernstein’s (2007) ‘bounded authenticity’ and Hochschild’s (1983) emotional labour framework. Thus, I shifted from descriptive to analytical coding to understand how the data attends to the research questions I posed.

The final re-visiting of the data involved a closed structural analysis, which clearly established dominant themes and grouped together examples of the themes. After examining these forums, it became clear that the sampled data was sufficient for the purposes of this study because no new or relevant data emerged and the category was well-developed (Saldana, 2009). It was also clear that the emerging analysis was relevant to my research questions in an interesting and significant way (Tracy, 2013). 


\section{B. Theoretical Framework}

\section{Marxist Feminist Theory}

I will draw, in part, from Friedrich Engel's contributions to Marxist feminist theory to describe how sugar dating has the potential to reformulate the value of social reproduction. In 1884, Engels wrote The Origin of the Family, Private Property and the State, which examined the rise of women's oppression as a product of the rise of class society and the nuclear family. Specifically, the shift from a feudal system to the ownership of private property created the distinction of two types of labour: 'productive' and 'unproductive' labour. Productive labour results in goods or services that have monetary value in the capitalist system, and are thus compensated by the producers in the sphere and involves tasks that people perform to benefit themselves and their families, rather than for the purpose of receiving a wage - i.e. cooking, cleaning and having children (Weeks, 2011). While both forms of labour are necessary, women were historically confined to the domestic sphere and performed unpaid labour. This has led to contentious debate concerning whether unproductive labour should have an economic value, and if this will liberate women. ${ }^{33}$ While these debates are important, I am not addressing this topic explicitly. Rather, I suggest that in theory, sugar dating allows women to capitalize on their desirable physical traits and social skills, in order to receive economic gain. This has the potential to disrupt the assumption that women's extensive engagement with social and intimate labour is a natural expression of their gender, and therefore does not merit compensation. This also allows women to achieve social mobility individually, without the historically necessary inherited factors such as class or family standing - or even achieved factors such as marriage (Nayar, 2016).

\footnotetext{
${ }^{33}$ For example, see: (Hartmann, 1979)
} 
Moreover, one interpretation of Marxist feminism is that all marriages have transactional aspects that are exchanged. In this sense, marriages have the same underlying feature of a 'sugar baby/sugar daddy' relationship to some degree. As Engels writes, monogamous marriage:

was not in any way the fruit of individual sex love, with which it had nothing whatever to do; marriages remained as before marriages of convenience. It was the first form of the family to be based not on natural but on economic conditions - on the victory of private property over primitive, natural communal property. (as cited in Jagar, 1988, p. 65)

Engels argues that women are exploited subjects who sacrifice their bodies for the sake of financial security in marriage - not for 'love'. Moreover, Engels claims that through the rise of private property ownership:

Marriage itself remained, as before, the legally recognized form, the official cloak of prostitution (Engels, 1914, p. 56).

In Engels' conception, the transactional nature of marriage is exploitative and inherent, but is unspoken. In this sense, sugar dating differs by relying on the frank negotiation of what is typically unstated in a traditional dating relationship. Sugar babies are encouraged to reflect on their emotional and material needs and desires and to communicate them - the latter, in particular - more explicitly than would otherwise be appropriate within the norms of conventional romance. Engels argues that all romantic relationships are inherently transactional. Participants, in sugar dating are at the very least, clear-eyed about this aspect of their relationship, and able to exercise more agency over its terms than would otherwise be expected.

However, akin to critiques of Marxist feminists, this partial liberation is not a universal achievement among women. Rather, the concept of 'value,' while never truly defined in Marxist theory, is subject to capitalist understandings of productivity; what is in 'demand' is what is valued. In the context of sugar dating, a sugar babies' race, gender, age, and resemblance to 
mainstream standards of beauty - may allow some women to better capitalize and mobilize their power. This will be taken into consideration in the analysis.

\section{$\underline{\text { Boundaries }}$}

I will draw on Elizabeth Bernstein's (2007) notion of 'bounded authenticity' to suggest that sugar babies enjoy a temporary, 'authentic' relationship so long as it is clearly distinguished through a controlled, predictable economic exchange (p. 103). Between $1994-2002$, a time where most street-based sex workers were moving to indoor locations because of the advent of the Internet, Bernstein (2007) interviewed 15 sex-positive sex workers, who were mainly white and middle-class in San Francisco. Bernstein (2007) explored the shifting relationships between independent escorts and clients through the 'Girlfriend Experience', which was the first time it had been acknowledged and discussed in academic context (Sanders, 2015). She noted that what was being purchased in the indoor market versus the outdoor market was not sex per se - but rather, intimacy (which may or may not involve sex). Bernstein writes that both escorts and clients desire an authentic relationship, but one that is clearly bound by a financial exchange. Specifically, she states:

successful commercial transactions are ones in which the market basis of the exchange provides an important emotional boundary for both worker and client, but one which can also be temporarily subordinated to the client's desire for authentic interpersonal connection (p. 483).

This is not only a sought after commodity for clients, but as Bernstein (2007) later discusses, it is also something that independent middle-class sex workers desire. Therefore, emotional boundaries are not only temporarily subordinated to the client's desire, but also to the sex workers. She calls this "bounded authenticity", where money is used as the 'clarifying effect' for distinction between commercial and non-commercial relationships (p. 483). In this sense, I 
argue that the attachment of an 'allowance' - whether it be financial compensation or gifts constitutes a crucial element in the erotic exchange, not merely for the sake of material provision, but at emotional levels as well (Sanders, 2015).

\section{$\underline{\text { Blurred Lines }}$}

I will borrow from Goffman's (1959) dramaturgical theory to examine how sugar babies 'perform' for their sugar daddy. In dramaturgical theory, social interaction is analyzed in terms of how people live their lives as if they were actors performing on a stage, examining their status and role. They engage in a process referred to as "impression management" which gives a specific impression in the minds of others, with the key feature being that they try to prevent embarrassment from themselves and others (Goffman, 1959, p. 76). According to Goffman (1959), we use 'sign vehicles' to present ourselves to others. The most commonly employed 'sign vehicles' are social setting, appearance and matter of interacting. The social setting is the material and conceptual space where certain behavior is to be performed. The appearance would be the physical traits, so perhaps emphasizing an attractive figure or fetishized image (i.e. naughty school-girl) (Goffman, 1959, p. 15). The manner of interacting would be the attitudes sugar babies convey to make a certain impression.

Essential to this process is the distinction between "front stage" and "back stage" behavior. Implicit in the terms, "front stage" behavior is visible to the audience and part of the performance, whereas "back stage" occurs when there is no audience present and the performer can step out of character without fear of disrupting a performance (Goffman, 1959, p. 488). According to Goffman (1959), boundaries are important to help separate the back stage and front stage self - as the performer should be able to control who has access to the performance, when 
and how. I suggest that sugar babies consciously engage in 'impression management' when they're in their sugar relationship. However, I suggest that sugar dating requires a more complicated, emotional process of impression management than Goffman's (1959) theory suggests.

To further nuance this theory, I will borrow from Hochschild's (1983) 'emotional labour' framework to understand how emotions are also being managed for reasons beyond merely embarrassment. Hochschild (1983) defines emotional labour as "the management of feeling to create a publically observable facial and bodily display" (p. 7), bringing attention to how people manage their own feelings as a way to create a particular emotional state in another person. Hochschild (1983) argues that there is a difference between emotional work and emotional labour. The former is the type of work conducted privately, and not in the context of paid labour. Some of the interactions that individuals would have on a traditional date, or in a traditional relationship are a good example of this. Although individuals engage in emotional work in the private sector regularly, this is not a major concern for Hochschild (1983). Rather, Hochschild (1983) is most concerned about emotional labour in the context of paid employment, because she claims that it is this type of work that causes people to be estranged from their true selves. However, I argue that 'sugar dating' blurs the lines between what could be classified as paid and unpaid labour, and therefore the distinction between emotion work and emotional labour. While sugar babies technically operate in the informal economy, a financial exchange is a crucial component in their relationships. Along the same lines of other scholars who have applied Hochchild's (1983) emotional framework to examine the labour involved in the sex industry - 
most popularly independent escorts who offer the girlfriend experience ${ }^{34}-$ I suggest that this conceptualization can be applied to sugar babies.

Hochschild (1983) argues that emotional labour has two distinctive features. First, surface acting is the "body language, the put-on sneer, the posed shrug, the controlled sigh", whereas deep acting is where "display is a natural result of working on feeling, the actor does not try to seem happy or sad but rather expresses spontaneously ... a real feeling that has been selfinduced." (p. 35). She states "in deep acting we make feigning easy by making it unnecessary" (Hochschild, 1983, p. 33). She uses the example of the Delta airline employee who suppresses her anger at a passenger who insults her. In 'acting deeply' ('unconsciously'), this Delta airline employee forgets what she would have felt if she were not pretending to feel something else. Due to deep acting, and the exploitation of her emotional labour by employers, Hochschild (1983) argues this type of labour is inherently exploitative because it creates emotional dissonance and estranges people from themselves. While I have found that 'sugar babies' are required to engage in surface acting (and front-stage presentations) and potentially in deep acting to manipulate their emotions to produce an 'authentic' response for their sugar daddy, I take issue with this being inherently exploitative. Rather, because the lines between a sugar relationship and a traditional relationship are purposely blurry, sometimes sugar babies do in fact have an authentic reaction. Moreover, sugar babies may not be unconscious of their supposed subjugation in these relationships, but rather are reflexively negotiating their options given the current economic conditions. The next Chapter will explore the key findings in the context of the social and economic climate examined in Chapter 1, and the theories discussed above.

\footnotetext{
34 Including but not limited to Bernstein (2007), Frank (1998), Love (2013), Sanders (2008) and Zelizer (2005).
} 


\section{Chapter 4: Findings}

The findings discussed are derived from semi-structured interviews with two Canadian sugar babies, as well as from a textual analysis of SA's LetsTalkSugar online discussion forum. For clarity, the findings have been grouped into broad themes, including: how sugar babies conceptualize their sugar relationships - why do they engage in sugar dating, and how they justify it; who engages in sugar dating; how sugar babies distinguish themselves from sex workers; and the primary challenges of sugar dating.

To the extent that dominant attributes and attitudes can be generalized, the picture that emerges from the findings is highly nuanced, and often rife with contradiction. Sugar babies garb their sugar relationships in the aesthetic of traditional romance, but make a point of distinguishing between sugar daddies and boyfriends; they seek 'trust,' 'chemistry' and 'connection' but take care not to lose sight of the underlying financial basis of their relationships. Sugar babies forcefully distinguish themselves from sex workers, but concede that sex is usually a key part of their sugar relationships. Sugar babies present themselves as confident, independent agents, pursuing financial goals that would otherwise be unattainable, yet face difficulties navigating an imbalanced relationship that can leave them vulnerable; they assert that they can stop at any time, yet concede a lack of other viable options. As will be seen, the experiences of sugar babies draw on familiar strands from both traditional dating and sex work, weaving them together into something wholly unique.

\section{A. How do sugar babies conceptualize the sugar dating relationship?}

\section{$\underline{\text { Similarities and Differences in 'Sugar Dating' to Traditional Relationships }}$}

Sugar babies frequently invoke traditional romantic discourses such as 'chemistry', or describe seeking their 'prince charming'. For example, sugar babies reported online and in the 
interviews that they will seek partners with whom they would have an authentic connection based off of 'chemistry', 'good looks,' 'trust' and 'connection'. As one sugar baby states, her "[potential sugar daddy] is about 20 years [her] senior, in great shape, down to earth, interesting, very funny, exciting, and quite good looking. [She] was interested immediately. [She] went home to google him and was really surprised to find that he is very wealthy (hundreds of millions), which is almost irrelevant..."

Similarly, Sasha stated: "My sugar daddy is definitely hot, in like - an 'old man' kind of way. He has the salt and pepper hair, dresses nicely and we do actually have chemistry... and he has a fat wallet."

When asked the differences between a sugar relationship and a traditional relationship, the online community suggests that it's only a matter of degree. Sugar babies will often claim they want to find 'the one', and employ discourses such as "knight in shining armour", "prince charming" and "my one true sugar daddy". Sugar babies are encouraged to emotionally invest in their sugar relationship the same way that they would in a traditional relationship. Moreover, sugar babies frequently emphasize the mutuality of the relationship - in terms of emotional and physical chemistry - and are reprimanded by other sugar babies if they report having to 'force' themselves to engage in sexual intimacy. However, none of the posts analyzed or interviewees referred to their sugar daddy as their boyfriend.

Somewhat contradictorily, the online community frequently suggests and encourages sugar babies to date multiple sugar daddies, or more importantly - married sugar daddies, who are "less clingy", and "understand the boundaries more so than those who are single". As one sugar baby posts: "Everyone who's had a successful arrangement has been with a married man. If you think you haven't, you're fooling yourself." On the other hand, Sasha says: "I would never be in a sugar relationship with a married sugar daddy. Talk about drama. I also don't think that's fair to 
his wife. Women have to stick together in that sense. If he's widowed - then sure." Jolene did not comment if her sugar daddies were married.

The interviewees were more forceful in their differentiation between a sugar daddy and a boyfriend. According to Jolene, the main differences between a sugar relationship and a traditional relationship are "what [they] do and [the] expectations. You can be emotionally attached to both, but it feels different - most of the time, compared to a traditional partner." Similarly, Sasha states:

There's no way I would put in the same amount of time and effort into my appearance for a regular boyfriend. My regular boyfriend would hear me bitch about my day, see me first thing in the morning when I've rolled out of bed - you know, the normal stuff. When I'm with my sugar daddy, I have to be 'on'. There's an 'acting' aspect to it, you know? I laugh at all his jokes, I don't ask too many questions. I let him talk about him, and don't care if he doesn't ask me too many questions. Whereas with a regular boyfriend, I would be like 'why haven't you asked about my day yet??' A 'sugar dating' relationship is not as natural... he's my sugar daddy - NOT my boyfriend.

Moreover, the interviewees seemed less concerned than the online community with having an 'authentic' connection, focusing instead on securing financial help. As Sasha states, when she was seeking a sugar daddy, she "want[ed] someone who [she] could actually enjoy spending time with, but more importantly that I know would be worth spending time with."

Nevertheless, sugar babies collectively referred to traditional relationships as "drama", "timewasting" and "messy", that prevent individuals from fulfilling their own needs and self-interest. On the LetsTalkSugar forum, sugar babies frequently refer to how they - as part of the 'millennial' generation - are focused on enhancing their own lives. It is clear that to both the online community and the interviewees, SA provides sugar babies with a niche platform where they can communicate their demands more explicitly. 
This distinction between sugar and traditional relationships is highlighted by the degree to which sugar babies complain about men who are utilizing SA for non-sugar objectives, like seeking out a traditional relationship without offering any financial compensation. For example, as one sugar baby points out:

So recently I have been finding a large amount of SD's saying that they aren't interested in the transactional part of a relationship or that because they want something serious, they don't see the need to discuss finances. Why on earth are these guys on SA if they have no intention of being financially supportive in any way shape or form. I feel like that is the whole point of this site... Has anyone had any similar experiences or have any advice on how to convey that message to POT SD's without sounding shallow?? [sic]

Sasha echoed this sentiment: “This isn't e-harmony, this isn't match.com... there are other websites if you're looking for a traditional, romantic relationship." Similarly, Jolene states that many sugar daddies claim that they are "just here because the girls are prettier." She continues,

this is extremely common. It probably makes up $80 \%$ of the people on here. It's not 'I don't want this to feel transactional'. It's 'I'm not going to give you anything, I'm just here because you're pretty'. It's maddening. $80 \%$ don't want an exchange, and middle-income who think they can offer $\$ 200$ for a whole night, or $\$ 200$ and consider that to be an arrangement. There's very few people where \$200 a month would be enough to spend time with them. Like they could make that by picking up a few extra shifts - rather than hanging out with an old guy who has nothing to offer them - not even knowledge.

In this sense, sugar babies openly accept the economic underpinnings in their sugar relationships.

\section{$\underline{\text { Mutual Benefit }}$}

The main divergence of sugar dating from traditional dating is the explicit setting out of expectations and limits in the beginning to define the terms of a 'mutually beneficial arrangement'. While the nature of the mutually beneficial relationship seems to vary on a caseby-case basis, it tends to represent an equitable exchange between both partners, with money and intimacy being essential components. In this conception, whether it is the money from a sugar 
daddy or the affection and attention from a sugar baby, the exchange of benefits should result in an equal exchange in this dating market.

This mutual benefit is the primary justification cited by sugar babies for their participation in sugar dating. Indeed, sugar babies often justify their decision with reference to the current economic conditions and the fact that they enjoy their work. However, the enjoyment of their work is typically linked directly to the benefit they receive, and contrasted with the absence of benefit when engaging in traditional dating. As Jolene states:

The financial side is like amazing - because being a student, being young is hard - the job market is not great, cost of living is going up, hard to make ends meet, having someone help you with that is pretty awesome. The trips, the dinners, the amazing restaurants - even if you don't end up in an arrangement with them, you still have a nice meal out of it and occasionally cash as well.

She also emphasizes that she enjoys her work, though this too is infused with the language of mutual benefit: "I enjoy going out with older guys anyways. Why would I go out with guys my own age - who can barely afford to take me out to dinner - and have nothing to offer me - in terms of finances, or even knowledge or connections?"

Similarly, Sasha says:

If I can go for dinner with a man and get paid - like, a lot - a lot - of money every time we go out - to pay attention to him, to look good for him, to laugh at his jokes. Why would I not do that? I'm only occasionally intimate with him. The lines are drawn - I know what he wants, and he knows what I want. I get to pay off my student debt and get a delicious dinner.

However, the mutuality of the exchange is a key feature that works in both directions. On LetsTalkSugar, users reprimand other users if they exploit the relationship for their own selfinterest and undermine the supposed equity of the exchange. For example, sugar babies are deemed 'sugar brats' by sugar daddies if they expect money up-front without providing a clear indication that they intend on offering intimacy or companionship. On the other hand, sugar daddies are deemed 'salty' or 'splenda daddies' by other sugar babies if they overstate their 
ability or desire to financially compensate or reward a sugar baby, but initiate intimacy anyway.

For example, one woman recalls her experience admitting her primary motivation was financial

incentive, followed by authentic connection:

[Potential sugar daddy] said he was very busy and don't have time to date but he will not pay to play. When I said I preferred an arrangement first and if we develop love feelings for each other down the road, we can talk about traditional relationship. I say that because I see many vulnerable girls being taken advantage by salt daddies who just manipulate them to have sex without providing support. Then he called me a sugar brat because I said maybe he should move on to look for someone else. Of course I blocked him and moved on.

As suggested by this quote, there appears to be a proper etiquette that sugar daters must follow during the early courtship phase to support the development of a mutually beneficial relationship. This includes sugar babies and sugar daddies interacting in a way that simultaneously invokes a traditional romantic script whilst making clear that both parties accept the economic underpinnings of the sugar relationship. While money and intimacy are recognized as key elements of what constitutes a mutually beneficial arrangement, they are also somewhat ironically suppressed or hidden in the early stages. This suggests that sugar daters are bound by normative ideals of dating, despite actively transgressing them.

\section{B. Who is a sugar baby?}

\section{Physical Appearance}

Sugar babies speak candidly of the value of their desirable physical and emotional traits. It is expected that a sugar baby must fit within a Western standard of beauty, with the concept of "girl-next-door" and "blonde hair/blue eyed/big boobed" being frequently referenced on both the forum and in the interviews. Racialized sugar babies often complain that they struggle finding a potential sugar daddy because sugar daddies openly desire the "white, blonde, girl-next-door" 
type (some of whom explicitly state this in their profile). As one self-identified 'brown' sugar

baby posts:

Being a sugar baby is hard, but being a brown sugar baby is harder. We constantly have to work twice as hard to prove ourselves to these men. When most of these woman have to just be light bright or near white. Constantly trying to prove these men that you're not an idiot. Honestly I think I'm done with this. I'm starting to waste my time. I don't know how anyone can do this white, black, Asian. I have no clue. But I'm tired. So I'm done.

Similarly, another sugar baby complains:

I just joined and am already regretting it. After reading WHITE WOMEN ONLY about 50 thousand times. Lmao. Wondering if there are any similar sites that cater to black women because this just doesn't seem like the place.

However, one sugar baby (who appears to be Caucasian from her profile picture) responded:

There are a lot of physical preferences like in any other dating site. And there are plenty of successful ethnic Sugar Babies around. There is a tendency of blaming I'm black, I'm this, I'm that... I could blame all odds against my type too. Truth is, it is if you throw the hands in the air and lament, you won't get a SD. It takes time, effort, preparation, mindset and most of all stand your grounds.

Another racialized sugar baby responds:

well being that Ive gotten racist messages and have read profiles that say WHITE ONLY I think its safe to assume. I'm not blaming anything. Its actually quite obvious. I think I'd have better luck simply leaving my house. Lol. Also, this is clearly a bit of an issue on this website because I thread dedicated to ethnic sb's titled: "Sugar can come in all sorts of shapes, sizes and colors". In the Sugar Bowl, there seems to be a set type of Sugar Baby that determines "the desired look," but who says they have to? So it isn't just me. And I think you would understand unless you've gone through it. Ive had great luck on other sites I think this one may just have more of a certain demographic, [is] all.

On the other hand, some racialized sugar babies note that they are highly desirable

because of their 'exotic' and/or racially ambiguous appeal. A self-identified 'black' sugar baby responds:

Let me first and foremost tell you that some of the most successful SBs have and are Black women. Don't ever allow other people's negativity to influence you. You have to stop feeling that you will never accomplish your goals because of your race. For every man who lists "No Black Women" there are five more who are scrambling to find a 
beautiful Black SB. Naturally this is a struggle than many non-Black people have little understanding of.

This suggests that sugar daddies may have distinct racial preferences, providing some sugar babies with an advantage to capitalize on their physical traits. On the other hand, Jolene emphasizes that excelling at the more performative aspects of sugar dating is more important for a sugar baby than fitting a certain physical profile:

You don't have to be the typical, blonde 'pretty girl'. But the job description - as I'll call it - you need to look your best. You want to be someone that they're proud to have on their arm, whether it's because you're making yourself that person - it's part of your role. It may be getting dolled up and putting effort into your physical appearance - which I find, is necessary if you're going to be a sugar baby. Reading up on current events - you don't have to be educated, that's not a requirement. But still be intelligent, still be witty.

In Jolene's conception, sugar babies capitalize on their physical and intellectual traits, as they play the 'role' of a sugar baby. This performativity helps distinguish their 'sugar' relationship from a 'traditional' relationship.

\section{$\underline{\text { Students }}$}

Sugar babies are typically registered in post-secondary education or are recent graduates, and the LetsTalkSugar forum seems to be disproportionately populated with students. Sugar babies consistently report to each other that part of their motivation for sugaring is to pay for schooling expenses, including tuition, textbooks, rent on their apartments and paying back student loans. Sugaring allows the students to meet academic demands while 'working' less hours. Some sugar babies ridicule but also sympathize with the students who are working in a minimum-wage, part-time job. As one sugar baby notes, "I can work at Starbucks for 8 hours and make $\$ 80$, or I can spend an evening with a sugar daddy and make $\$ 500$. You do the math.” On the other hand, Sasha points out: 
I really only have to 'work' one day a week, which is when I see my sugar daddy. But I also have to do other maintenance-related things, like making sure my nails are done my hair looks nice - that I have a 'new' outfit that he'll like. I also go to the gym four times a week, minimum. But like, I would rather be doing that than working minimumwage somewhere, and coming home to be too exhausted to do my schoolwork.

In this sense, while 'sugar babies' spend less time 'working', they do have to invest their money and expend their energy outside of their relationship to help maintain their appearance. This type of body-work suggests sugar babies possess a certain socio-economic status and privilege which enables them to be presentable to their sugar daddy (Miller-Young, 2014). In addition, some students anticipated the high-costs of post-secondary education and joined SeekingArrangement proactively. As one sugar baby asks:

I plan on being a sugar baby once I turn eighteen, it's only to pay for college and to pay for an apartment for myself to live in when I'm older. I plan on being a vet so, I would want a sugar daddy to pay for vet college as well [...] what exactly goes on in a sugar baby/ sugar daddy relationship?

New sugar babies often report being unsure of what a sugar relationship entails. While seasoned sugar babies are keen to offer advice to newbies, they also caution them about making their financial motivation explicit. However, there seems to be a general consensus amongst sugar babies that financial aid is patchy across North America, and often does not provide adequate support.

Somewhat ironically, despite the fact that 'students' comprise $40 \%$ of SA's population, sugar babies are reprimanded by sugar daddies who state that their sugar dating motives are to finance their education, or pay off student debt.

As one sugar baby posts with a subject heading 'I feel desperate':

I initially didn't think of becoming a sugar baby anytime soon, because I didn't feel it was the life for me, you know?

However, my university has had an issue where our financial aid has been cut, and i need around $\$ 1600$ so I won't get kicked out. 
I initially tried looking for a job, but due to my bad knees and lack of experience, no one will hire me.

Any advice on how to make this much quickly?

Sugar babies are told that sugar dating is not a way to make quick cash. Sugar daddies often respond to posts like the one above telling them to find alternative methods of financial aid, like "getting a job", "applying for scholarships", "trying stripping” or "web-camming". One interpretation of this reaction is that SA markets itself on sugar babies being motivated to 'sugar' out of pleasure - not out of desperation or necessity. Thus, while sugar daddies may desire the sexualized student status - or the naughty schoolgirl - they do not like this fantasy to be disrupted by the vulnerable reality of this population. On the other hand, they may be trying to circumvent legal barriers that sugar dating may pose.

\section{Distinction Between Sugar Babies and Sex Workers}

Although sugar babies openly accept the explicit economic underpinnings of a sugar dating relationship, they are discouraged from framing their relationship as an explicitly sexual transaction. As Jolene points out:

You have to be careful when you're asking for what you want. A lot of these guys are really touchy talking about money. Which is ironic because they have no problem bringing up sex. It's annoying - they think they can have full-on sexual conversations not like 'are you comfortable having sex with me' (i.e. will you do this, that, will you show me your boobs - detailed), and then once you ask 'what are you comfortably providing financially?" they're like 'woah woah woah'.

Notably, there are legal risks to approaching a sugar relationship as a sexual service. This may be one reason why sugar babies actively distance themselves from associations with professional 'sex workers', particularly 'escorts'. This is demonstrated explicitly, where many sugar babies claim "I believe sugar dating is $1000 \%$ different than escorting", or "I am not a PROSTITUTE!!!”. Some sugar babies acknowledge that sex is involved, but clarify that their 
arrangements are not solely about sex for money. More significantly, sugar babies seem to be

primarily concerned with circumventing the social, rather than legal barriers that sugar dating may entail. For example, Jolene states:

Sugar dating is not sex work. It is not prostitution. You are offering companionship in exchange for financial support. But - sex is usually involved. You can't be a sugar baby without assuming you're going to have sex with [your] sugar daddy. But it's not just about sex.

She continues:

Prostitution and sugar dating [are] similar. There's an exchange for capital for companionship and intimacy. But, you need to be attractive, engaging, have common sense, keep yourself safe. The biggest difference would be the motivation - and in some cases the exclusivity. So like, men seeking escorts the vast majority of the time are seeking sexual services - and sometimes that will include dinner, shopping, on arm for events. But I find when talking to sugar daddies - they're more invested in the welfare of the sugar baby. So it's less of 'this person has a service they can provide me' it's 'this person has a need, they're nice and I want to spend time with them'. I don't want to make a statement for everyone - but I do believe that with sugar arrangements they're different. If you're an escort looking for a client - you're not interested in making a connection and lasting long-term. I think when you're looking for a sugar daddy - you're looking for someone you genuinely like, and enjoy spending time with - and at the very least, is a friend.

In this sense, Jolene emphasizes the relationship component of their arrangement - one that is not bound by predetermined time constraints, and is based on mutual affection and at times, exclusivity. While the sugar babies do not state that sex workers lack the skills, or don't offer services that sugar babies have, the subtle distinctions arguably reflect a form of 'the girlfriend experience' (Bernstein, 2007; Nayar, 2016).

Moreover, the distinction between sugar baby and sex worker is supported by sugar daddies who are reprimanded when they reduce the social tie to a purely transactional exchange. For example, one LetsTalkSugar user stated:

So it seems that I found a POT and we have our first meet scheduled. From the start he was very blunt with what he wants, someone intelligent to talk to and take out, but 
ultimately is more in this for the sex. While I appreciate the honesty, this does have me feeling more like I would be an escort. I expressed that I will not have sex on a first date, that I need a chance to see if this will work and then go home and let it settle. He did agree to that, but his eagerness for sex makes me wonder if he really just wants an escort even though he says he wants more than that, but that this will be NSA (which I have no problems with). While talking on the phone, he did mention sugar briefly, but sounded as though it would be only when per meet and I have to put out. Which makes me further feel like an escort rather than a SB. I didn't say much in response thinking maybe discussing it in person would be better, or at least not so soon.

Through this comment, it is demonstrated that getting paid for sexual intimacy, without much ornamentation, makes this sugar baby feel uncomfortably like an 'escort'. This suggests that affective ties to sugar daddies are based on traditional romantic criteria, such as mutuality and individual choice and extend to both parties. While this is consistent with recent scholarship on sex work, arguably these expectations are intensified because sugar babies frame their arrangements as relationships, not as services (Bernstein, 2007). Moreover, by using the subtle distinction that sugar babies do not merely exchange sex for money, and that doing is socially and morally wrong, they are reproducing the stigma around sex work.

\section{Sugar Dating as Labour}

Sugar babies openly state that sugar dating is not an easy task. As one sugar baby comments: “you don't just get spoiled. Being a sugar baby is a lot of work. Hard work. If you're looking for easy money - you're in the wrong place.” Jolene echoes a similar sentiment:

I think [the media] is making a broad interpretation and missing the smaller details they're only showing half the details - they're showing half the picture and presenting it as the whole picture. I think it's really dangerous. This is an extreme example - but it's like "anyone can be a doctor. Anyone can be a chef. No, there's a specific skillset - there are requirements to the job. And it's like no - that's not the case. You have to have common sense, for one thing. You need to be able to meet the financial aspects. Even if it's not an allowance you're offering, you still need to provide the gifts or dinners or be successful that you can provide contacts or mentors. You need to be well put together even if you're not conventionally beautiful, if you're not well put together you're not 
going to be successful taking the time to read up on current events and be engaged in an intelligent conversation - they'll get bored if you're only talking about the Kardashian's. A lot of people who are coming into it after seeing the [mainstream media] articles are like: oh, all I have to do is show up. There's no job where all you have to do is show up not even modelling.

While acknowledging the benefits of sugar dating, and the lifestyle advantages it affords compared to typical student employment, sugar babies emphasize its demands in terms of emotional labour. Sugar babies are required to constantly embody their sugar daddy's fantasy companion, both emotionally and physically.

As Sasha states:

It definitely takes a high degree of emotional intelligence to be a sugar baby. There's a highly performative aspect of it. You're acting out the fantasy of a 'perfect' girlfriend. You always look your best, you don't cause drama, you give the sugar daddy what he wants. What this means - exactly - varies on a case-by-case basis. You have to monitor or regulate your reactions and expressions to make sure that [your sugar daddy] thinks you want to be there for them - not just for the money. Whether it's at dinner or in the bedroom, you have to seem like you're excited to be there. It can be exhausting, but sometimes you do actually have fun.

Moreover, they are required to take precautions due to the vulnerabilities associated with sugar dating.

\section{G. Challenges and Vulnerabilities of Sugar Dating}

Economic Power Imbalance

One of the main challenges cited by sugar babies was not knowing how much allowance they would receive for an 'initial' dinner date. Moreover, users report feeling frustrated if they have invested emotional energy in the early stages of courtship but have not been adequately compensated. As Jolene states:

Sometimes you'll go for dinner with someone, and they won't offer you a gift - you have no intention of seeing again - and they were tiresome to spend time with. I got all dolled 
up, I came all the way here, you didn't get any financial support or gifts - you didn't make a connection so there's no future there. It's a waste of time basically.

Thus, sugar babies won't necessarily receive any financial compensation until the arrangement is established. This seems to be a relatively new trend. According to Jolene:

From the conversations with people who have been doing this for years, and the people who just started doing it --- it would be good if you always received something for your time. But with there being a whole lot of sugar daddies who are not really familiar with the traditional way that things work - that's not often the case. The best explanation that I have for that - is that all of the new sugar daddies who have no idea what they're doing they're (pauses) they're lazy. They don't want to put the effort in. They think because they have the money, they should be able to get whatever they want. As opposed to, you jumped through hoops for me so now I'll give you a treat.

\section{$\underline{\text { Lack of Experience and Established Norms }}$}

More seasoned sugar babies argue that newcomers are entering the sugar community without conducting adequate research to prepare and protect themselves. As Sasha states "they don't know what they're signing up for." On the LetsTalkSugar forum, sugar babies are often referred to various sugar blogs written by SA contributors. However, as Jolene points out: "the contributors are trying to give good advice, but at the same time - the goal of the blogs is not to protect the women necessarily, it's to promote the website and draw more people to the website."

Both Jolene and Sasha think that the mainstream media is misrepresenting the sugar dating subculture. Jolene states:

I think it's misleading. It's the way they talk about it gives the impression that anyone can be a sugar baby and anyone can be a sugar daddy. You have to be a certain person, certain attitude and be comfortable with certain things. For the sugar daddy, you have to have money. You can't just be making $\$ 70 \mathrm{~K}$ a year. The way it's talked about it's like 'ANYONE can do it'. The way they talk about it - it's like it's the cake that anyone can make - like oh, it's easy! It's dangerous the way people talk about it. There's a huge influx of girls coming in as sugar babies, who have no idea how to protect themselves, don't do any research. You look at the online community where sugar babies are. And anyone who doesn't do their research - they're like 'why the hell would they do that?' 
Sugar babies who report on the forum recognize that sugar dating remains stigmatized, and they will often keep their identity a secret. For example, some students ask how to explain to their parents how they received new gifts, or were going away for a weekend with their sugar daddy. The users responded with only letting individuals who they trust know about their relationships, and if individuals seemed suspicious, then to explain it was an older boyfriend.

This stigma and the concomitant reluctance of sugar babies to share their identities with friends and loved ones can lead to vulnerability on the part of sugar babies, as indicated by the following post on LetsTalkSugar:

Hi, fellow Sugar Babies! I am very new to sugaring; I joined SeekingArrangement last December and learning everything the hard way. I have seen quite a few Sugar Daddies who are interested in domestic and international travel. I know the importance of having an emergency contact when away from home, but there is no way I can tell my parents (who would mistake what I do for prostitution), friends (I'm a very shy person, so I don't have any), or co-workers (my employment would be terminated due to the potential negative publicity). I also want to avoid any law enforcement, which would be embarrassing (I could be seen as a prostitute) and, again, lead to losing my job. Would someone be a contact for me for dates and other trips. Thank you so much for reading, and Happy Sugaring!

This post also touches on the issue of the ill-defined legal grey area occupied by sugar dating.

This too can result in vulnerability, as relayed by Jolene:

I discovered this recently - and it was a little bit traumatic - but crossing the border, uhm... if they find evidence of you being a sugar baby, you can be barred from entry from the United States. I was crossing the border this weekend actually - or trying to - to meet someone for the first time. All we had planned was a weekend of partying - we didn't talk about sex or anything - but I didn't know what he did for work. So I had a really...rude and moody customs officer --- and when I couldn't' answer that question, he got more irritable. I was answering everything else fine; I wasn't fidgeting or nervous. But, when I said I don't actually know, he said how - I said I never asked.

He sent me to secondary customs - they're allowed to go through phone back there. So they went through my phone, found evidence of me being a sugar baby and doing massage - despite not doing anything illegal - or going to do anything illegal - I was barred from entering the country simply by being a sugar baby. After it happened, I posted it on my tumblr account - within less than 24 hours, there were 400 notes with people saying the same thing happened or how to protect yourself. How did I know that I would be barred from the country for not doing anything illegal? 
I was talking to the guy I was going to be meeting - I have a tinder account - I have a twitter account for my massage personality - and my Seeking Arrangement account and that was used as evidence of prostitution. They said this is considered a form of prostitution - like most people, they simplify it down to an exchange of sex for money. I said I know the difference between the two, I know the difference - they're not the same thing. You can't tell someone who has done both, that they're the same - if you haven't lived it you don't know. You can only see it from the outside. There was no way to foresee it - my mom knows what I do, while she was waiting for me to fly back, she did some research - and they've stopped people for a whole bunch of stupid, arbitrary reasons. So basically, make sure if you're travelling - make sure you have your story straight.

Indeed, Jolene and Sasha, as seasoned sugar babies, state that the risks of 'sugar dating' exceed the risks of traditional dating. As Jolene states:

I would say yes - but only because you would do things you wouldn't necessarily do off of a regular dating site. Just because of the promise of money. You're more likely to take risk because of the financial gain. Which is why you hear stories about girls meeting guys at their houses for the first time. Either having sex with them because they promised them money or getting raped and getting beat up. And they're like how did this happen? And you're like 'well, you didn't tell anyone where you were going. They didn't give you money up-front, and they didn't take the time to do their research.' This is all stuff I've heard through the online community.

In contrast to the established and commonly understood norms and rituals that govern traditional dating, the combination of the relatively novelty of sugar dating, its occupation of a legal grey area, and its ongoing stigmatization makes it difficult for potential sugar babies to adequately prepare themselves. Sasha admits:

When I started I had no idea what I was doing. So, I did my research on literally every news source that discussed 'the sugar baby phenomenon', I watched the Lisa Ling documentary, I read the blog posts on the actual SeekingArrangement website. But they're all giving you different information.

Sasha believes that, as essentially a dating website, SA should not "have the responsibility of [teaching sugar babies] how to protect themselves. Like it's a dating website - you don't see 'don't' get into cars with strangers' - it's assumed you'll protect yourself." However, she argues 
that "the advice website run by SeekingArrangement, I think they have the responsibility of informing people." As she elaborates:

It's definitely clear that SA is going to frame 'sugar dating' in a way that is marketable and that skirts any legal consequences. They're all discussing the same issues - is this prostitution, are the girls being exploited, [sugar babies] are either whores or empowered women - yadda, yadda, yadda. My concern is that these new sugar babies will get the wrong advice, and make a stupid decision because of the stigma around [sugar dating]. Or, that there will be generalizations that 'sugar dating' is inherently exploitative - when I've had a really positive experience with it. So yeah, I don't really have a solution to that. But it's definitely a problem.

This quote neatly encapsulates many of the complexities and controversies of sugar dating. In reality, sugar babies are neither "exploited" nor fully “empowered women," but are something new, and in between. They are typically young women utilizing modern communications technology to seek out arrangements, whose parameters they are able to negotiate with greater openness and agency than is typical of traditional dating. Sugar babies achieve a degree of financial independence otherwise unattainable, but to do so must embody a fantasy.

Yet, the openness of these negotiations is still tempered by conventional romantic norms - sugar babies who are perceived as unduly focused on financial benefit are reprimanded, as are sugar daddies whose sole focus is sexual companionship. Furthermore, the arrangements themselves are described and garbed in traditional romantic discourse, for reasons both social and legal. Participants in sugar dating seek to avoid legal sanction, but are also aware of the taboo nature of their arrangements, and thus they fear social stigma that could result if they were 'outed.'

Furthermore, sugar dating clearly benefits many of its participants, but is also rife with the potential for vulnerability and abuse. While it is not inherently exploitative, it is undeniably 
premised on financial and power inequalities. These contradictions and their implications will be explored more fully in Chapter 5. 


\section{Chapter 5: Analysis}

It is clear from these findings that sugar dating occupies an amorphous and ambiguous middle ground on the spectrum ranging from sex work to traditional romantic relationship. As discussed in Chapter 1, SA is, on its surface, not unlike other dating websites. The main divergence is that expectations and limits are explicitly articulated and set out regarding intimacy and expected material benefit by individual users. These terms then form the basis of negotiations to determine the contours of a 'mutually beneficial arrangement'.

This key distinction is transgressive to contemporary understandings of prescribed gender roles in a heterosexual relationship. SA provides a platform for sugar babies to communicate their demands and desires more clearly than normative dating culture normally allows, while explicitly negotiating for economic benefit. In this sense, sugar babies are required to reflect on their needs and desires, subverting the emotional management and self-sacrifice that research suggests women commonly experience in conventional dating (Bradshaw, Kahn \& Saville, 2010; Leisring, 2012; Sprecher, Schmeeckle \& Felmlee, 2006) Moreover, sugar babies are encouraged to put value on the energy that they expend in relationships, suggesting that intimacy is not 'free'. In theory, sugar babies mobilize their desirability to gain social mobility, subverting traditional order that gives precedence to ascribed factors such as their family's socio-economic status, or through the formal economy. However, as will be discussed below, this power is subject to several constraints, which prevent some sugar babies from achieving their sugar objectives.

\section{$\underline{\text { A. Limits of Textual Analysis }}$}

Prior to embarking on the analysis, some brief caveats are necessary. As previously mentioned, the methodology employed is not without its shortcomings. The textual analysis of 
the LetsTalkSugar forum provides insight into a unique communicative environment for sugar babies. Freed from the unavoidable and understandable concerns of stigma and judgment engendered by an interview, this forum allows sugar babies to communicate with peers with similar lived experiences to their own, hidden behind the relative anonymity of the Internet. In such a forum, many of the participants possess an implicit and shorthand understanding of some of the more challenging aspects of the occupation that may prove difficult to articulate to those who have not experienced it. It is logical to expect that such a community, brought together by shared experience, would facilitate a level of honesty and introspection not shared with outsiders - that the forums of LetsTalkSugar would form a sort of uniquely insightful communal diary.

An oral interview has the benefit of capturing different kinds of communicative nuances. Behind a computer, a pregnant pause is invisible, and the backspace easily covers the participant's backtracking. However, as a social interaction, the interview still has a performative aspect to it, which unavoidably colours the data gathered. Some degree of self-regulation on the part of the interviewee must be expected, given the nature of the interviewee/interviewer relationship. Thus, I was reflexive throughout the interview process, enabling me to thoughtfully examine any biases or preconceptions I had regarding topics that were discussed - ranging from my own views of the student experience to my (numerous) experiences with the 'messiness' of traditional dating (Tracy, 2013). With those caveats aside, my analysis is as follows.

\section{B. Agency, Freedom and Power}

The structure of a sugar relationship is built upon on the equitable exchange of companionship and intimacy for economic benefit. Sugar babies are encouraged to articulate expectations for, and negotiate the parameters of, this exchange with an openness that violates 
conventional dating norms. In this sense, sugar babies are afforded more agency to establish the precise bounds of their relationships than they would likely have in the traditional dating market.

Moreover, by placing economic value on their intimacy and companionship, sugar babies are afforded a new method of gaining access to capital. Indeed, many sugar babies describe the opportunity for financial gain as the primary benefit and motivator of sugar dating over conventional dating. Through the former, sugar babies are able to monetize and commodify elements of a relationship - intimacy, attention, companionship, sex, and the like that they would be 'giving away for free' in a conventional relationship. As Jolene put it: "Why would I go out with guys my own age - who can barely afford to take me out to dinner - and have nothing to offer me - in terms of finances, or even knowledge or connections?" In this sense, sugar babies question the assumption that traditional relationships are empowering and fulfilling, as well as the presumption that such intimacy is 'free' of economic or other demands. This in turn challenges the notion that commercialization of sex is inherently exploitative or oppressive to women. Sugar babies argue, openly and frankly, that if they are going to 'date' or offer 'intimacy', they may as well get paid for it.

In this sense, sugar babies reflect some Marxist feminists' calls to recognize the value of social reproduction. Marx who is often credited as the first to analogize prostitution as work, wrote that "prostitution is only a specific expression of the general prostitution of the labourer" (emphasis in original, as cited in Love et al., 2013 p. 17). Whereas some feminist scholars have interpreted this to mean that the prostitute and the labourer are alike in that both sell their bodies (Van Der Veen, 2001), others have expanded on Marx's thinking to explain that because sexual and reproductive labor produces life, satisfies human needs, and reproduces the laboring population, it is a form of productive labour (Agathangelou, 2004; Love et al., 2013; Truong, 
1990). Although sugar babies are not 'selling sex' per se, but rather 'offering companionship or intimacy', they are capitalizing on what is historically unpaid.

The ability of sugar babies to monetize these traditionally unpaid aspects of romance affords opportunities for social mobility that may otherwise be unavailable. In particular, sugar dating has become an important tool for many sugar babies to address the high costs of education, as well as increasing cost of living in many urban centres. In contrast to a youth labour market characterized by low paid, unstable employment, sugar dating is, to many, an attractive and high-paying option for alternative employment. Sugar babies boasted about being able to graduate debt-free, and ridicule the students who are stuck working in minimum wage jobs. Indeed, through SBU, SA explicitly frames sugar dating as a form of 'alternative financial aid' for students.

However, there are questions that remain unclear. For example, if sugar babies were offered other, non-sugar options that would provide a similar rate of compensation, would they still decide to pursue their relationships? How much agency are sugar babies exercising if this is the only lucrative option available to them? While these are very important questions, they are not the focus of my analysis.

As such, rather than understanding sugar dating exclusively from a gendered perspective (sugar dating as a metaphor for women's experiences under a patriarchal society), I suggest that sugar dating can be better understood in terms of how sexual labour is organized within the broader capitalist context, including its class and racial dimensions. In this sense, I do not suggest that sugar babies are inherently exploited, misguided or in need of saving (Love et al., 2013). Rather, they are rational actors freely making economic decisions based on a cost-benefit 
analysis. That being said, the findings reveal that their agency and opportunities for social mobility are tempered by several important constraints, as will be discussed below.

\section{Constraints on Power, Freedom and Agency}

\section{The Specter of Sex Work}

Premised, at root, on the exchange of intimacy for financial benefit, sugar dating clearly skirts the bounds of what is traditionally understood as sex work. In light of the potential for legal sanction and social stigma, sugar babies vehemently distinguish themselves from sex workers. Almost universally, they take the position, as articulated by one user of LetsTalk Sugar, that "sugar dating is $1000 \%$ different than escorting." Or, in the words of another, slightly pithier user: "I am not a PROSTITUTE!!!"

These posts speak to the fact that sugar babies define themselves primarily with reference to what they are not. They are not girlfriends; they are certainly not escorts; they are emphatically not prostitutes. Sugar babies recognize that their arrangements blur the lines between conventional dating and commercial exchange, and the specter of sex work consequently lurks over all aspects of sugar relationships. In effect, they employ a set of strategies to separate themselves from sex workers. For example, sugar babies speak euphemistically of 'intimacy,' 'companionship,' 'gifts,' and 'mutual benefit' to describe their exchanges. This vague language helps skirt the legal implications of trading sex for money. Perhaps more importantly, it allows sugar babies themselves to describe their arrangements as distinct from sex work. Lost, it seems, in these self-drawn distinctions is the fact that, escorts too often refer to financial compensation for their time as a 'donation' or a 'tribute' (Blevins \& Holt, 2009; Sinacore et al., 2014; Weitzer, 2010). 
Sugar babies rely on the notion of 'time', claiming that they are interested in a relationship that lasts long-term. Moreover, sugar babies occasionally invoke paternalistic narratives to describe their relationship with their sugar daddy. When Jolene speculates a sugar daddy's desire for a sugar baby, rather than an escort, she states: "[ $\mathrm{t}]$ hey're more invested in the welfare of the sugar baby. So it's less of 'this person has a service they can provide me' it's 'this person has a need, they're nice and I want to spend time with them."' Interestingly, this distinction draws parallels to 'the girlfriend experience', where commercialized services mirror a "genuine connection" with, and mutual pleasure enjoyed by, a sex worker (Bernstein, 2007, p. 125; Nayar, 2016). Moreover, Bernstein (2007) found that the middle-class, independent escorts she interviewed did not want to be perceived as clock-watchers, as they would be deemed as professionalizing the experience too much (Van Meyl, 2014).

In light of these parallels, it is important to examine how and why sugar babies draw these subtle distinctions between themselves and sex workers. Indeed, while one might expect the sugar baby community to articulate a uniquely sympathetic and nuanced view of traditional sex workers, given the mere shades of grey that separate the two practices, the reverse is often the case. Sugar babies tend to express clichéd and stereotyped views of traditional sex workers, while the online community is quick to reprimand sugar babies who are acting too 'desperate,' or seem overly focused on financial benefit, to the exclusion of romantic ideals. In their successful avoidance of the 'whore stigma' (Pheterson, 1993), sugar babies reinforce the divide between 'good sex' and 'bad sex' (Bell, 1987; Bernstein, 2007; Miller-Young, 2014). Through the stigmatization of sex workers, sugar babies, who are themselves stigmatized, are able to distinguish themselves from a community perceived as more deviant than their own. 
Several scholars have analyzed this social process of oppositional definition or distinction (Bell, 1987; Bernstein, 2007; Sanders, 2005; Sinacore et al., 2015). Goffman (1963) suggested that in spite of not conforming to social norms, those who are stigmatized still apply these norms to themselves and to others. In effect, scholars have documented the process whereby women will ambiguously engage in the sex worker identity, but distinguish themselves as more of less respectable in certain spaces by attributing the stigma to others (Carrier-Mors, 2015; Haeger \& Deil-Amen, 2014). In effect, many sugar babies attempt to negotiate their stigma by marking themselves as more respectable than sex workers, and perpetuating stereotypes about them (Bernstein, 2007).

This process suggests that while mainstreaming and normalization of sex work has certainly progressed, it is not yet fully accomplished. Moreover, the oppositional distinction employed by sugar babies constrains their agency to negotiate the terms and conditions of their arrangements. Negotiation must be conducted with euphemism, and must occur within the context of a process that mirrors traditional courtship to a large degree. Both sex workers and sugar babies exchange intimacy for financial benefit; however, the former is able to negotiate the exchange far more openly.

Beyond the use of euphemism and the stigmatization of sex work, sugar babies borrow from the language and aesthetic of traditional romantic discourses in order to further distinguish themselves from sex work. This too constrains their agency and ability to monetize their labour power and social reproduction. These constraints will be discussed below. 


\section{The Constraints of Traditional Romance}

Sugar babies frame their arrangements as relationships, not as services. As such, they insist that they pursue their romantic partners based on individual choice and subjective emotional criteria (Illouz, 1997). This is particularly evident among the users of LetsTalkSugar, who seem to be predominantly newer, less experienced, and perhaps less jaded. These sugar babies speak of finding their 'prince charming,' or 'the one,' implying that their ideal sugar relationship will be both monogamous and founded on romantic love, in addition to the mutual benefit based on a financial - intimacy exchange. Indeed, even the more experienced interviewees emphasized their desire for 'chemistry,' 'trust,' and 'connection' as components in their arrangements.

Yet, these romantic ideals have limitations that constrain the agency and monetizing ability of sugar babies. Sugar babies are encouraged to create emotional boundaries to ensure that their efforts are not exceeding their 'sugar' objectives. As discussed in the findings, they insist on a distinction between sugar daddies and boyfriends, expressing concern when the lines between the two seem to be blurring, and cautioning against men who were overly 'clingy.' Unlike a traditional romantic relationship, sugar babies expressed their preference for married men - or multiple sugar daddies - on the basis that such arrangements tend to have clearer boundaries. Both online users and the interviewees complained about men who attempted to use SA as a traditional dating site, or who offered inadequate compensation for the sugar babies' companionship. In so doing, the sugar babies demonstrated the preeminent value of economic exchange in their motivations for engaging in sugar dating.

In this sense, I argue that the attachment of an 'allowance' - whether it be financial compensation or gifts - constitutes a crucial element in the erotic exchange, not merely for the sake of material provision, but at emotional levels as well (Sanders, 2015). This reflects 
Bernstien's (2007) notion of 'bounded authenticity', which suggests that middle-class, independent escorts enjoy a temporary, 'authentic' relationship so long as it is clearly distinguished through a controlled, predictable economic exchange (p. 103). While Bernstein (2007) uses various dichotomies (i.e. commercial and non-commercial encounters, personal/professional life) to understand the need for this attachment, I suggest that sugar dating occupies a new space that messily blurs these dichotomies. Under this premise, I suggest that the need for this 'clarifying effect of payment' (Bernstein, 2001, p. 399) is even more crucial to help sugar babies maintain their boundaries and achieve their sugar objectives.

While the presence of 'trust,' 'chemistry' and 'connection' allows sugar babies to enjoy their work, to a degree - a recurring theme in the findings - it also complicates the boundaries of these exchanges. As one sugar baby complains, her [sugar daddy]:

has asked me to travel with him to several up coming events and I would love to go. We really do have an amazing time together. But now I am worried that I accidentally crossed some invisible line. Now it feels like I have a boyfriend as I am meeting all his needs. That's only an issue BC I finished a contract job end of Oct and need an income to survive [...] So the question is, ONE: How do I get financial help from him without losing the sincerity. I appreciate the gifts but I need $\$ \$ \$$ for bills. TWO: Why hasn't he offered without me asking?

As this quote suggests, the hybrid nature of sugar dating complicates the establishment of the necessary emotional boundaries, which can result in confusion, uncertainty, and occasionally exploitation of sugar babies (Sanders, 2015). The need to both integrate yet restrain emotions can make creating and maintaining desired boundaries difficult (Sanders, 2015). The complication is exacerbated by the ongoing nature of the relationship. In contrast to sex workers, the length of time tends not to be an element of the arrangements that is negotiated in advance (Bernstein, 2007).

Sugar dating's reliance on traditional romantic discourses results in a situation in which the fundamental elements of sex work - the exchange of intimacy for money - must be negotiated 
and garbed in the language and rituals of traditional courtship. Sugar babies are hampered by a persistent normative heterosexual romantic script used to govern the process of their economic exchange (Bernstein, 2007). This too limits the agency of sugar babies.

While this script indicates a certain degree of respectability, it also hinders some sugar babies from achieving their sugar objectives (Bernstein, 2007). In this script, men are expected to make sexual advancements while women are the passive recipients who create boundaries; both parties reach an agreement based on mutuality and individual choice (Sanders, 2005, 2015). In effect, despite the fact that SA encourages transgressive gender roles, where women can explicitly state their financial demands, they must do so within gendered constraints. For example, sugar babies often complain that they must not assert their financial goals prematurely in the 'courtship' phase, or they will be perceived as desperate or 'sugar brats'. On the other hand, if they do not set out their objectives in advance, then they may be investing their time without adequate financial compensation. Finally, sugar babies themselves protest when sugar daddies violate this script, complaining about feeling 'escort-ish' if a sugar daddy initiates intimacy in exchange for financial compensation without building some type of emotional connection.

In effect, sugar babies are trying to inscribe their practices within proper respectability while also transgressing them (Carrier-Moisan, 2014). While intimacy and financial compensation are key components in sugar arrangements, they are both hidden or suppressed in the courtship phase in a far more complicated way than a commercial transactional encounter. Their hidden nature creates barriers to frank and open negotiation by self-interested sugar babies.

\section{Constrained by Male Heterosexual Fantasy}

In order to have a successful arrangement, sugar babies must conform to a heterosexual fantasy. While sugar babies insist that they are not sex workers, they do emphasize the labour 
required to play the 'fantasy girlfriend' role. Sugar babies emphasize that successful sugar dating requires diligent performance, physical upkeep and the consistent demonstration of emotional traits typically desirable in a romantic partner - emotional intelligence, wit, and the like. According to Goffman's (1956, p. 114) theory of "impression management", I suggest that SeekingArrangment - or more broadly, sugar dating subculture - is the setting or the conceptual space where these performances take place.

Women play the 'role' of a sugar baby, which encompasses highly desirable physical and emotional traits, fulfilling an idealized, 'fantasy' girlfriend. The mechanism that is used to separate the 'front stage' and 'back stage' self is promise of economic exchange, which Bernstein (2007) also refers to as the 'clarifying effect' for commercial sex workers. In this sense, when they are with their 'sugar daddy' - they are on the 'front stage', consciously engaging in impression management to fulfil their 'sugar' obligations.

While sugar babies embody notions of 'surface acting' (consciously acting like they are having fun), and also deep acting (where they have internalized this romantic ideal, and their reactions are authentic, if self-induced) (Hochschild 1983), I argue that the exercise of deep acting is conscious and not inherently exploitative. Sugar babies report enjoying their time with their sugar daddy, and feel empowered by the financial reward. This suggests that sugar babies do not embody a 'false consciousness' through deep acting, but rather are making a reflexive negotiation of their options in the current social and economic climate (Nayar, 2016). Moreover, because of the degree to which material benefit is linked to enjoyment of the sugar relationship in the minds of sugar babies, there is a conscious and important emotional boundary (Bernstein 2007, p.483). 
Nevertheless, agency and opportunities for social mobility afforded to sugar babies are constrained by the degree to which they can embody a 'fantasy.' While acting processes can certainly assist in this endeavor, there are several inherent attributes - class, race and physical attributes - that greatly affect the perceived value of a sugar baby within the SA market, as discussed below.

\section{Class Constraints}

Sugar babies openly capitalize on their desirable physical and intellectual traits, and describe the bodywork required to maintain their appearance for their sugar daddy (Miller-Young, 2014). Tasks such as getting a new outfit, or having their nails and hair done requires financial resources and time that may not be feasible for all women. Moreover, by virtue of a disproportionate proportion of sugar babies being enrolled in, or recently graduating from, a post-secondary institution, they possess a sexualized 'student' status, which is reportedly highly desired by clients of sex workers (Roberts et al., 2007). This also indicates a certain level of privilege and social mobility that may not be afforded to other marginalized sex workers (Nayar, 2016). On the other hand, while students disproportionately represent the 'sugar baby' population, they are reprimanded when they explicitly make financial requests for tuition or school-related expenses. One could speculate that by admitting financial need, sugar babies are disrupting the clean, 'sexy student' fantasy, and revealing that they are indeed part of a vulnerable population. Consistent with recent scholarship on sex work, such admissions break the illusion that students are 'sugaring' purely out of desire, rather than financial necessity (Bernstein, 2007; Sanders, 2005, 2015). 


\section{Race Constraints}

In addition to class constraints, my findings indicate that the race and/or ethnic background of sugar babies impacts significantly on their perceived desirability for potential sugar daddies. Sugar babies report a general preference among sugar daddies for girls that embody the stereotype of the white, 'blonde hair/blue eyed/big boobed,' 'girl-next door.' Furthermore, sugar babies who are members of racialized minorities, particularly those who are 'black' and 'brown' frequently describe facing obstacles ranging from difficulty attracting the attention of sugar daddies to strong racial preferences.

While the study of sugar dating remains in its infancy, these findings mirror trends identified by scholarship of both the traditional sex industry and traditional online dating. In terms of the former, scholarship on the sex industry discusses the different hierarchies of value that organize the production, distribution and consumption of some services, such as pornography (Carter \& Giobbe, 2006; Miller-Young, 2009; Hill-Collins, 2006). According to this logic of sexual economy, some bodies are worth more than others; yet all are evaluated and commodified through the lens of race, gender, class and sexuality (Miller-Young, 2009).

For example, in Miller-Young's (2009) study, she discovers that black professional adult porn actresses have been vocal about issues of wage inequality, employment marginalization, and interpersonal bias, even as they assert their autonomy in choosing to work in the pornography industry. She claims that the sex industry treats most sex workers as disposable, and black women are the most devalued; they are hyper-disposable. Rather, it's the young, blonde, lithe, busty, white woman that is constructed as the most valuable sexual commodity. ${ }^{35}$

\footnotetext{
${ }^{35}$ Miller-Young (2009) discusses how white women's bodies are the primary currency of the multi-billion dollar adult entertainment business. They are the focus of companies like Vivid, Hustler, and Wicked, and they are the 'cash cows' for an industry that is immensely lucrative for major US corporations such as AT\&T, TimeWarner, and DirectTV that profit from selling hardcore over pay-per-view cable channels, video on demand, the internet, and
} 
These valuation regimes are not confined to the sex industry. Most comparably, some scholarship on online dating suggests that users have strong racial preferences - with white men being most desirable and black women being the least desirable in heterosexual relationships. ${ }^{36}$ Indeed, as Christian Rudder, co-founder of OkCupid, a mainstream traditional dating website, writes: "You can actually look at people who've combined 'white' with another racial description. Adding 'whiteness' always helps your rating! In fact, it goes a long way toward undoing any bias against you" (Roderique, 2017).

The experiences of sugar babies mirror this dichotomy. Sugar babies who possess the most sought after physical attributes of white femininity (white, blonde, blue eyes, big boobs) will emphasize this in their profiles, and will accordingly command more attention from sugar daddies. The increased demand provides these sugar babies with a greater selection in terms of potential sugar daddies, as well as increased leverage with which to negotiate the parameters of a sugar relationship.

In contrast, racialized sugar babies command less attention from and value within the dating marketplace. They tend to face a correspondingly smaller selection of potential sugar daddies, and therefore possess less leverage over the terms of the 'mutually beneficial relationship.' In the limited cases when the race of minority sugar babies becomes an asset, it is usually because their race lends them an exotic 'otherness' that is fetishized by certain sugar daddies. In these limited cases, race is still essential to the established value of the sugar baby within the marketplace of SA. ${ }^{37}$

in millions of hotel rooms each year. Coloured sex workers hold much less currency for these corporations because they receive significantly less demand compared to white female bodies.

36 There is also some scholarship that indicates there are strong racial preferences in gay online dating, i.e. (Lundquist \& Lin, 2015)

37 Through the online forum, there is some mention that sugar daddies on SA are predominately white, middle-aged men. However, it is unclear is there is a correlation between a sugar daddy's race and their racial preferences. 
Undoubtedly, SA affords more agency to sugar babies, in terms of establishing the terms of the economic exchange that undergirds their relationships, than is typical of a traditional dating relationship. Nevertheless, this agency is exercised within the confines of a competitive dating marketplace that values race in a manner mirroring both the traditional sex industry and traditional dating. As such, while sugar dating encourages women to assign value to their 'social labour', the race and physical attributes of sugar babies serve as key determinants, and in some cases, constraints, of their perceived value in the eyes of potential sugar daddies.

\section{$\underline{\text { Vulnerabilities as Constraints }}$}

Although sugar dating provides sugar babies with an untraditionally high degree of power and agency in terms of advance negotiation of the parameters of their relationships, it also creates uncommon vulnerabilities. The lack of established and commonly understood norms, of the type that govern traditional dating, leads to hesitation on the part of many sugar babies to actually assert their financial goals in a manner necessary for the establishment of a true 'mutually beneficial relationship.' This inexperience can exacerbate the imbalances in what is already an economically unbalanced power relationship.

Furthermore, sugar babies recognize that sugar dating remains highly stigmatized amongst the general public, and is regularly conflated with 'prostitution' - at the very least morally, if not legally. They are therefore often reluctant to share that aspect of their lives with friends and family, depriving them of a support network that they would otherwise turn to for guidance, emotional support and safety when navigating an unfamiliar and potential fraught dating environment. Consistent with scholarship on student sex workers, sugar babies implied that they did not want to disclose sugaring to classmates and professors because of how the 
stigma is associated (Lantz, 2005; Murphy, Dunk-West \& Chonody, 2015; Rosenbloom \& Fetner, 2001).

Finally, sugar dating's occupation of a legal grey area that undoubtedly falls somewhere along the spectrum of sex work creates real legal vulnerabilities on the part of sugar babies. They are subject to the dictates of authorities to which the similarities of sugar dating to traditional sex work may be sufficient justification to treat the two as indistinguishable. The young age and relative lack of power of sugar babies can create barriers for them to assert perfectly valid defenses to these actions. It has been a recurring theme throughout this analysis that sugar dating is a thoroughly unique phenomenon. It is to be expected that such a phenomenon, while creating opportunities for uncommon degrees of agency, might also engender uncommon degrees of vulnerability.

\section{$\underline{\text { Sugar Dating as its Own Phenomenon }}$}

As discussed above, sugar babies are afforded a certain degree of social mobility through sugar dating. However, this freedom and agency is subject to important constraints. Although sugar dating itself is not criminalized in Canada, it occupies a legal and social grey area that skirts the bounds of criminalized sex work. As such, sugar daters are constrained by the threats of legal sanction and social stigma, and use euphemistic terms to code their language accordingly. Furthermore, the specter and stigma of sex work lurking at the margins of sugar dating results in sugar babies defining themselves primarily in opposition to sex workers. Although they are not girlfriends, they are certainly not escorts or prostitutes. ${ }^{38}$ However, the subtle distinctions that sugar babies rely on overlook the similarities in the economic conditions

\footnotetext{
${ }^{38}$ Despite some sugar babies encouraging other sugar babies to date married men, and openly boasting about the perks of this emotional boundary, the posts I examined did not discuss sugar babies' playing the role of a "mistress".
} 
in which other women (ranging from street-based sex workers to escorts) turn to individualized strategies for survival and social mobility (Nayar, 2016).

Furthermore, the oppositional definition engaged in by sugar babies constrains the freedom with which they negotiate and engage in sugar relationships, including by leading them to garb and govern their relationships with the language, and to an extent the norms, of conventional dating. Sugar babies seek to inscribe the practice of 'sugar dating' into a certain respectability, while also transgressing it (Bernstein, 2007; Carrier-Moisan, 2014). Yet, in so doing they acquiesce, at least to a degree, to constraints built into the traditional romantic script. SA encourages sugar babies to bluntly assign value to their intimacy and social labour, yet they cannot negotiate bluntly; rather, the business aspects of the commercial exchange must be worked out through a process that mirrors traditional courtship. The successful sugar baby does not sit across a boardroom table from a potential sugar daddy; she (and it is almost always she) flirts, she seduces, she entices, and she raises the issues of remuneration in a gentle, subtle way.

Finally, the ultimate value of sugar babies is dependent on their ability to play the role of a 'fantasy' girlfriend. In conforming to this standard, they are still restricted by capitalist ideologies of class and race. In addition, the provision of this type of 'girlfriend' intimacy is not restricted to sugar dating; it is a growing trend among sex workers.

Clearly the sugar world draws heavily upon trends and forces that are features of both traditional romance and the sex industry. What is new is sugar dating's blending of these elements to creates a unique conceptual space that both enhances the degree of power and agency exercised by sugar babies, and constraints it in ways both traditional and novel. 


\section{Chapter 6: Conclusion}

This thesis contributes to a small body of research that attempts to provide nuanced societal understandings of the 'sugar baby phenomenon' in a Canadian context. To date, most of what is known about their experiences comes from anecdotal accounts filtered through print, online, and television media. As is typically the case with accounts of students working in the sex trade, such media will focus on the more sensationalist or salacious aspects of sugar dating, with the result that the true lived experience of sugar babies is difficult to ascertain through these channels. Sensationalism aside, there is certainly empirical evidence that this phenomenon is becoming more widespread, as has been documented in the United Kingdom (Barns, 2016; Bullen, 2017), Australia (Barraclough, 2017), the United States (Sellinger-Morris, 2016). However, there remains a dearth of academic research in a Canadian context, which this study seeks to improve.

By drawing on data from a textual analysis and two qualitative in-depth interviews, I have attempted to go beyond the sensationalised media representations to examine the experiential realities of sugar dating as articulated by a series of sugar babies. I believe that this approach is best suited to discerning any pattern of common or recurring motivations and factors that lead sugar babies to pursue this line of work. Additionally, this method is best suited to identifying any elements that are common to how sugar babies experience sugar dating.

It bears repeating that this study does not suggest that there is necessarily a correlational relationship between the student debt crisis and increased registration to SA. To test any hypothesis that would interrogate whether increased tuition fees and the student debt crisis correlates to the increase of student sugar babies registered to SA, comparative longitudinal research would be needed (Sanders, 2015). Still, if the trend of increasing student use of SA 
continues, there are questions to be asked about the degree to which increasing levels of sugar dating correlate to the broader rise of participation in the informal economy, particularly among working class and middle class students (Sanders, 2008). Moreover, additional research should directly examine how being a sugar baby influences academic outcomes and persistence.

This study, however, is but one snapshot of what the multi-layered, complex sugar dating phenomenon represents. There are a variety of outstanding areas of research that will better help nuance this understanding. The next possible step would be to conduct research on the trajectory of sugar babies - particularly, their transition, or lack thereof out of a sugar relationship. Sugar babies suggest that this is a temporary, transitional phase that they intend to exit once they have graduated, or paid off their student debts. However, are there any potential trappings, incentives or cycles that entice sugar babies to stay in a sugar relationship? And is this necessarily a bad thing? Have any sugar relationships evolved into traditional relationships, ending in marriage? If so, are there any differences in how power and agency are negotiated and exercised?

In addition, I would like to investigate how these gendered dynamics shift between a male sugar baby and a female sugar mommy, as well as how non-gender binary sugar babies navigate their relationship with sugar daddies or sugar mommies (or sugar parents). As briefly hinted at in the analysis, how does the race of a sugar baby implicate how they or why they capitalize certain physical or emotional traits?

Notwithstanding these caveats, my findings reveal that the motivations and experiences of sugar babies are complex and at times seemingly contradictory. Perhaps unsurprisingly, given that sugar dating occupies the amorphous middle ground between the traditional visions of sex work and dating, the phenomenon blends the language and experience of these two seemingly polarized concepts. Sugar dating follows the rhythms and rituals of conventional dating, but is 
preceded by an explicit exchange of services for economic benefit, which serves as the foundation of the relationship. Sugar babies enjoy having an authentic connection with their sugar daddies, but this is complicated by the economic exchange at the heart of it. Sugar babies enjoy a standard of living that would otherwise be out of reach because of sugar dating, but there is taxing emotional labour involved in constantly living up to their sugar daddy's every expectation and fantasy. Yet, if the financial compensation has been discussed and agreed upon, sugar babies seem to feel empowered playing the 'role' of a sugar baby - reflecting Bernstein's (2007) notion of 'bounded authenticity'. Sugar babies invoke traditional romantic discourses to describe their relationship in an attempt to normalize it, but arguably to also circumvent the legal implications that could arise. Rife with contradiction, sugar dating is a thoroughly modern phenomenon, but one that hearkens back to an old, and longstanding vision of the economic, sexual, and power dynamic between men and women.

However, this is not to suggest a vision of sugar babies trapped in a Victorian race against time to secure male financial support before their youth and beauty withers away. Rather, the frank negotiation necessary to any sugar relationship has given many sugar babies a new confidence to accept nothing less than fulfillment of all expectations - reflecting some of Marxist feminists' demands. For example, as one user comments:

I thought I'd give you a somewhat different perspective on what might attract women to the sugar bowl. I'm 46, divorced, no kids, and no debt. I am financially stable, so any gifts I receive can be saved for a rainy day or applied towards preventative aging measures: botox, fillers, personal training, etc... Much needed perks at this age. Since I don't need the money, why am I here? Because this is the first time I've ever been encouraged to ask for everything I want from a man and been able to get him to be honest about what he wants from me. There's no fear of having your heart broken or feelings hurt because you establish the expectations and boundaries of the relationship ahead of time. 
Ultimately, this study demonstrates that 'sugar dating' is a complex phenomenon where different, and often traditionally gendered forms of power are mobilized, negotiated and reworked in a thoroughly modern and still-developing context. 


\section{$\underline{\text { Appendices }}$}

\section{Appendix A: Oral Consent Script}

Hello, my name is Sarah Daly and I am a Master's student in the department of Law and Legal Studies at Carleton University. I am under the supervision of Professor Ummni Khan.

I would like you to participate in a study on "Sugar Babies and Sugar Daddies: An Exploration of Sugar Dating in Canadian Universities." This study aims to explore the characteristics of individual's engagement in the sugar dating subculture, including motives, the nature of the courtship and personal experiences. There was no funding provided for this study.

This study involves one $60-90$ minute interview that will take place on Skype. With your consent, the interview will be audio-recorded. Once transcribed, the audio-recording will be destroyed.

As this project will ask you about your engagement in "sugar dating", there are some social and emotional risks. While this risk is expected to be minimal, I will take precautions to protect your identity. This will be done by keeping all responses anonymous and allowing you to request that certain responses or identifying details not be included in the final project. Participants are not obliged to answer every question, and can choose to not answer any they are not comfortable with. Should you feel any distress, please let me know and I will give you contact information for counseling services available both online and near your location. This information will also be provided at the end of the interview.

You may withdraw at any time, up to February $1^{\text {st }}, 2017$ by letting me or my research supervisor know. If you choose to withdraw, all the information you provided will be destroyed.

As a token of appreciation, you will be offered a $\$ 20$ gift card to amazon.ca which will be emailed directly to you upon completion of the interview.

All research data, including audio-recordings and my notes will be encrypted. Any hard copies of data (including any handwritten notes or USB keys) will be kept in a locked cabinet at Carleton University. Research data will only be accessible by me and my supervisor.

Once the project is completed, all research data will be kept for five years and I may use it for other research projects on this same topic. At the end of five years, all research data will be destroyed.

If you would like a copy of the finished research project, please let me know. I will then provide you with an electronic copy.

The data collected will be through Skype servers, which are located in the United States and are subject to U.S. laws on data privacy.

You can reach me at sarahdaly@cmail.carleton.ca or 613-520-3690 ex. 1872. My supervisor can be reached at ummni_khan@carleton.ca or 613-520-2600 ex. 1547. 
The research has been cleared by Carleton University Research Ethics Board-A (Clearance \#105670). Should you have any ethical concerns related to your involvement in this research, please contact Dr. Andy Adler, Chair of Carleton University Research Ethics Board-A at ethics@carleton.ca or at 613-520-2600 ext. 2517

Do you have any questions or need clarification?

Do I have your permission to begin: ___ Yes No (If no, thank them for their time.)

Do you agree to be audio-recorded: ___ Yes No 


\section{$\underline{\text { Appendix B: Interview Questions }}$}

Demographic information:

1. What is your gender?

2. What is your sexual orientation?

3. What is your race?

4. What is your age?

5. What is your occupation?

6. What is your education level?

a. Are you currently in school?

b. Do you have any student debt?

7. Do you mind me asking if you are married?

a. Can you tell me a little more about that?

RQ1: What are the reasons for women and men to become Sugar Daddies and Sugar Babies?

1. How did you find out about Seeking Arrangement?

2. How would you define a Sugar Daddy and Sugar Baby Relationship?

3. What are your reasons for joining Seeking Arrangement?

a. What type of partners do you look for on Seeking Arrangement?

\section{RQ 2: How do women and men characterize an arrangement?}

1. What is an arrangement?

2. What does it mean for the arrangement to be mutually beneficial?

3. What type of men/women do you typically encounter on SA? 
RQ3: How does a "sugar baby" or "sugar daddy" relationship differ from a traditional relationship?

4. Do you have multiple arrangements?

5. Do you have (non sugar?) relationships outside of an arrangement?

a. Is there even a difference?

b. And if so, what are those differences?

6. How is the arrangement typically decided?

7. How do you set expectations?

8. What makes a good arrangement?

9. What do you enjoy about it or what are its benefits?

10. Are there any aspects that you do not enjoy?

11. When do you know that you are ready to move from the Internet to meeting in person?

12. What do you talk about ahead of time with possible partners?

13. To what extent do you believe you have a choice on the agreed upon terms of the arrangement?

14. Do you always receive what you feel you deserve? Why or why not?

15. Have you had to end an arrangement before?

a. Why?

b. How did you end the arrangement?

\section{RQ4: How do "sugar daddies" and "sugar babies" identify within their relationship?}

1. What have you read about "sugar dating" in mainstream media?

a. How does this make you feel?

b. Do you think there's any truth in their comments?

2. How does a sugar dating relationship differ from a conventional "non sugar" relationship?

3. What are the differences between a "prostitution" and a sugar baby/sugar daddy relationship?

4. Do you feel protected on the website and in an arrangement?

5. What risks, if any, do you feel you take when being in an arrangement? 
6. Does anyone know that you're a [sugar baby] or [sugar daddy]?

a. Why or why not?

7. Is there anything else you would like to share with regards to your "sugar dating" experience? 


\section{Bibliography}

Agathangelou, A. M. (2004). The global political economy of sex: desire, violence, and insecurity in Mediterranean nation states. New York: Palgrave Macmillan US.

Klausner, A \& Hauswirth, H. (2017, February 23). Don't treat me like an ATM, and I wont treat you like a hooker. Retrieved March 1, 2017, from http://nypost.com/2017/02/23/dont-treat-me-likean-atm-and-i-wont-treat-you-like-a-hooker/

Androutsopoulos, J. (2008). Potentials and Limitations of Discourse-Centred Online Ethnography. LanguageInternet, 5, 20 pages.

Atkinson, S. (2016, July 1). What Do Fergie's "M.I.L.F Money" Lyrics Mean? The Instant Summer Jam Is A Wee Bit Confusing. Retrieved April 2, 2017, from https://www.bustle.com/articles/170301-what-do-fergies-milf-money-lyrics-mean-the-instantsummer-jam-is-a-wee-bit-confusing

Attwood, F. (2006). Sexed Up: Theorizing the Sexualization of Culture. Sexualities, 9(1), 77-94.

Baker, E.-R. (2016, January 20). What It's Like to Be a Male Sugar Baby. Retrieved March 18, 2017, from https://www.vice.com/en us/article/the-often-lucrative-but-sometimes-oppressive-lifestyleof-being-a-male-sugar-baby

Barns, S. (2016, August 25). Student, 20, gets rich, older men to fund her VERY extravagant lifestyle. Retrieved from https://www.thesun.co.uk/living/1659692/student-20-gets-rich-older-men-tofund-her-very-extravagant-lifestyle-but-slams-claims-shes-a-gold-digger/

Barraclough, C. (2017, February 1). 100,000 Aussie students have signed up to become Sugar Babies. Retrieved April 4, 2017, from http://www.news.com.au/lifestyle/relationships/dating/sugarbabies-100000-aussie-students-have-signed-up-to-find-a-sugar-daddy/newsstory/b2874068fc3df08d20b8e7dae88ac9c4

Bell, L. (1987). Good girls/bad girls. Seattle, Washington: Women's Press.

Berg, H. (2014). Working for Love, Loving for Work: Discourses of Labor in Feminist Sex-Work Activism. Feminist Studies, 40(3), 693-721.

Bernstein, E. (2001). The Meaning of the Purchase: Desire, Demand and the Commerce of Sex. Ethnography, 2(3), 389-420.

Bernstein, E. (2007). Temporarily yours: intimacy, authenticity, and the commerce of sex. Chicago: University of Chicago Press.

Betzer, F., Köhler, S., \& Schlemm, L. (2015). Sex Work Among Students of Higher Education: A Survey-Based, Cross-Sectional Study. Archives of Sexual Behavior, 44(3), 525-528. 
Blevins, K. R., \& Holt, T. J. (2009). Examining the Virtual Subculture of Johns. Journal of Contemporary Ethnography, 38(5), 619-648.

Bradshaw, C., Kahn, A., \& Saville, B. (2010). To Hook Up or Date: Which Gender Benefits? Sex Roles, 62(9-10), 661-669.

Brents, B. G., \& Sanders, T. (2010). Mainstreaming the Sex Industry: Economic Inclusion and Social Ambivalence. Journal of Law and Society, 37(1), 40-60.

Brodesser-Akner, T. (2015, August 27). How Sugar Daddies Make It Happen. Retrieved April 4, 2017, from http://www.gq.com/story/sugar-daddies-explained

Brook. (2015, November 13). Sugar Slang Dictionary. Retrieved March 16, 2017, from https://www.letstalksugar.com/news/sugar-slang-dictionary/

Brown, W. (2005). Edgework. Princeton, N.J.: Princeton University Press.

Bruckert, C., \& Hannem, S. (2013). To Serve and Protect? Social Profiling and Police Abuse of Power in Ottawa. In E. Van der Meulen, E. M. Durisin, \& V. Love (Eds.), Selling Sex: Experience, Advocacy and Research on Sex Work in Canada. Vancouver: UBC Press.

Bruess, C. J. S., \& Pearson, J. C. (1993). 'Sweet Pea' and 'Pussy Cat': An Examination of Idiom Use and Marital Satisfaction Over the Life Cycle. Journal of Social and Personal Relationships, 10(4), 609-615.

Bullen, J. (2017, February 26). "Sugar baby" reveals hidden dangers behind £1,000-a-month sex and dating career. Retrieved April 4, 2017, from http://www.mirror.co.uk/news/uk-news/men-thinkyoure-pet-sugar-9919714

Bungay, V., Oliffe, J., \& Atchison, C. (2016). Addressing Underrepresentation in Sex Work Research: Reflections on Designing a Purposeful Sampling Strategy. Qualitative Health Research, 26(7), 966-978.

Campbell, A. (2015). Sex Work's Governance: Stuff and Nuisance. Feminist Legal Studies, 23(1), $27-45$.

Canadian Labour Congress. (2016, August 11). Young Canadians need more opportunities | Canadian Labour Congress. Retrieved March 26, 2017, from http://canadianlabour.ca/news/newsarchive/young-canadians-need-more-opportunities

Carrier-Moisan, M.-E. (2015). "Putting femininity to work": Negotiating hypersexuality and respectability in sex tourism, Brazil. Sexualities, 18(4), 499-518.

Carter, V., \& Giobbe, E. (2006). Duet: Prostitution, Racism, and Feminist Discourse', in Jessica Spector. In J. Spector (Ed.), Prostitution and Pornography: Philosophical Debate about the Sex Industry (pp. 17-39). Stanford: Stanford University Press. 
CBC First Hand. (2016, October 27). Sugar Sisters. Retrieved April 3, 2017, from http://www.cbc.ca/firsthand/sugar-sisters

Coconutsbangkok. (2017, March 15). Don't call me a sugar daddy: Junta member charged for slapping server at Greyhound. Retrieved March 16, 2017, from https://coconuts.co/bangkok/news/dont-call-sugar-daddy-junta-member-charged-slapping-servergreyhound/

Collins, P. H. (2006). New Commodities, New Consumers: Selling Blackness in a Global Marketplace. Ethnicities, 6(3), 297-317.

Colosi, R. (2012). Dirty Dancing: An Ethnography of Lap Dancing. Cullompton, UK: Willan.

Cordero, B. (2015). Sugar culture and SeekingArrangement.com participants: What it means to negotiate power and agency in sugar (Doctoral Dissertation: Master of Arts in Communiation Studies). California State University, Sacramento.

Crafton, L. P. (2011). Transgressive theatricality, romanticism, and Mary Wollstonecraft. Ashgate.

Cribb, R. (2015, February 20). Is the sugar daddy/sugar baby phenomenon a kind of prostitution? | Toronto Star. Retrieved October 20, 2016, from https://www.thestar.com/life/2015/02/20/is-thesugar-daddysugar-baby-phenomenon-a-kind-of-prostitution.html

Cusick, L., Roberts, R., \& Paton, S. (2009). Higher and further education institution policies on student and staff involvement in commercial sex. Journal of Higher Education Policy and Management, 31(2), 185.

Davis, E. M., \& Fingerman, K. L. (2015). Digital Dating: Online Profile Content of Older and Younger Adults. The Journals of Gerontology Series B: Psychological Sciences and Social Sciences, gbv042.

DeCurtis, C. (2003). Prostitution, Sex Tourism on the Internet: Whose Voice Is Being Heard? Computers and Society, 33, 3-11.

Deil-Amen, R. (2011). Socio-Academic Integrative Moments: Rethinking Academic and Social Integration Among Two-Year College Students in Career-Related Programs. The Journal of Higher Education, 82(1), 54-91.

Department of Justice. (2014, December 1). Technical paper: Bill C-36, Protection of Communities and Exploited Persons Act. Retrieved January 16, 2017, from http://www.justice.gc.ca/eng/rppr/other-autre/protect/p1.html\#edn58

Dobson, A. S. (2014). Laddishness Online. Cultural Studies, 28(1), 142-164. 
Dolman, K. (2008, February 19). Selling sex to study. Retrieved April 4, 2017, from http://www.thetimes.co.uk/article/selling-sex-to-study-dswswrrf56g

Donaldson James, S. (2009, May 15). Sugar Daddy Sites Draw Blackmailers. Retrieved March 20, 2017, from http://abcnews.go.com/Business/AheadoftheCurve/story?id=7578033\&page=1

Doucet, A. (2007). Feminist methodologies and epistemology. In 21st century sociology: a reference handbook (pp. 26-32). Thousand Oaks, CA: Sage.

Doyle, J. (2016, October 25). John Doyle: A tale of sugar daddies and transactional dating - a big so what? Retrieved March 20, 2017, from http://www.theglobeandmail.com/arts/television/johndoyle-a-tale-of-sugar-daddies-and-transactional-dating-a-big-so-what/article32516100/

Duval Smith, A. (2006, October 31). Thousands of students "join sex trade to fund degrees." Retrieved February 2, 2017, from http://www.independent.co.uk/news/world/europe/thousandsof-students-join-sex-trade-to-fund-degrees-422287.html

Edwards, J. (2012, April 27). How This Never-Been-Kissed MIT Nerd Built A \$10 Million "Sugar Baby" Dating Empire. Retrieved April 4, 2017, from http://www.businessinsider.com/brandonwade-mit-nerd-built-a-10-million-sugar-baby-dating-empire-2012-4

Egan, R. D. (2005). Emotional Consumption: Mapping Love and Masochism in an Exotic Dance Club. Body \& Society, 11(4), 87-108.

Engels, F. (1914). Socialism, Utopian and scientific. (E. Aveling, Trans.). Charles H. Kerr \& Company.

Tessler, E. (2015, October 30). Yes, Your Dating Preferences Are Probably Racist. Retrieved March 20, 2017, from https://theestablishment.co/yes-your-dating-preferences-are-probably-raciste58ae2fd625d\#.iuask5ps0

Frank, K. (1998). The Production of Identity and the Negotiation of Intimacy in a 'Gentleman's Club'. Sexualities, 1(2), 175-201.

Fullick, M. (2013). "Gendering” the Self in Online Dating Discourse. Canadian Journal of Communication, 38(4), 545-562.

Glocker, M. L., Langleben, D. D., Ruparel, K., Loughead, J. W., Gur, R. C., \& Sachser, N. (2009). Baby Schema in Infant Faces Induces Cuteness Perception and Motivation for Caretaking in Adults. Ethology : Formerly Zeitschrift Fur Tierpsychologie, 115(3), 257-263.

Gobind, J., \& du Plessis, G. (2015). Sugar Daddy: The Student Attraction. Gender \& Behaviour, $13(2), 6720$.

Goffman, E. (1956). The presentation of self in everyday life. New York: Anchor Books. 
Goffman, E. (1963). Stigma: Notes on the management of a spoiled identity. Engle-Woods Cliffs: Prentice-Hall.

Goodnight, G. T., Hingstman, D., \& Green, S. (2015). The student debt bubble: Neoliberalism, the university, and income inequality. JOURNAL OF CULTURAL ECONOMY, 8(1), 75-100.

Government of Canada, D. of J. (2014, December 1). Technical Paper: Bill C-36, Protection of Communities and Exploited Persons Act. Retrieved April 3, 2017, from http://www.justice.gc.ca/eng/rp-pr/other-autre/protect/p1.html

Government of Ontario, M. of F. (2016, July 20). 2016 Ontario Budget | Improving Access to Postsecondary Education. Retrieved September 1, 2016, from http://www.fin.gov.on.ca/en/budget/ontariobudgets/2016/bk1.html

Greenslade, B. (2014, November 19). Sugar daddies help their "babies" - a growing trend in Canada | Globalnews.ca. Retrieved September 12, 2016, from http://globalnews.ca/news/1680178/sugardaddies-help-their-babies-a-growing-trend-in-canada/

Gross, K. (2006). Students working in the Melbourne sex industry: education, human capital and the changing patterns of the youth labour market. Youth Studies Australia, 25(3), 61.

Haeger, H., \& Deil-Amen, R. (2010). Female College Students Working in the Sex Industry: A Hidden Population. NASPA Journal About Women in Higher Education, 3(1), 4-27.

Hartmann, H. I. (1979). The unhappy marriage of marxism and feminism: Towards a more progressive union. Capital and Class, 8(8), 1-33.

Hay, M. (2016, December 6). A Brief History of MILF Porn. Retrieved April 2, 2017, from https://www.vice.com/en_us/article/krotka-historia-pornografii-milf

Heldman, C., \& Wade, L. (2010). Hook-Up Culture: Setting a New Research Agenda. Sexuality Research and Social Policy, 7(4), 323-333.

Hervey, G. (2016, July 21). To pay for college, more students are becoming sugar babies. Retrieved February 1, 2017 from http://college.usatoday.com/2016/07/21/to-pay-for-college-morestudents-are-becoming-sugar-babies/

Hochschild, A. R. (1983). The managed heart: commercialization of human feeling. Berkeley: University of California Press.

Hodgson, C. S., \& Simoni, J. M. (1995). Graduate Student Academic and Psychological Functioning. Journal of College Student Development, 36(3), 244.

Holt, T. J., \& Blevins, K. R. (2007). Examining sex work from the client's perspective: Assessing johns using on-line data. DEVIANT BEHAVIOR, 28(4), 333-354. 
Hughes, D. M. (2004). Prostitution Online. Journal of Trauma Practice, 2(3-4), 115-131.

Jaggar, A. M. (1988). Feminist Politics and Human Nature (Philosophy and Society). Rowman \& Littlefield Publishers.

Johnson, A. (2012, May 21). "Sugar dating" website leaves bitter taste. Belfast Telegraph (Belfast, Northern Ireland). Belfast. Retrieved from http://search.proquest.com/docview/1014401059

Jones, A. (2014, October 10). "Daddies Date Babies" Asks: Who's Your Sugar Daddy? Newsweek, Global Ed.; New York, 163(14). Retrieved from http://search.proquest.com.proxy.library.carleton.ca/docview/1567141341/citation/6AC9DD880 $\underline{4734477 \mathrm{PQ} / 1}$

Jones, A. (2016). "I Get Paid to Have Orgasms": Adult Webcam Models' Negotiation of Pleasure and Danger. SIGNS, 42(1), 227-256.

Klausner, A., \& Hauswirth, H. (2017, February 23). Don't treat me like an ATM, and I wont treat you like a hooker. Retrieved from http://nypost.com/2017/02/23/dont-treat-me-like-an-atm-and-iwont-treat-you-like-a-hooker/

Koken, J. (2012). Independent Female Escort's Strategies for Coping with Sex Work Related Stigma. Sexuality \& Culture, 16(3), 209-229.

Lane, F. S. (2000). Obscene profits. New York: Routledge.

Lantz, S. (2003). Sex work and study: students, identities and work in the 21st century. The University of Melbourne, Australia. Retrieved from Department of Education, Policy and Management.

Lantz, S. (2005). Students Working in the Melbourne Sex Industry: Education, Human Capital and the Changing Patterns of the Youth Labour Market. Journal of Youth Studies, 8(4), 385.

Lavoie, F., Thibodeau, C., Gagné, M.-H., \& Hébert, M. (2010). Buying and Selling Sex in Québec Adolescents: A Study of Risk and Protective Factors. Archives of Sexual Behavior, 39(5), 11471160 .

Lazar, M. M. (2007). Feminist Critical Discourse Analysis: Articulating a Feminist Discourse Praxis. Critical Discourse Studies, 4(2), 141-164.

Leisring, P. A. (2013). Physical and Emotional Abuse in Romantic Relationships: Motivation for Perpetration Among College Women. Journal of Interpersonal Violence, 28(7), 1437-1454.

Livingston, E. (2016, February 4). This is why sugar daddies must stop exploiting sexually curious teenagers. Retrieved March 20, 2017, from http://www.independent.co.uk/voices/teenage-girlsneed-the-space-to-explore-their-sexuality-and-sugar-daddies-must-stop-exploiting-them$\underline{\text { a6853076.html }}$ 
Logan, S. (2017, January 16). Hundreds of university students find sugar daddies online, negotiate average \$2,700 a month allowance. Retrieved March 20, 2017, from http://news.nationalpost.com/news/canada/hundreds-of-university-students-find-sugar-daddiesonline-negotiate-average-2700-a-month-allowance

Lowes, L., \& Prowse, M. A. (2001). Standing outside the interview process? The illusion of objectivity in phenomenological data generation. International Journal of Nursing Studies, $38(4), 471-480$.

Lundquist, J. H., \& Lin, K.-H. (2015). Is Love (Color) Blind? The Economy of Race among Gay and Straight Daters. Social Forces, 93(4), 1423-1449.

Mattson, H. (2005). Ivy League Stripper. New York, NY: Arcade Publishing.

McIntosh, J. (2016, February 25). Cash-strapped students looking to "sugar baby" website. Retrieved August 17, 2016, from http://www.ottawacommunitynews.com/news-story/6354150-cashstrapped-students-looking-to-sugar-baby-website/

McKeon, L. (2013, March 20). Girlfriends for Hire: the rules of Toronto's new sugar daddy economy. Retrieved March 30, 2017, from http://torontolife.com/city/the-sweetened-life/

McNair, B. (2002). Striptease Culture. London;New York: Routledge.

McWilliams, S., \& Barrett, A. E. (2014). Online Dating in Middle and Later Life Gendered Expectations and Experiences. Journal of Family Issues, 35(3), 411-436.

Miller, A. (2011). Sugar dating: A new take on an old issue. Buff. J. Gender L. \& Soc. Pol'y, 20, 33.

Miller, K. (2015, July 13). What It Really Means To Be A Sugar Baby. Retrieved March 18, 2017, from http://www.refinery29.com/2015/07/90355/sugar-baby-summit-2015-seeking-arrangement$\underline{\text { tips }}$

Miller-Young, M. (2010). Putting Hypersexuality to Work: Black Women and Illicit Eroticism in Pornography. Sexualities, 13(2), 219-235.

Miller-Young, M. (2014). A taste for brown sugar. Durham: Duke University Press.

Milne, J. (2006, October 8). Female students turn to prostitution to pay fees. Retrieved April 1, 2017, from http://www.timesonline.co.uk/tol/life_and_style/ education/students/article665019

Milrod, C., \& Weitzer, R. (2012). The Intimacy Prism: Emotion Management among the Clients of Escorts. Men and Masculinities, 15(5), 447-467. 
Moffatt, P. G., \& Peters, S. A. (2004). Pricing Personal Services: An Empirical Study of Earnings in the UK Prostitution Industry. Scottish Journal of Political Economy, 51(5), 675-690.

Motyl, J. (2013). Trading sex for college tuition: how sugar daddy "dating” sites may be sugar coating prostitution. Penn State Law Review, 117(3), 927.

Motz, T. (2014, February 9). Sugar daddy website has coeds justifying prostitution. Retrieved March 30, 2016, from http://nypost.com/2014/02/09/sugar-daddy-website-has-coeds-rationalizingprostitution/

Murphy, H., Dunk-West, P., \& Chonody, J. (2015). Emotion work and the management of stigma in female sex workers' long-term intimate relationships. Journal of Sociology, 51(4), 1103-1116.

Nasrulla, A. (2016, February 19). Thousands of Canadian university students seek "sugar daddies." Retrieved August 16, 2016, from https://ca.finance.yahoo.com/blogs/insight/thousands-ofcanadian-university-students-seek-163217307.html

Nayar, K. I. (2016). Sweetening the deal: dating for compensation in the digital age. Journal of Gender Studies, 1-12.

Nelson, E. (1993). Sugar daddies: "Keeping" a mistress and the gentleman's code. Qualitative Sociology, 16(1), 43-68.

OECD. (2015). Education at a Glance 2015: OECD Indicators. Paris: OECD Publishing.

Osborne, J. W., \& Walker, C. (2006). Stereotype Threat, Identification with Academics, and Withdrawal from School: Why the most successful students of colour might be most likely to withdraw. Educational Psychology, 26(4), 563.

Oxford English Dictionar. (2017). daddy - definition of daddy in English | Oxford Dictionaries. Retrieved March 30, 2017, from https://en.oxforddictionaries.com/definition/daddy

Pardiwalla, A. (2016, April 20). Sugaring: A New Kind of Irresistible. Retrieved from http://www.huffingtonpost.com/anahita-pardiwalla/post 10274 b 9683356.html

Park, A. (2015, July 21). Dad Bod Explained, By Science. Retrieved March 30, 2017, from http://time.com/3965114/dad-bod-explained/

Partridge, E. (2015). A Dictionary of the Underworld: British and American. New York, NY: Routledge.

Partridge, E. (1949). A dictionary of slang and unconventional English: Colloquialisms and catchphrases, solecisms and catachreses, nicknames, vulgarisms and such Americanisms as have been Naturalized (3rd ed.). GB: Routledge \& Keagan Paul. 
Pateman, C. (1999). What's wrong with prostitution? Women's Studies Quarterly, 27(1-2), 53.

Pateman, C. (1988). The Sexual Contract. Stanford, CA: Stanford University Press.

Patton, M. Q. (2015). Qualitative research \& evaluation methods. Thousand Oaks, CA: SAGE Publications, Inc.

Peters, L. (2015, May 1). What Is “Dad Bod?” Here's Everything You Need To Know About The Phrase And Phenomenon. Retrieved March 30, 2017, from https://www.bustle.com/articles/80345-what-is-dad-bod-heres-everything-you-need-to-knowabout-the-phrase-and-phenomenon

Pheterson, G. (1993). The Whore Stigma: Female Dishonor and Male Unworthiness. Social Text, 37, 39.

Pheterson, G. (1990). The category "prostitute" in scientific inquiry. Journal of Sex Research, 27(3), 397-407.

Polkinghorne, D. E. (2005). Language and Meaning: Data Collection in Qualitative Research. Journal of Counseling Psychology; Washington, 52(2), 137-145.

Pornhub. (2017, January 4). Pornhub's 2016 Year in Review - Pornhub Insights. Retrieved April 2, 2017, from https://www.pornhub.com/insights/2016-year-in-review

Prasad, M. (1999). The morality of market exchange: Love, money, and contractual justice. Sociological Perspectives, 42(2), 181-213.

Quinn, D. M., \& Chaudoir, S. R. (2009). Living with a concealable stigmatized identity: The impact of anticipated stigma, centrality, salience, and cultural stigma on psychological distress and health. Journal of Personality and Social Psychology, 97(4), 634-651.

Quinn, J. F., \& Forsyth, C. J. (2005). describing sexual behavior in the era of the internet: a typology for empirical research. Deviant Behavior, 26(3), 191-207.

Ranzini, G., \& Lutz, C. (2016). Love at first swipe? Explaining Tinder self-presentation and motives. Mobile Media \& Communication, 2050157916664559.

Reed, L. R. (2015, January). Sugar Babies, Sugar Daddies, and the Perceptions of Sugar Dating. ProQuest Dissertations Publishing. Retrieved from http://search.proquest.com/docview/1707929260

Robb, A. (2014, May 25). Why Do Adult Romantic Partners Call Each Other “Baby?” Retrieved March 30, 2017, from https://newrepublic.com/article/117881/why-do-people-call-significantothers-baby 
Roberts, R., Bergström, S., \& La Rooy, D. (2007). Sex work and students: an exploratory study. Journal of Further and Higher Education, 31(4), 323.

Roberts, R., Golding, J., Towell, T., \& Reid, S. (2000). Mental and physical health in students: The role of economic circumstances. British Journal of Health Psychology, 5(3), 289-297.

Roberts, R., Jones, A., \& Sanders, T. (2013). Students and Sex Work in the UK: Providers and Purchasers. Sex Education: Sexuality, Society and Learning, 13(3), 349.

Roberts, R., Sanders, T., Myers, E., \& Smith, D. (2010). Participation in sex work: students' views. Sex Education, 10(2), 145.

Robinson, B. A. (2015). "Personal Preference" as the New Racism. Sociology of Race and Ethnicity, 1(2), 317-330.

Rolfe, G. (2006). Validity, trustworthiness and rigour: quality and the idea of qualitative research. Journal of Advanced Nursing, 53(3), 304-310.

Ronen, S. (2010). Grinding On the Dance Floor. Gender \& Society, 24(3), 355-377.

Rosenbloom, S. R., \& Fetner, T. (2001). Sharing Secrets Slowly: Issues of Classroom Self-Disclosure Raised by Student Sex Workers. Teaching Sociology, 29(4), 439.

Ross, B., \& Gómez-Ramírez, O. (2014). Extinguishing the "Temptation of Monetary Inducements": The State Regulation and Stigmatization of Adult Entertainment Recruiters on Post-secondary Campuses in British Columbia. Canadian Theatre Review, 158(158), 39-43.

Rottenberg, C. (2014). The Rise of Neoliberal Feminism. Cultural Studies (London, United Kingdom), 28(3), 418.

Ruffin, S. (2006, April 8). Ex-stripper shares stories of empowerment, degradation. Retrieved April 4, 2017, from http://www.collegiatetimes.com/news/ex-stripper-shares-stories-of-empowermentdegradation/article 317d88a2-dc7e-5fcc-9407-59afed54c304.html

Sagar, T., Jones, D., Symons, K., Bowring, J., \& Roberts, R. (2015). Student participation in the sex industry: higher education responses and staff experiences and perceptions. Journal of Higher Education Policy and Management, 37(4), 400-412.

Saldaña, J. (2009). The coding manual for qualitative researchers. Los Angeles, CA: Sage.

Sanders, T. (2005). “It's Just Acting": Sex Workers' Strategies for Capitalizing on Sexuality. Gender Work and Organization, 12(4), 319-342.

Sanders, T. (2008). Male Sexual Scripts: Intimacy, Sexuality and Pleasure in the Purchase of Commercial Sex. Sociology, 42(3), 400-417. 
Sanders, T. (2013). Paying for Pleasure: Men Who Buy Sex. London;New York: Routledge.

Sanders, T., \& Hardy, K. (2015). Students selling sex: marketisation, higher education and consumption. British Journal of Sociology of Education, 36(5), 747-765.

Saxon, T. (2017, January 13). Is the University of Guelph a Sugar Baby University? Retrieved April 4, 2017, from https://www.guelphtoday.com/local-news/is-the-university-of-guelph-a-sugarbaby-university-509484

Seeking Arrangement. (2014, November 4). Standard, Premium, Or Diamond Membership: What's The Difference? « SeekingArrangement Blog. Retrieved from http://blog.seekingarrangement.com/2014/11/04/standard-premium-diamond-membership-whatsdifference/

Seeking Arrangement. (2017, February 14). SeekingArrangement - Press \& Media. Retrieved February 14, 2017, from https://www.seekingarrangement.com/press/

Selinger-Morris, S. (2016, September 10). Thank you, Daddy: The rise of "sugar" relationships [Text]. Retrieved March 20, 2017, from http://www.abc.net.au/news/2016-09-10/inside-theworld-of-sugar-relationships/7822586

Sevcikova, A., \& Daneback, K. (2011). Anyone who wants sex? Seeking sex partners on sex-oriented contact websites. SEXUAL AND RELATIONSHIP THERAPY, 26(2), 170-181.

Sharp, K., \& Earle, S. (2012). Cyberpunters and cyberwhores: Prostitution on the internet. In Y. Jewkes (Ed.), Dot.cons: crime, deviance and identity on the internet. Cullompton: Willan Publishing.

Shaver, F. M. (2005). Sex Work Research Methodological and Ethical Challenges. Journal of Interpersonal Violence, 20(3), 296-319.

Sinacore, A. L., Jaghori, B., \& Rezazadeh, S. M. (2015). Female University Students Working in the Sex Trade: A Narrative Analysis/Les étudiantes à l'université travaillant dans l'industrie du sexe : une analyse narrative. Canadian Journal of Counselling and Psychotherapy, 49(1), 40-56.

Singh, S. (2016, March 31). Secret life: student sex work. Retrieved April 4, 2017, from http://thethunderbird.ca/2016/03/31/secret-life-student-sex-work/

Skidmore, S. (2015, February 1). Some university students seeking "sugar daddy" relationships for tuition, rent | Toronto Star. Retrieved August 17, 2016, from http://globalnews.ca/news/2731765/university-students-seeking-sugar-daddy-relationships-topay-for-tuition-rent/

Smith, S. (2005). Women and Socialism: Essays on Women's Liberation. Haymarket Books. 
Snapp, S., Lento, R., Ryu, E., \& Rosen, K. S. (2014). Why do they hook up? Attachment style and motives of college students. Personal Relationships, 21(3), 468-481.

Sprecher, S., Hatfield, E., Cortese, A., Potapova, E., \& Levitskaya, A. (1994). Token Resistance to Sexual Intercourse and Consent to Unwanted Sexual Intercourse: College Students' Dating Experiences in Three Countries. The Journal of Sex Research, 31(2), 125 - 132.

Sprecher, S., Schmeeckle, M., \& Felmlee, D. (2006). The Principle of Least Interest: Inequality in Emotional Involvement in Romantic Relationships. Journal of Family Issues, 27(9), 1255-1280.

Squires, B. (2016, May 18). Why Women Like to Call Men "Daddy" During Sex. Retrieved March 30, 2017, from https://broadly.vice.com/en_us/article/why-women-like-to-call-men-daddyduring-sex

Statistics Canada Government of Canada. (2016, September 7). The Daily — Tuition fees for degree programs, 2016/2017. Retrieved March 20, 2017, from http://www.statcan.gc.ca/dailyquotidien/160907/dq160907a-eng.htm

Steinmetz, K. (2016, June 18). This Is Where the Word "Dad" Comes From. Retrieved March 30, 2017, from http://time.com/4369110/fathers-day-dad-word-etymology/

Sweeney, K. A., \& Borden, A. L. (2009). Crossing the Line Online: Racial Preference of Internet Daters. Marriage \& Family Review, 45(6-8), 740-760.

Tavris, C. (2008). Pleasure and Danger: Exploring Female Sexuality. Feminism \& Psychology, 18(4), 557-563.

Teitel, E. (2016, February 19). "Sugar Babies" and "Sugar Daddies" an uncomfortable arrangement: Teitel | Toronto Star. Retrieved September 12, 2016, from https://www.thestar.com/news/canada/2016/02/19/sugar-babies-and-sugar-daddies-anuncomfortable-arrangement-teitel.html

The Online Slang Dictionary. (n.d.). Sugar Definition. OnlineSlangDictionary.com. Retrieved April 4, 2017, from http://onlineslangdictionary.com/meaning-definition-of/sugar

Tomura, M. (2009). A Prostitute's Lived Experiences of Stigma. Journal of Phenomenological Psychology, 40(1), 51-84.

Tracy, S. J. (2010). Qualitative Quality: Eight “Big-Tent” Criteria for Excellent Qualitative Research. Qualitative Inquiry, 16(10), 837-851.

Tracy, S. J. (2013). Qualitative research methods: collecting evidence, crafting analysis, communicating impact. West Sussex, UK: Wiley-Blackwell.

Truong, T.-D. (1990). Sex, money and morality - prostitution and tourism in Southeast Asia. London: Zed Books. 
Tsiplakou, S. (2009). Doing (Bi)Lingualism: Language Alternation as Performative Construction of Online Identities. PRAGMATICS, 19(3), 361-391.

Unger, R. K. (1998). Positive Marginality: Antecedents and Consequences. Journal of Adult Development, 5(3), 163-170.

Unger, R. K. (2000). Outsiders inside: Positive marginality and social change. Journal Of Social Issues, 56(1), 163-179.

Universities Canada. (2017). Facts and stats. Retrieved February 14, 2017, from http://www.univcan.ca/universities/facts-and-stats/

Vance, C. S. (1984). Pleasure and danger: exploring female sexuality. Boston: Routledge \& K. Paul.

Van der Meulen, E., Durisin, E. M., \& Love, V. (2013). Selling sex: experience, advocacy, and research on sex work in Canada. Vancouver: UBC Press.

Van Der Veen, M. (2001). Rethinking Commodification and Prostitution: An Effort at Peacemaking in the Battles over Prostitution. Rethinking Marxism, 13(2), 30-51.

Van Meyl, K. (2014). On the Separation of Personal and Professional: Sex, Work, Law, the Girlfriend Experience, and the Interpersonal Relationships of Independent Escorts. Carleton University, Ottawa.

Vice. (2015, November 5). I Spent a Month Dating Sugar Mamas and I Wouldn't Do It Again. Retrieved March 18, 2017, from https://www.vice.com/en_us/article/i-spent-a-month-datingsugar-mamas-and-i-wouldnt-do-it-again

Wade, B. (2017). College Sugar Babies - Sugar Baby University. Retrieved March 20, 2017, from https://www.seekingarrangement.com/sugar-baby-university/

Wallard, J. (2013, February 21). "Sugar Daddy" has a sweet history. Retrieved April 2, 2017, from http://www.reporterherald.com/ci_22623737/sugar-daddy-has-sweet-history

Weeks, J. (2011). Un-/Re-Productive Maternal Labor: Marxist Feminism and Chapter Fifteen of Marx's Capital. Rethinking Marxism, 23(1), 31-40.

Weitzer, R. (2010). Sex For Sale: Prostitution, Pornography and the Sex Industry (2nd ed.). Routledge.

Wiles, J. L., Rosenberg, M. W., \& Kearns, R. A. (2005). Narrative analysis as a strategy for understanding interview talk in geographic research. Area, 37(1), 89-99.

Willman, A., Levy, A., \& Ditmore, M. H. (2010). Sex work matters: exploring money, power, and intimacy in the sex industry. New York, London: Zed Books. 
Wong, J. (2014, January 27). More Maritime students turn to sugar daddies to pay for tuition | Globalnews.ca. Retrieved November 24, 2016, from http://globalnews.ca/news/1110604/moremaritime-students-turn-to-sugar-daddies-to-pay-for-tuition/

Worthen, M. G. F. (2016). Sexual Deviance and Society : A sociological examination. Abingdon, GB: Routledge.

Zelizer, V. A. (2005). The Purchase of Intimacy. NJ: Princeton University Press.

Zelizer, V. A. R. (2011). Economic lives: how culture shapes the economy. United Kingdom: Princeton University Press.

Zimmermann, E. (2015). Sugar for Sale: Constructions of Intimacy in the Sugar Bowl. Laurier Undergraduate Journal of the Arts, 2(2), 16.

$\underline{\text { Cases }}$

Canada (Attorney General) v. Bedford, 2013 SCC 72, [2013] 3 S.C.R. 110. 